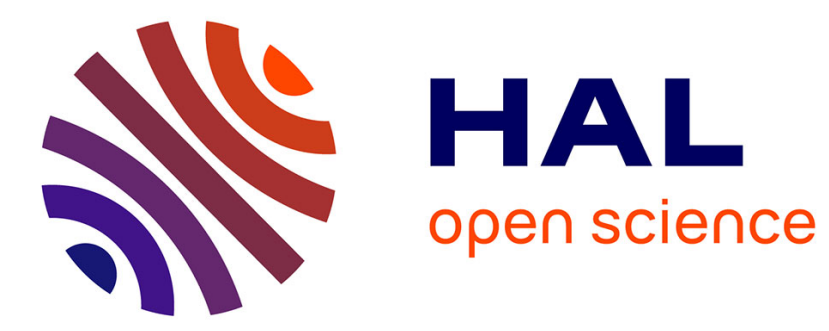

\title{
Sea surface temperature associations with the late Indian summer monsoon
}

Pascal Terray, Pascale Delécluse, S. Labattu, Laurent Terray

\section{To cite this version:}

Pascal Terray, Pascale Delécluse, S. Labattu, Laurent Terray. Sea surface temperature associations with the late Indian summer monsoon. Climate Dynamics, 2003, 21, pp.593-618. 10.1007/S00382003-0354-0 . hal-00770815

\section{HAL Id: hal-00770815 https://hal.science/hal-00770815}

Submitted on 27 Jun 2016

HAL is a multi-disciplinary open access archive for the deposit and dissemination of scientific research documents, whether they are published or not. The documents may come from teaching and research institutions in France or abroad, or from public or private research centers.
L'archive ouverte pluridisciplinaire HAL, est destinée au dépôt et à la diffusion de documents scientifiques de niveau recherche, publiés ou non, émanant des établissements d'enseignement et de recherche français ou étrangers, des laboratoires publics ou privés. 


\title{
Sea Surface Temperature Associations
}

\section{with the Late Indian Summer Monsoon}

\author{
By \\ P. Terray (1,2), P. Delecluse (1), S. Labattu (1), L. Terray (3) \\ (1) Laboratoire d'Océanographie Dynamique et de Climatologie, Paris, France
}

(2) Université Paris 7, Paris, France

(3) CERFACS, Toulouse, France

Submitted to Climate Dynamics

Revised version (April 2003)

January, 2003 


\begin{abstract}
This paper uses recent gridded and historical data in order to assess the relationships between interannual variability of the Indian Summer Monsoon (ISM) and Sea Surface Temperature (SST) anomaly patterns over the Indian and Pacific oceans.

Interannual variability of ISM rainfall and dynamical indices for the traditional summer monsoon season (June-September) are strongly influenced by rainfall and circulation anomalies observed during August and September, or the Late Indian Summer Monsoon (LISM). Anomalous monsoons are linked to well-defined LISM rainfall and large-scale circulation anomalies. The east-west Walker and local Hadley circulations fluctuate during the LISM of anomalous ISM years. LISM circulation is weakened and shifted eastward during weak ISM years. Therefore, we focus on the predictability of the LISM in this study.

Strong (weak) (L)ISMs are preceded by significant positive (negative) SST anomalies in the southeastern subtropical Indian Ocean, off Australia, during boreal winter. These SST anomalies are mainly linked to south Indian Ocean dipole events, recently studied by Behera and Yamagata (2001), and to the El Niño-Southern Oscillation (ENSO) phenomenon. These SST anomalies are highly persistent and affect the northwestward translation of the Mascarene high from austral to boreal summer. The southeastward (northwestward) shift of this subtropical high associated with cold (warm) SST anomalies off Australia causes a weakening (strengthening) of the whole monsoon circulation through a modulation of the local Hadley cell during the LISM. Furthermore, it is suggested that the Mascarene high interacts with the underlying SST anomalies through a positive dynamical feedback mechanism, maintaining its anomalous position during the LISM.

Our results also explain why a strong ISM is preceded by a transition in boreal spring from an El Niño to a La Niña state in the Pacific and vice versa. An El Niño event and the associated warm SST anomalies over the southeastern Indian Ocean during boreal winter may play a key role in the development of a strong ISM by strengthening the local Hadley circulation during the LISM. On the other hand, a developing La Niña event in boreal spring and summer may also enhance the eastwest Walker circulation and the monsoon as demonstrated in many previous studies.
\end{abstract}




\section{Introduction}

The asian summer monsoon is a dominant feature of the boreal summer atmospheric circulation. The Asian monsoon region may be defined as the areas where both the atmospheric circulation and associated precipitation regime reverse with season. However, it is now recognized that three major subcomponents can be identified in the Asian monsoon system: the Indian Summer Monsoon (ISM), the East Asian Summer Monsoon (EASM) and the Western North Pacific Summer Monsoon (WNPSM). The interested readers are referred to the works of Lau et al. (2000) and Wang et al. (2001) for further details. Prediction of the asian summer monsoon, particularly the ISM, is one of the major challenges of climate research (Webster et al., 1998).

In the context of ENSO-monsoon relationships, the WNPSM and EASM seem more predictable than the ISM since WNPSM and EASM rainfall anomalies are significantly correlated with Niño3.4 Sea Surface Temperature (SST) anomaly in the preceding winter. On the other hand, many investigators have found it very difficult to interpret lead-lag relationships between the ISM and ENSO, given that both are phase-locked to the annual cycle (Webster and Yang, 1992). A strong (weak) ISM often occurs in the developing phase of La Niña (El Niño) events (Wang et al., 2001; Meehl and Arblaster, 2002a). Thus, attempts to ascribe cause and effect to either ENSO or the ISM are likely not to be very illuminating. The so-called "boreal spring barrier" in ENSO indices (Torrence and Webster, 1998) explains why these indices are not good predictors for the ISM, though many studies have attempted to use ENSO as a base predictor (Webster et al., 1998). Despite a very long history of research, the potential predictability of the ISM is still the subject of much debate and investigation both with numerical (coupled) models and observational analysis. However, up to now, the 
statements of Normand (1953) with regard to the ISM are still valid: "The Indian monsoon therefore stands out as an active, not a passive feature in world weather, more efficient as a broadcasting tool than an event to be forecast”.

Despite the pessimistic conclusion of Normand, some recent studies have suggested that ISM rainfall variability consists of a large scale persistent rainfall anomaly and an independent fluctuating intraseasonal component (Webster et al., 1998, Krishnamurthy and Shukla, 2000). In this conceptual framework, predictability of the ISM depends on the relative contributions of these two components. The mechanisms responsible for this persistent rainfall anomaly are not well understood. Furthermore, other studies suggest that ISM rainfall interannual variability is primarily the result of different manifestations of the intraseasonal variability associated with the duration/intensity of active cycles during the monsoon season (Palmer, 1994; Annamalai et al., 1999; Lawrence and Webster, 2001). Consequently, a first step toward achieving a better understanding of ISM predictability is to characterize the influences of the various surface boundary conditions (SST, snow cover and mass, soil moisture) on the ISM subsystem as suggested by Charney and Shukla (1981).

The relationship between tropical SST and the ISM has been the subject of many studies in the past decades. Due to its close proximity and the importance of both the land-sea meridional thermal contrast and the SST-convection relationship for the strength of the ISM, the Indian Ocean may play a role in ISM interannual variability. Historically, however, the Indian Ocean has been viewed as a passive element of the ISM system (Webster et al., 1998). Most previous observational studies have concluded that the Indian Ocean has no significant influence on ISM interannual variability, due to the lack of a significant relationship between various ISM indices and Indian Ocean SST (Shukla, 1987; Webster et al., 1998). On the other 
hand, a number of recent modeling studies have demonstrated that Indian Ocean SST anomalies in certain areas under certain conditions can significantly affect the ISM variability (Chandrasekar and Kitoh, 1998; Meehl and Arblaster, 2002b). However, most of the previous studies have focused either on northern or equatorial Indian Ocean SST and their relationships with convection during boreal summer. Very few studies have drawn attention to the Southern Indian Ocean and its relationships to the ISM variability since earlier studies by Krishnamurti and Bhalme (1976), Cadet (1983) and Meehl (1987) that have suggested a shift of the Mascarene High in association with monsoon strength.

In the present study, we will reassess the relative importance of Indian Ocean SST on ISM variability in light of recent advances in Indian Ocean climate research (Webster et al., 1999; Saji et al., 1999; Behera and Yamagata, 2001). The focus is on the interannual variability and predictability of ISM rainfall and circulation. We are primarily concerned with the nature of predictability and its link to local (Indian Ocean) and remote SST forcing. Our most important result is that Southern Indian Ocean SST anomaly is a major precursory signal for the ISM. This result is fundamental to the predictability of ISM rainfall since the Indian Ocean SST anomaly appears one or two seasons before the ISM onset.

The datasets and methods used in this study are described in section 2 . Section 3 depicts the temporal and spatial structures of ISM rainfall and circulation variability. Observational analysis of the ISM-SST relationships is presented in section 4. The conclusions are given in section 5 .

2. Data and methods 
The monthly (June-September) area weighted rainfall series for each of the 29 Indian meteorological subdivisions and the area weighted monthly rainfall series for all India, for the period 1871-1998, have been used in this study in order to describe ISM rainfall variability over the Indian subcontinent (Parthasarathy et al., 1995).

The circulation associated with ISM rainfall has been examined by using National Centers for Environmental Prediction (NCEP) reanalysis datasets (Kalnay et al., 1996). Monthly mean Sea Level Pressure (SLP), winds and stream function at standard pressure levels from the reanalysis data for the period January 1948 to December 1999 were used in most calculations, though stream function data were only available from 1958. The Empirical Orthogonal Function (EOF) reconstructed SST analysis of Smith et al. (1996) during the period 19501998 (hereinafter referred to as the Reynolds SST analysis) are used to study lead-lag relationships between the ISM and Indo-Pacific SST.

We also examine the surface wind and SST data from the Comprehensive Ocean-Atmosphere Data Set (COADS) in order to validate our findings. The COADS data used here cover the period 1948-1992. The noisy nature of the COADS data was partially overcome by averaging the observations over different key areas. The monthly time series for the different areas were determined as follows:

(i) First, the 1950-1980 interval was used as a reference period in calculating a climatology for each calendar month and each $2^{\circ}$ box from the COADS dataset, provided that data for at least 10 years with more than 5 observations per month were available in the period. The monthly means for each $\mathrm{i}$ grid point and $\mathrm{j}$ month were computed as a weighted average 

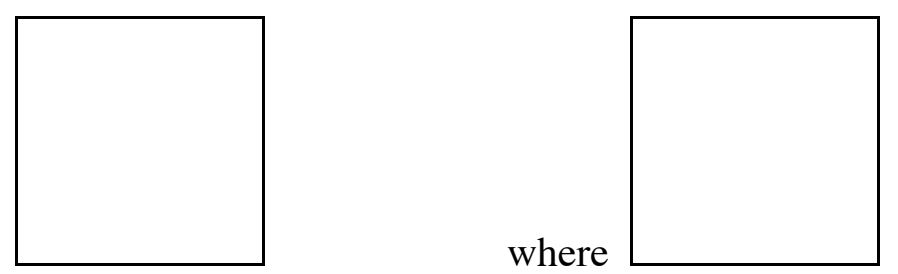

Here $\mathrm{X}_{\mathrm{ijk}}$ is the value computed for the ith box, jth month and kth year. $\mathrm{N}_{\mathrm{ijk}}$ is the number of ship-observations used in computing $\mathrm{X}_{\mathrm{ijk}}$. $\mathrm{W}_{\mathrm{ijk}}$ is in the neighborhood of 1 if $\mathrm{N}_{\mathrm{ijk}}>10$ and near 0.5 if $\mathrm{N}_{\mathrm{ijk}}$ equals 5 .

(ii) After this first step, time monthly anomaly series for each $2^{\circ}$ box during the $1950-1980$ period were computed by simply subtracting from each value this climatology, provided that neither the datum nor the climatology were missing. These anomalies were then spatially averaged over the selected areas by using the same weighting scheme (e.g., $\mathrm{W}_{\mathrm{ijk}}$ ) as used in the computation of the climatology.

Various ENSO indices (SST Niño3, SLP Darwin and Tahiti time series) are finally adapted from the NCEP website (http://www.cpc.ncep.noaa.gov/). From the SLP Tahiti and Darwin time series, a Southern Oscillation Index (SOI) was simply derived as the difference of the monthly (or seasonally) standardized values (zero mean and unit variance) at both stations (Tahiti minus Darwin).

Composite and correlation analyses have been performed to highlight the space-time structure of ISM variability and the complex SST-ISM relationships. For all correlations computed in this study the statistical significance of the result has been assessed with a classical two tail ttest without taking into account the serial correlation of the time series. This is justified by the fact that all the correlations are based on yearly sampled series (a large time increment) showing white noise spectra and insignificant lag-1 autocorrelations. When computing a 
correlation with a time series from COADS, the standardized anomalies for the other time series are always computed with respect to a climatology computed from the 1950-1980 period. A new method was used in order to replace the more common (and inappropriate) Student's t-test to establish the significance of our composites. The procedure was adapted from French statistical literature (Lebart et al., 1995, pp. 181-182) and is described in Appendix A. As designed, the procedure aims at determining the aspects of our composites that are significantly distinct from the background variability in the available data, not in a hypothetical population. This procedure is appropriate for exploratory studies and tries to cure some of the problems raised by Nicholls (2001) on the insignificance of significance testing in climate research. All the critical probabilities associated with our composites are calculated with this method. Note finally that various significance levels $(0.1,1,10 \%)$ are plotted on the figures in agreement with the suggestions of Nicholls (2001).

Wavelet analysis (Torrence and Compo, 1998) has been used to reveal the temporal structure of the various time series. Morlet wavelet transforms display the variance of a time series as a continuous function of time and frequency. In addition, a global wavelet spectrum can be deduced from the wavelet spectrum. Significance testing using a white noise background has been done following Torrence and Compo (1998) for most time series.

3. Dominant modes of seasonal variations in the Indian Summer Monsoon

To discuss the interannual variability of the ISM, a measure of ISM strength must be defined. There have recently been considerable investigations on the definition of valuable rainfall or dynamical monsoon indices. Wang and Fan (1999) compared a variety of dynamical indices computed from the NCEP reanalysis and concluded that large discrepancies still exist during 
some years between convection/rainfall and dynamical indices for the ISM. Annamalai et al. (1999) studied the behavior of the ISM using ERA and NCEP reanalyses and suggested that the All India Rainfall Index (AIRI) defined by Parthasarathy et al. (1995) is currently the most accurate measure of rainfall over the Indian subcontinent. Consequently, we first reexamine the monthly and seasonal AIRI in order to describe the main features of ISM rainfall variability over India.

Table 1 presents basic statistics (means and standard deviations) of the monthly AIRI. The correlations among the monthly AIRI during boreal summer as well with the seasonal AIRI are also given in Table 1. All these statistics have been computed during the 1871-1998 period. India experiences a maximum in precipitation in July, with a rapid decline in September. The latter is related to the fact that the monsoon has already withdrawn from the northern parts of India in September (Krishnamurthy and Shukla, 2000). However, the interannual variability of the seasonal AIRI is also linked to the interannual variability of the Late Indian Summer Monsoon (LISM), during August and September. Both standard deviations of the monthly AIRI and the correlation of these indices with the seasonal AIRI increase from the onset (June) to the withdrawal of the ISM (September). It is noteworthy that the correlation between the June and seasonal AIRI is only 0.38, while the correlation between the September and seasonal AIRI is as high as 0.64. Another interesting feature is that correlations between succeeding monthly AIRI also increase during the boreal summer. This supports the notion of a seasonally persistent rainfall anomaly pattern, at least for the months of the LISM (Webster et al., 1998; Krishnamurthy and Shukla, 2000). The preceding results also suggest that the mechanisms sustaining ISM interannual variability are somewhat different during the early and late ISM (Ailikun and Yasunari, 2001). 
In order to further investigate these aspects of ISM variability, EOF analysis of the seasonal rainfall anomalies over the 29 meteorological Indian subdivisions during the 1871-1998 period has been performed. The EOFs and the associated principal components are computed from the correlation matrix of the anomalies. The first three EOFs of the standardized seasonal anomalies are shown in Figure 1. The spatial loadings associated with each EOF can be interpreted as correlation coefficients between the corresponding Principal Component (PC) and the ISM rainfall time series of the 29 Indian subdivisions. The first EOF is associated with $30 \%$ of the seasonal variance. This EOF has the same sign over almost all of India, though the spatial loadings are particularly high over the western part of the Indian subcontinent. The second EOF is associated with $13 \%$ of the seasonal variance, and opposes the central part of India with the foothills of the Himalayas and the southern tip of India. The third EOF described $10 \%$ of the variance and is associated with a more complicated spatial pattern. Global wavelet power spectrum of the PC1 time series (Fig. 1d) shows that EOF1 basically describes the spatial pattern of ISM rainfall anomalies associated with the Tropospheric Biennial Oscillation (TBO; Meehl, 1997; Meehl and Arblaster, 2002a). Significant power in the decadal range is also observed in Figure 1.d. The wavelet spectrum of PC2 shows significant spectral peaks at 4 and 12 years while the PC3 wavelet analysis shows substantial variance around the 4 years time scale (not shown). The correlation coefficient between PC1 and the seasonal AIRI is 0.88 while the correlation coefficient between PC2 and the seasonal AIRI is only -0.16 and is insignificant at the $5 \%$ level. Interestingly, PC3 has also a high and significant correlation $(0.42)$ with the AIRI. In summary, these results suggest that EOF1 is associated with the dominant mode of ISM rainfall interannual variations over India. Further substantiating this finding, we note that the spatial pattern depicted by EOF1 shows striking similarities to the flood or drought ISM rainfall composites presented by Terray (1995) or Krishnamurthy and Shukla (2000). 
The atmospheric circulation associated with the dominant modes of ISM rainfall variations is now examined using the NCEP-NCAR reanalysis and the COADS dataset. We have used three dynamical monsoon indices from the NCEP-NCAR reanalysis in order to link the rainfall variability to the broad-scale ISM circulation in this study. The three dynamical indices are:

- The Indian Monsoon Index 1 (IMI1) suggested by Wang et al. (2001), defined as the difference of the standardized zonal wind anomalies at $850 \mathrm{hPa}$ between a southern region of $5^{\circ}-15^{\circ} \mathrm{N}, 40^{\circ}-80^{\circ} \mathrm{E}$ and a northern region of $20^{\circ}-30^{\circ} \mathrm{N}, 70^{\circ}-90^{\circ} \mathrm{E}$. This dynamical index reflects the intensity of the westerly flow over the Arabian Sea and the lower tropospheric vorticity anomalies associated with the Rossby wave response to the ISM trough and convective heating.

- In summer, southwesterlies at the surface and northeasterlies at upper levels prevail over the Asian region. At $1000 \mathrm{hPa}$, the flow of the Southern Hemisphere crosses the Equator mainly near the African coast and forms the so-called Somali jet. At $200 \mathrm{hPa}$, the most outstanding feature is a huge anticyclonic circulation, the so-called Tibetan Plateau high, centered over the southern part of the Tibetan Plateau. At this level, the cross-equatorial flow from the Northern Hemisphere to the Southern Hemisphere is mainly concentrated along the southeastern periphery of the Tibetan high. Therefore, another ISM dynamical index may be defined as the difference between the standardized wind anomaly on the southwest-northeast axis at $1000 \mathrm{hPa}$, area-averaged over the region $43^{\circ} \mathrm{E}-55^{\circ} \mathrm{E}, 5^{\circ} \mathrm{S}-11^{\circ} \mathrm{N}$ (hereafter Somali jet area), and the standardized wind anomaly on the southwest-northeast axis at $200 \mathrm{hPa}$ area-averaged over the region $70^{\circ} \mathrm{E}-110^{\circ} \mathrm{E}, 5^{\circ} \mathrm{N}-30^{\circ} \mathrm{N}$ (hereafter the Tibetan High area). Hereafter, this time series is referred to as the Indian Monsoon Index 2 (IMI2). 
- Finally, the Indian Ocean meridional wind shear index (VSI) is defined as the difference between the standardized meridional wind anomalies at 1000 and $200 \mathrm{hPa}$ area-averaged over the same regions used to define IMI2. The VSI is similar to the Monsoon Hadley Index proposed by Goswami et al. (1999), except the $1000 \mathrm{hPa}$ and $200 \mathrm{hPa}$ meridional wind time series have been standardized before computing the difference and the meridional wind at low levels is only averaged over the Somali jet area. This index intends to quantify the cross-equatorial Hadley circulation over the Indian Ocean during boreal summer.

Various surface wind indices have also been computed from the COADS dataset with the technique explained in section 2:

- The wind anomaly on the southwest-northeast axis area-averaged over the Somali jet area (hereafter WSOMAI).

- The zonal wind anomaly area-averaged over the west Arabian Sea area $\left(7^{\circ}-21^{\circ} \mathrm{N}, 51^{\circ}\right.$ $\left.63^{\circ} \mathrm{E}\right)$. Hereafter, this time series is referred to as the zonal wind West Arabian Sea Index (UWARAI).

- The wind anomaly on the southwest-northeast axis area-averaged over the east Arabian Sea area $\left(7^{\circ}-21^{\circ} \mathrm{N}, 63^{\circ}-75^{\circ} \mathrm{E}\right)$. Hereafter, this time series is referred to as the wind east Arabian Sea Index (WEARAI).

Table 2 presents the correlation coefficients between the seasonal AIRI, the first three PCs of ISM rainfall and the seasonal dynamical indices constructed from the NCEP reanalysis and COADS dataset. The correlation coefficients have been computed during the 1948-1998 and 1948-1992 periods for the NCEP and COADS indices, respectively. All the seasonal ISM circulation indices show high and significant correlations with rainfall ISM PC1 and AIRI, 
particularly IMI1 and IMI2. On the other hand, no significant correlations are found with rainfall PC2, except for IMI1. In addition, if the monthly dynamical indices are correlated with the seasonal rainfall PC1 (Table 3), a systematic display of monthly correlations is found. The monthly correlations gradually increase during the ISM and reach their maximum during the LISM. These systematic relationships suggest that the dominant mode of ISM rainfall variations is associated with large-scale circulation anomalies in the Asian monsoon region and that these anomalies are much more pronounced during the LISM. Both the zonal wind shear and the cross-equatorial Hadley circulation during the LISM are significantly linked to the seasonal rainfall anomalies over the Indian subcontinent. Additionally, wavelet analysis of the LISM (August and September) IMI1 shows substantial variance in the 2-3year period range during most of the data record (Fig. 2). Similar results are obtained with IMI2 or VSI (not shown). Thus, the TBO appears to be a fundamental characteristic of dynamical indices during the LISM.

To further identify the atmospheric patterns associated with strong and weak ISM years, rainfall, wind and stream function composites were constructed for the period 1948-1998 from the NCEP reanalysis. Using the criterion that years with seasonal AIRI anomalies greater than 1 standard deviation are categorized as strong monsoons and years associated with anomalies of less than -1 standard deviation are considered weak monsoons, there are 8 strong ISM years and 11 weak ISM years during the recent 51 years. The strong ISM years are 1956, 1959, 1961, 1970, 1975, 1983, 1988 and 1994. The weak ISM years are 1951, 1965, 1966, 1968, 1972, 1974, 1979, 1982, 1985, 1986 and 1987. The 850 and $200 \mathrm{hPa}$ seasonal wind composites with respect to strong and weak ISMs (not shown) are almost identical to those based on IMI1 presented by Wang et al. (2001). The results verify the findings that the upper-level monsoon circulation is coupled with the low-level monsoon circulation and that 
both reflect the rainfall anomalies associated with the monsoon trough over the Indian subcontinent. However, composite analysis of monthly dynamical and rainfall indices with respect to strong and weak ISM years again reveals that ISM interannual variability is strongly influenced by the LISM circulation and rainfall anomalies (Tables 4 and 5). Moreover, the significance of the results increases from June to September for most of indices, particularly for the indices related to the Hadley circulation, the Somali jet and the low-level monsoon winds.

The $200 \mathrm{hPa}$ stream function composites for strong and weak ISM years during the early and late ISMs, presented in Figure 3, illustrate these facts and show another remarkable feature of the circulation patterns associated with anomalous ISM years. Positive (negative) values of the stream function denote clockwise (anticlockwise) motions. It can be noticed immediately that in the upper troposphere, both the Tibetan Plateau and Mascarene highs are strengthened (weakened) during the LISM of the flood (drought) years. Furthermore, it may be deduced from the composite maps that the tropical easterly jet is stronger (weaker) and that both anticyclones are shifted westward (eastward) during LISM of flood (drought) years. This verifies an earlier result of Chen and Van Loon (1987) with a much larger dataset. Significant teleconnection patterns with extratropical latitudes in both hemispheres are also notable during LISM. Interestingly, the $200 \mathrm{hPa}$ stream function composite standardized anomalies during the early ISM (June and July) are much less defined and are not significant at the $10 \%$ confidence level over the Indian region excepted for areas around Madagascar during weak early ISMs.

All the results presented above suggest that changes in the three-dimensional monsoon system are involved during the flood and drought years. But what is very striking is that the anomalous signal is particularly strong and significant during the LISM. Therefore, the 
traditional ISM season could be divided into two sub-periods June-July and AugustSeptember. These results are important to the predictability of ISM rainfall, since they suggest that the dominant mode of ISM variability may be an integral part of a low-frequency coupled ocean-atmosphere-land fluctuation which is dominant during the LISM.

\section{Observed SST relationships}

We now examine the lead-lag relationships between the ISM and Indo-Pacific SST. The focus is on precursory signals of rainfall and circulation variability associated with both ISM and LISM. We are particularly concerned with potential predictability of the (L)ISM and its link to local (Indian Ocean) and remote (Pacific) SST forcing.

\section{a. (L)ISM-Indo-Pacific SST relationships}

We first illustrate the role of Pacific and Indian SST on ISM circulation anomalies with a composite analysis of the Reynolds SST dataset based on ISM AIRI. The strong and weak ISM years used to construct the composites are the same as those used in the preceding section. Composite standardized SST anomalies over the Indo-Pacific areas during January, February and March preceding the weak ISM years are shown in Figure 4. A weak LISM is preceded in northern winter by cold SST anomalies over the tropical Indian Ocean and a SST dipole pattern in the subtropical southern Indian Ocean with a positive anomaly to the southeast of Madagascar and a negative anomaly to the west of Australia (positive south dipole event hereafter). This dipole pattern strengthens from January to March, and both the positive and negative anomalies become significant in March. The extent and significance of the cold SST anomalies are, however, much more distinct. This dipole pattern is similar to the SST 
dipole events studied recently by Behera and Yamagata (2001). We will refer to this SST dipole as the south Indian Ocean SST dipole to avoid confusion with the tropical Indian Ocean dipole of Saji et al. (1999). Inspection of the composite wind and latent heat flux anomalies shows that during the mature phase of positive south dipole events, the subtropical Mascarene high is strengthened and shifted southward (not shown). This is followed by the amplification of the southeasterlies along the eastern edge of this anticyclone associated with enhanced evaporation and upper ocean mixing off Australia. A decrease in the latent heat loss due to reduced evaporation in the western subtropical Indian Ocean is also observed during austral summer. From January to February of weak ISM years, the SST anomalies in the equatorial Pacific also resemble a decaying La Niña state with cold SST anomalies in the central-eastern equatorial Pacific and positive SST anomalies in the western equatorial Pacific, though this pattern is not significant. Inspection of the composite fields for the years preceding weak ISM years corroborates the fact that cold SST anomalies in the equatorial eastern Pacific and the Indian Ocean can be traced back to the preceding winter. The strong ISM SST composites are presented in Figure 5. These composites approximately reverse the structure seen in the weak ISM SST composites, particularly in the southern subtropical Indian Ocean and the tropical Pacific. For example, in February-March preceding strong ISM years, significant warm SST anomalies are observed in the eastern part of the southern Indian Ocean off Australia, and are associated with negative SST anomalies south of Madagascar (negative south dipole events hereafter). From January to February of strong ISM years, a decaying El Niño state is also observed in the Pacific, with warm SST anomalies in the central-eastern equatorial Pacific and tropical Indian Ocean, negative SST anomalies in the subtropical mid-Pacific, and positive SST anomalies in the eastern North Pacific. The strong ISM SST composites are, however, less defined than the corresponding weak composites in terms of significant features. 
Composites of SST based on early and late ISM AIR indices have also been formed in order to elucidate the role of SST boundary forcing on the ISM. Using the criteria that years with early (late) ISM AIRI anomalies greater than 1 standard deviation are categorized as strong early (late) ISM years and that years associated with early (late) ISM AIRI anomalies less than -1 standard deviation are considered weak early (late) ISM years, there are 6 (8) strong and 6 (9) weak early (late) ISM years during the recent 51 years. The strong early ISM years are 1956, 1961, 1971, 1977, 1990 and 1994. On the other hand, the strong LISM years are 1955, 1958, 1961, 1970, 1973, 1975, 1983 and 1988. The weak early ISM years are 1965, 1972, 1974, 1979, 1987 and 1992. Finally, the weak LISM years are 1951, 1952, 1965, 1966, 1968, 1972, 1979, 1986 and 1991. Composite standardized SST anomalies over the IndoPacific areas during February-March preceding the weak/strong early and late ISM years are shown in Figure 6. The SST composites for the early and late ISMs are strikingly different suggesting that the SST boundary forcing associated with the early and late ISMs is reversed. Moreover, the significance of the SST anomalies over the Indian and Pacific oceans is only marginal for the early ISM composites. However, inspection of the early ISM SST composites during April-May suggests a significant influence of a developing El Niño (La Niña) during weak (strong) early ISM years (not shown). On the other hand, positive (negative) dipole events in the southern Indian Ocean are significant precursors of weak (strong) LISM years as for the weak (strong) ISM years (Figs. 4 and 5). Interestingly, another SST dipole is established over the central and eastern North Pacific for weak (strong) LISM years, resembling that occurring during the decay phase of La Niña (El Niño) events (Larkin and Harrison, 2001). This North Pacific dipole fades away during boreal spring preceding weak or strong LISM years (not shown). Thus, the LISM SST composites emphasize the role of extratropical SST anomalies onto LISM variability. The symmetry of the strong and weak 
LISM SST composites, both in terms of anomaly patterns and significant features, is also remarkable compared to the strong and weak ISM SST composites.

The main conclusion we can draw from the previous composite analyses is the large signal found in the subtropical southern Indian Ocean and North Pacific both for ISM and LISM. This corroborates the existence of key regions for (L)ISM prediction and TBO transitions, outside the equatorial Pacific (Meehl, 1997; Meehl and Arblaster, 2002a). These hypotheses deserve further exploration in the next sections. Due to the strong similarity between the ISM and LISM SST composites, we focus particularly on the LISM in the rest of the paper.

\section{b. (L)ISM-ENSO relationships}

We now analyze the lead-lag relationships between various ENSO indices and interannual variability of the (L)ISM in more details.

The lag-correlations of ISM and LISM AIR indices with Niño3 SST anomalies in the preceding and following months are plotted in Figure 7a. This figure illustrates the complexity of the relationship between the ISM AIRI and Niño3 SST anomalies used as an ENSO index. The Niño3 SST anomalies in January and February before the ISM have a weak positive correlation with ISM rainfall. From February to June, the correlations become gradually negative and significant. Finally, highly significant negative correlations occur in late summer, fall and winter, suggesting that anomalous monsoons provide very favorable conditions for triggering cold/warm events in the Pacific during the following winter, or at least for enhancing an ongoing warm/cold event (Kirtman and Shukla, 2000). On the other hand, Niño3 SST anomalies in the previous winter do not seem to help in forecasting the 
intensity of the following ISM as a whole. This illustrates the problem of the so-called predictability barrier that affects ENSO indices during boreal spring (Torrence and Webster, 1998). However, the correlations of winter (January and February) Niño3 SST anomalies with the LISM AIRI are significant at the 5\% level (Fig. 7a). This suggests that the LISM will be strong (weak) after El Niño (La Niña)-like conditions during the preceding winter. These SST anomalies decay and switch sign in boreal spring, as for the full ISM. The cooling (warming) continues until the following winter.

Lead-lag relationships between Southern Oscillation indices (SOI and Darwin SLP) and (L)ISM dynamical indices (IMI1, IMI2, VSI) have also been investigated (Figs. 7b and 7c). The results suggest the existence of a long-range potential predictability of LISM dynamical indices related to the interhemispheric Hadley circulation over the Indian Ocean based on SO indices (Fig. 7c). This is consistent with Figure 7a in showing that the LISM AIRI is more predictable than the ISM AIRI. On the other hand, the LISM IMI1 is no more predictable than the ISM IMI1 in the context of ENSO-monsoon relationships (Fig. 7b). Another conspicuous feature in Figure $7 \mathrm{~b}$ is the higher observed correlation between the SOI and the LISM IMI1 after the ISM onset as compared to the correlation between the SOI and the ISM IMI1.

A strong ISM is preceded by a transition from an El Niño state to a La Niña state and vice versa (Wang et al. 2001). These relationships which are inherent in the TBO transitions during northern spring (Meehl and Arblaster, 2002a) corroborate the earlier finding of Shukla and Paolino (1983) who have suggested that the trend of ENSO indices in the preceding spring is a better predictor of the ISM than the indices themselves. However, Figure 7a shows that all these features are mainly associated with the LISM and not with the whole ISM. Second, the fact that the LISM is more affected by the anomalous state of ENSO in the 
previous winter than the ISM as a whole, seems to be linked to the Hadley circulation over the Indian Ocean.

\section{c. (L)ISM-Southern Indian Ocean SST relationships}

To further substantiate the importance of the south dipole mode in the southern Indian Ocean, we have computed area-averaged SST monthly anomalies for two key regions in the subtropical Indian Ocean. The regions are the eastern $\left(71^{\circ} \mathrm{E}-121^{\circ} \mathrm{E}, 5^{\circ} \mathrm{S}-25^{\circ} \mathrm{S}\right)$ and western $\left(50^{\circ} \mathrm{E}-75^{\circ} \mathrm{E}, 35^{\circ} \mathrm{S}-45^{\circ} \mathrm{S}\right)$ southern Indian Ocean. Hereafter the corresponding SST time series are referred to as the South East Indian Ocean Index (SEIOI) and the South West Indian Ocean Index (SWIOI), respectively. Finally, we define a South Dipole Mode (SDM) time series as the difference between the monthly (or seasonally) standardized SWIO and SEIO indices. The different time series have been computed both from COADS and Reynolds datasets in order to demonstrate the robustness of the results.

The wavelet spectra of the winter (January-March) SST SEIO and SDM indices from the Reynolds dataset have a leading energy peak at a period of 30 months, significant at the $90 \%$ confidence level against a white (or red) noise spectrum (SDM is shown in Fig. 8). The time series computed from COADS give similar results. Winter SST SDM indices fluctuate with a quasi-biennial rhythm, similar to the (L)ISM rainfall and dynamical indices. In addition, the cross-correlations between the winter SEIOI time series and the (L)ISM rainfall and dynamical indices are very high and significant (Table 6). It is interesting to observe that the lag-correlations increase significantly using the LISM indices, particularly for the meridional wind shear index (VSI). This suggests that the SST anomalies over the SEIO may play a key role in the interannual variability of the interhemispheric Hadley cell and more generally with 
the variability of the entire ISM circulation system, since the lag-correlations are statistically significant with all the (L)ISM indices. In order to confirm these results, we have computed the lag-correlations between the winter SEIOI and monthly wind anomalies in selected ISM key areas from the COADS SST and wind data (Fig. 9). The key-areas are the same as used in section 3: the Somali jet area, the West and East Arabian Sea. The correlations increase substantially and are highly significant for the LISM, particularly for the meridional wind along the east coast of tropical Africa and the zonal wind over the East Arabian Sea. The above results obtained from the COADS dataset again suggest that the strength of the crossequatorial surface flow during the LISM is predictable using the winter SEIOI.

However, a necessary condition for a winter SEIO SST anomaly influence on the next LISM is the persistence of these winter SST anomalies through late summer. To investigate this feature, the lag-correlations between SEIOI, SWIOI and SDM in each month and SEIOI, SWIOI and SDM in the preceding winter (January, February, March) have been computed, as shown in Figure 10. A similar analysis has been performed with the Niño3 SST index and SOI in order to illustrate the remarkable persistence of the SDM SST indices in northern spring and summer. A strong persistency is seen from winter to the succeeding spring, summer and fall for the SDM SST indices, particularly for the SEIOI. In contrast, the autocorrelation of the ENSO indices decay rapidly, and no significant lag-correlations are found after spring. This lack of persistence in northern spring is a common feature of many ENSO indices and is generally attributed to the phase locking of ENSO to the annual cycle (Torrence and Webster, 1998). However, the main point is that SEIOI transitions do not occur during northern spring, but later in boreal fall (Nicholls, 1984; Saji et al., 1999, Webster et al., 1999; Meehl and Arblaster, 2002a). Surprisingly, SWIOI and SDM also show some persistence 
until the end of the next ISM. Similar results are obtained with SDM SST indices computed from the COADS data.

At this point, it is worthwhile to describe our working hypotheses for the influence of the SEIO SST anomalies on ISM variability. There are two competing ways ISM variability could be affected by SEIO SST anomalies. First, the cross-equatorial flow may bring in additional moisture due to the increase in local evaporation when positive SST anomalies occur over the SEIO. As the southern tropical Indian Ocean supplies about two-thirds of the moisture that accounts for ISM precipitation (Hastenrath and Greischar, 1993), a larger moisture content over the SEIO could lead to increased moisture convergence in the monsoon trough, thereby enhancing the whole monsoon system. The second scenario involves the fact that the LISM is strongly linked to fluctuations of the interhemispheric Hadley cell and the low-level cross-equatorial gyre over the Indian Ocean that connects the monsoon trough to the Mascarene high at the surface. Both circulation features are partly linked to the strength or position of the Mascarene High in the Southern Indian Ocean and we propose that the SEIO SST anomalies may exert an influence on the LISM through a modulation of the position of the Mascarene high during boreal summer. Colder (warmer) than normal SST in the SEIO from spring to fall may be postulated to increase (decrease) surface pressure and wind divergence and provide a remote forcing for the ISM atmospheric circulation by delaying the seasonal transition of the Mascarene high and shifting to the East (West) the position of this anticyclone during boreal summer.

In order to test the validity of these two postulates, Figure 11 shows the lead-lag correlations between monthly SDM SST indices and LISM dynamical and rainfall indices. The persistence of the positive correlation between monthly SEIO SSTs and the LISM VSI is 
remarkable. This result is in agreement with the role of the SEIO SST anomaly on the Hadley circulation mentioned above. However, the most striking feature in Figure 11 is that the magnitude of the correlation coefficients increases in August. This suggests a local atmospheric response to the SEIO SST anomaly that may act as a positive dynamical feedback on the SDM SST. Further insight into the validity of our two postulates is provided by composites of wind, SLP, latent heat flux and SST with respect to weak and strong LISM years. Figures 12 and 13 show the wind and SLP composites, respectively. Associated with a strong LISM are strong low-level westerly and southwesterly flows over the Arabian Sea. The circulation pattern suggests an enhancement of the monsoon low-level interhemispheric gyre circulation. Worth noting is the reduced southerly flow into the Bay of Bengal. Only one branch of cross-equatorial flow, along the east coast of Africa, can be identified during strong LISMs. Another conspicuous feature during strong LISMs is the existence of significant circulation anomalies over the southern Indian Ocean (south of $10^{\circ} \mathrm{S}$ ). Significant anticlockwise circulation anomalies are apparent around Madagascar while clockwise circulation anomalies are prominent between $70^{\circ} \mathrm{E}$ and Australia. These anomalous circulations suggest a westward shift of the Mascarene high during strong LISMs and support the second postulate. The strong LISM SLP composite (Fig. 13) is in agreement with this conclusion since it shows a tilted band of negative SLP anomalies stretching from the North Arabian Sea to the SEIO with significant negative SLP anomalies observed over the North Arabian Sea and off Australia (Fig. 13). This leads to a stronger interhemispheric pressure gradient in the western Indian Ocean, resulting in a stronger Somali jet. Furthermore, another effect of the anomalous position of the Mascarene high is a weaker interhemispheric flow into the Bay of Bengal (Fig. 12) associated with a weaker interhemispheric pressure gradient in the eastern Indian Ocean. The reverse wind and SLP patterns are observed during weak LISMs (Figs. 12 and 13). Moreover, the wind anomalies in the southern Indian Ocean reach 
the $0.1 \%$ significance level in the weak LISM wind composite. These wind anomalies suggest a significant southeastward shift of the Mascarene high during weak LISMs. The weak LISM SLP composite corroborates again this hypothesis though the statistical significance of the SLP anomalies is lower than for the strong LISM SLP composite (Fig. 13). Another interesting feature of the weak LISM wind composite is a significant teleconnection pattern in the Northern hemisphere. A key feature of the wind and SLP composites shown in Figures 12 and 13 is thus the shift of the Mascarene high in association with monsoon strength. This feature was documented as far back as Krishnamurti and Bhalme (1976) and led these authors to advance the notion of ISM circulation system. However, the possible association between the shift of the Mascarene High and the southern Indian Ocean SST anomalies was not documented by Krishnamurti and Bhalme (1976) and we explore this relationship now.

The latent heat flux and SST composites are shown in Figures 14 and 15, respectively. Positive values indicate heat loss from the ocean and vice versa for the latent heat flux composites. Higher (lower) latent heat loss in the eastern (western) southern Indian Ocean region contributes to the amplification of the positive SDM pattern during weak LISM years (Figs. 11 and 15). This is again consistent with the southeastward shift of the Mascarene high during weak LISM years. In contrast, during strong LISM years, the latent heat loss is stronger (lower) in the western (eastern) southern Indian Ocean and produces colder (warmer) SST in the central and western (eastern) southern Indian Ocean (Figs. 14 and 15). This strengthens the negative SDM pattern (Fig. 11) and is again in agreement with the second postulate. If the first postulate were true, we would expect a damping of the SST anomalies through latent heat loss anomalies associated with stronger trade winds over the SEIO during strong LISM years and vice versa. However, the observed results show the reverse with amplified SDM SST anomalies during the LISM (Fig. 11) sustained by a positive wind- 
evaporation feedback (Figs. 14 and 15). This feature is inconsistent with the first postulate. Another interesting feature in Figure 15 is the absence of significant SST anomalies in the northern or equatorial Indian Ocean both for strong and weak LISMS.

Weak (strong) (L)ISMs typically occur during the onset and maturing stages of El Niño (La Niña) as illustrated in Figure 7. Thus, it may be argued that it is unclear to what extent SEIO SST anomalies actually force anomalies in ISM rainfall and circulation as compared to SST anomalies directly associated with ENSO. Furthermore, the maximum effect of ENSO is noted during LISM (Slingo and Annamalai, 2000; see also Fig. 7b) and ENSO also influences the Mascarene high intensity (Lau and Nath, 2000), thus obfuscating the role of local or remote forcing on ISM variability. On the other hand, SEIO SST anomalies emerge before the onset of El Niño or La Niña events in the Pacific which peak at the end of the year (Fig. 6). This is inconsistent with the hypothesis that the observed SST anomalies during boreal summer are solely a consequence of an ongoing ENSO. The analysis of Behera and Yamagata (2001) is also in agreement with this interpretation. Composites of (L)ISM rainfall, wind and stream function with respect to winter (January-March) SEIO SST anomalies are now formed in order to elucidate the role of local forcing (SEIO SST) for producing the observed evolution of anomalous LISMs displayed in Figures 12 and 13. Warm/cold years are defined in terms of winter SEIOI exceeding +/-0.75 standard deviation relative to the long-term mean. Warm years are 1958, 1959, 1964, 1970, 1978, 1983, 1988, 1992, 1995, 1998. Cold years are $1951,1952,1953,1956,1960,1965,1966,1968,1971,1974,1976,1982$. Out of the 10 warm SST SEIO years, only one is a deficient LISM rainfall year (negative LISM rainfall anomaly) and 6 years have LISM rainfall in excess of 0.75 standard-deviation above the longterm mean. Out of the 12 cold SST SEIO years, only 3 are excess LISM rainfall years 
(positive LISM rainfall anomaly) and 6 years have LISM rainfall less than 0.75 standarddeviation below the long-term mean.

Table 7 shows the results of the composite analysis of the (L)ISM rainfall and dynamical indices with respect to warm and cold SEIO SST years. These statistics indicate a robust link between (L)ISM rainfall and circulation features and SEIO SST anomalies. The relationship is particularly strong and significant for LISM rainfall and circulation indices related to the local Hadley circulation of warm SEIO SST years. The LISM composite rainfall anomaly associated with the cold SEIO SST years is also remarkable.

Rainfall composites were also prepared from the LISM rainfall series of the 29 Indian subdivisions (Fig. 16). The ISM rainfall composites have a similar structure but are little less significant (not shown). Deficient (heavy) rainfall over most of the Indian subcontinent observed during the cold (warm) years is accompanied by anomalies of the opposite sign for the northeastern part of India. Overall, the structures of the warm (cold) SEIOI rainfall composites have striking resemblances to the strong (weak) AIRI rainfall composites (Terray, 1995; Krishnamurthy and Shukla, 2000). In order to further investigate the influence of SEIO SST on monsoon circulation and the whole ENSO-monsoon system, the anomalous wind patterns at $850 \mathrm{hPa}$ during the LISM for warm and cold winter SEIO SST anomalies are shown in Figure 17. There is an opposite wind pattern in the Asian monsoon region for warm and cold SEIO SSTs. The structure of the warm SEIO SST wind composite indicates that an enhanced low-level cross-equatorial flow in the Somali jet area, a deeper ISM trough and a westward shift of the Mascarene high are significant characteristics of warm SEIO SST years (Fig. 17a). The spatial wind anomaly pattern over India and adjacent oceanic areas also reflects the intensity of the lower tropospheric vorticity anomalies associated with the Rossby 
wave response to the positive ISM rainfall and convective heating anomalies during warm SEIO SST years. Meanwhile, the cross-equatorial flow into the Bay of Bengal is reduced during the LISM of the warm SST years. The reverse structure is observed and is significant for the cold SEIO SST anomalies (Fig. 17d). Overall, the wind composite pattern of Figure 17a (17d) for the Indian Ocean bears a strong resemblance to the strong (weak) LISM wind composite in Figure 12a (Fig. 12d). Inspection of the stream function composites confirms that the whole three-dimensional LISM system is stronger (weaker) during warm (cold) SST years (not shown). Another interesting feature in Figure 17 is the very significant wind anomalies observed over the Pacific suggesting that the SST SEIO anomalies may also play a significant role in the evolution of El Niño or La Niña events and in TBO transitions of the coupled tropical system. The detailed analysis of these interesting features is beyond the scope of this paper. But, this significant relationship contradicts the idea that SST anomalies in the southern Indian Ocean are just the response to ENSO forcing and have no role to play in the ENSO-monsoon system.

While the determination of the relative role of SEIO SST and ENSO on the evolution of ISM can probably only be addressed with careful GCM experiments, the previous results together suggest that SEIO SST anomalies which are set up during boreal winter are a significant precursor for both the broad-scale LISM circulation and the ENSO evolution in the Pacific.

\section{Summary and discussion}

The principal purpose of this study has been to investigate the impact of Indo-Pacific SST anomalies on the ISM. Special emphasis has been given to Indian Ocean SST variability. 
Several investigators have addressed this problem before and contradictory results have been obtained for the Indian Ocean. However, most of these studies investigated the atmospheric response to SST anomalies over the equatorial or northern Indian Ocean. Only a few studies considered southern Indian Ocean SST anomalies. In this work, we have shifted our attention away from the northern and equatorial Indian Ocean and found that well-defined precursory signals for the ISM exist in the Southern Indian Ocean.

The ISM exhibits considerable interannual and intraseasonal variability. However, our analysis of observations indicates that strong and weak monsoons are strongly linked to persistent and well-defined rainfall and large-scale circulation anomalies during the LISM. During the LISM of the strong (weak) years, both the Tibetan Plateau and Mascarene highs are strengthened (weakened) and shifted westward (eastward) at $200 \mathrm{hPa}$. At the surface, the Somali Jet and the zonal wind over the Arabian Sea are strengthened (weakened) during the LISM of the strong (weak) years, suggesting an enhanced (decreased) cross-equatorial monsoon flow near the coast of East Africa. The whole three-dimensional monsoon fluctuates during the LISM of the anomalous years. It is difficult to explain why LISM is different from the beginning of ISM (in June and July). One possible reason is that the IntraSeasonal Oscillation (ISO) of ISM is strongest during the early ISM and that this ISO activity is highly variable from year to year (Lawrence and Webster, 2001). Moreover, summertime ISO activity is uncorrelated to SST variability according to Lawrence and Webster (2001). Another possible reason is that statistics computed from June and July may be strongly dependent on the date of the ISM onset, which is also uncorrelated with seasonal ISM rainfall (Rao and Goswami, 1988). Both reasons may contribute to mask the low-frequency signal during June and July. A final possible reason is that ENSO is strongly linked to the LISM as illustrated in section 4.b and by many others (Slingo and Annamalai, 2000). This question 
warrants further investigation. However, due to the well-defined and broad-scale circulation anomalies associated with the LISM of anomalous years, we focused on the predictability of the LISM in this study.

One important finding is that the Indian Ocean SST acts as a major boundary forcing for the LISM system. We found that SSTs over the southeastern Indian Ocean are significantly lower (higher) during the boreal winter of weak (strong) (L)ISM years. These SST anomalies result from a variety of physical processes. Among them, two factors seem most important. First, as has been well documented, our analysis shows that SST anomalies in the Indian Ocean tend to be in phase with those in the central and eastern Pacific, while those in the western Pacific tend to be out of phase, particularly during boreal winter. The eastern Pacific SST anomaly normally reaches a maximum (or a minimum) in boreal winter during El Niño (or La Niña) events. Thus, cold (warm) SST anomalies during boreal winter in the southeastern Indian Ocean off Australia are strongly associated with La Niña (El Niño) events in the Pacific (Kidson and Renwick, 2002). Second, these cold (warm) SST anomalies are considerably amplified in weak (strong) LISM years by positive (negative) south Indian Ocean dipole events, recently studied by Behera and Yamagata (2001). Positive south Indian Ocean dipole events are associated with a strengthening and southeastward shift of the Mascarene high during late austral summer. Southeasterlies west of Australia are enhanced and cold SST anomalies in the southeastern Indian Ocean are significantly amplified due to increased evaporation and upper ocean mixing during positive south dipole events. The reverse situation is observed during negative south dipole events. The SST anomalies set up by these various physical processes are highly persistent and are seen until the end of the following ISM. From austral summer to boreal summer, the Mascarene high normally migrates slightly northwestward. Our results suggest that the cold (warm) SST anomalies set up during late 
austral summer over the southeastern Indian Ocean affect this northwestward movement of the subtropical high. SLP and wind fields from NCEP reanalysis show a southeastward (northwestward) shift of the subtropical high at the surface during weak (strong) LISMs. The same pattern is observed during cold (warm) SEIO SST years. This southeastward (northwestward) shift causes a weakening (strengthening) of the whole monsoon circulation through a modulation of the interhemispheric Hadley cell during the LISM. Corresponding to positive (negative) SEIO SST anomalies, both the Somali jet and the zonal wind over the Arabian Sea are strengthened (weakened), suggesting an enhanced (reduced) cross-equatorial monsoon flow near the coast of East Africa.

The westward (eastward) shift of the Mascarene high during strong (weak) LISMs is associated with a cold SST anomaly in the western (eastern) part of the southern Indian Ocean through a wind-evaporation mechanism. Overall, these SST anomalies enhance the persisting SST dipole pattern in the southern Indian Ocean. The Mascarene high may also further interact with the underlying cold SST anomalies through a positive feedback mechanism that maintains its westward (eastward) position during wet (dry) LISMs. Namely, during LISM, a westward (eastward) shift of the Mascarene high may enhance the negative (positive) SDM SST, which in turn may reinforce the anticyclone. The exact process of this interaction remains an unanswered question and must be addressed with some GCM experiments.

The aforementioned scenario may also help our understanding of why weak ISMs are preceded in boreal spring by a transition from La Niña to El Niño, and vice versa. A developing El Niño in boreal spring and summer may influence the transverse large-scale monsoon through modulation of the geographical position of the Inter Tropical Convergence Zone over the eastern Indian Ocean and the western Pacific (Ju and Slingo, 1995; Ailikun and 
Yasunari, 2001). On the other hand, a La Niña event in boreal winter and the associated cold SST anomalies over the SEIO may also play a key role in the development of weak ISM years through a modulation of the intensity of the lateral monsoon, since the SST anomalies over the SEIO are highly persistent and affect the position of the Mascarene high during the next LISM. However, the relationship between Indian Ocean SDM events and ENSO should be investigated in more detail in order to elucidate the relative contribution of remote and local forcing onto ISM variability.

It is clear from our results that ISM interannual variability, particularly its relationship with the TBO, should be recast in a cross-equatorial context. Moreover, a thorough understanding of the interannual climate variability in the Indo-Pacific region or the TBO must take into account the southern Indian Ocean variability. Recent studies emphasize the role of the transverse monsoon and the tropical east-west circulation for the ISM interannual variability (Ju and Slingo, 1995; Lau and Nath, 2000). However, our principal result indicates that high quality SST precursory signals of the LISM or the TBO exist over the subtropical southeastern Indian Ocean in the preceding winter. A strong (weak) LISM is associated with a westward (eastward) shift of the Mascarene High, a modulation of the local Hadley circulation and a SEIO SST anomaly that may be traced back to the previous winter well before the onset of La Niña or El Niño events in the Pacific.

We have concentrated on the relationship between the ISM and Indian Ocean SST. However, our analysis suggests that LISM variability over India is also more associated, during the preceding winter, with events in the North-Pacific mid-latitudes than over the equatorial Pacific. Though the reason for this significant association is not clear and deserves further 
study, this result again shows that LISM variability is significantly affected by SST boundary forcing.

To what extent the SEIO and North Pacific SST anomalies exert an influence on the whole ENSO-monsoon system is an interesting question to be investigated in a future paper. Another important related task is to determine the role of SEIO SST anomalies and SDM events during the austral summer in the TBO (Meehl and Arblaster, 2002a, 2002b). Finally, it is well-known that significant long-term changes in the distribution of tropical Pacific and Indian Oceans SST have occurred around 1976-77 (e.g. Nitta and Yamada, 1989; Terray, 1994). This climatic shift has altered the SST-ISM and ENSO-ISM relationships (Clark et al., 2000; Kinter et al., 2002). How these interdecadal changes may affect the interannual SEIO SST-LISM relationship will be another important focus of our future work.

\section{Acknowledgments}

Thanks to A. Fischer and G. Reverdin for helpful comments and suggestions during the course of this research. Sebastien Masson provides graphical software for plotting the results.

\section{APPENDIX A}

The goal of composite analysis is to highlight the space-time evolution of a time series or a gridded dataset according to the variations of some index time series. The first step of the method consists in defining groups of years according to the values of the index time series. The second step involves the description of each group of years with the help of the gridded dataset or other time series. Usually, this description is obtained by computing composite means for each group of years. As the years used in the composite means are restricted to 
those years belonging to each group, the resulting maps may be useful to describe the spatial variability associated with each group of years identified by the index time series. While it is easy to compute composite means, assessing the significance of these composite maps is a more difficult task. This is often done with the help of a classical Student's two sample t-test (Morrisson,1990), where one sample consists of the years belonging to one group and the second sample of the other years (or the years belonging to another group). In the usual context of statistical inference, this procedure is used to test the hypothesis of equal population means on the basis of two random samples independently drawn from two normal populations with a common variance $\mathrm{s}^{2}$, but possibly different means. The assumptions of random selection and normality are essential for the validity of the test. As noted by Brown and Hall (1999), this classical test can not be used for statistical inference in composite analysis since composite means are computed from groups of years which are not randomly selected but rather by the value of the index time series. The assumption of normality is also difficult to verify and inappropriate here since the data distribution in each composite is unknown even if the original data distribution is assumed to be Gaussian. Finally, the Student's t-test is inappropriate in exploratory studies which are very common in climate research (Nicholls, 2001). Therefore, we need an alternative procedure for significance testing of our composites. In order to overcome the drawbacks of the Student's t-test, we suggest the following approach to assess chance of occurrence of the composite maps.

Let $\mathrm{x}_{1}, \mathrm{x}_{2}, \ldots, \mathrm{x}_{\mathrm{n}}$ be the raw time series of one grid point $\mathrm{X}$ in the dataset observed during the $\mathrm{n}$ years included in the composite analysis. and $s$ are the sample mean and the sample standard-deviation calculated on these $\mathrm{n}$ values. Suppose now that the $\mathrm{n}$ years are classified by means of an index time series into $\mathrm{k}$ groups and let $\mathrm{C}_{1}, \mathrm{C}_{2}, \ldots, \mathrm{C}_{\mathrm{k}}$ be the $\mathrm{k}$ groups of years. In common applications $\mathrm{k}$ is less than or equal to 3 . Finally, let $\mathrm{n}_{1}, \mathrm{n}_{2}, \ldots, \mathrm{n}_{\mathrm{k}}$ be the number of 
years in each group and be the means computed from the years belonging to each group. Suppose now that we want to assess if the $n_{j}$ values for the grid point $X$ observed during the years in class $\mathrm{Cj}$ are significantly different from the values observed on all the years.

This problem can be treated as the statistical testing of an hypothesis. The null hypothesis $\mathrm{H}_{0}$, as usually stated, is that these $n_{j}$ values were allocated in class $C_{j}$ at random and without replacement among the population of the $\mathrm{n}$ years included in the composite analysis. In order to test this hypothesis, we may compare the actual mean with the expected value of the mean, assuming the null hypothesis $\mathrm{H}_{0}$ is true. More precisely, it may be shown with the help of the theory of random sampling without replacement in a finite population, that is the expected value of the mean for the years in class $C_{j}$ and is the standard-error of the mean for the years in class $\mathrm{C}_{\mathrm{j}}$ if the null hypothesis $\mathrm{H}_{0}$ is true. In order to assess the validity of this null hypothesis, we may then compute the following sample criterion for each grid-point $\mathrm{X}$ in the dataset:

with

In statistical terms, large absolute values of this statistic indicate a strong departure from the null hypothesis. For example, $\mathrm{U}(\mathrm{X})=8$ means that the overall mean in class $\mathrm{C}_{\mathrm{j}}$ deviates from the sample mean by over 8 standard-deviations under the null hypothesis of a random selection of years in group $C_{j}$ in the finite population of the $n$ years.

Finally, the statistic $U$ may be used to compute critical probability, that is to say, the probability that, under the null hypothesis of a random selection of group $C_{j}$ in the finite 
population, the statistic $U$ takes values more discordant than the observed sampled criterion $\mathrm{U}(\mathrm{X})$. More precisely, this critical probability is

$\operatorname{PROB}(\operatorname{abs}(\mathrm{U})>\operatorname{abs}(\mathrm{U}(\mathrm{X})))$ if $\mathrm{H}_{0}$ is true

For this purpose, we need to find the null distribution of the $\mathrm{U}$ statistic. This null distribution may be estimated by means of simulation, as in bootstrapping techniques and (approximate) randomisation tests (Noreen, 1989), or approximated since it is possible to demonstrate that $\mathrm{U}(\mathrm{X})$ is approximately distributed as a Gaussian distribution with mean zero and standarddeviation unity if $\mathrm{H}_{0}$ is true by the use of an extension of the central limit theorem. This is the approximation which is used in the paper since simulations indicate that this approximation is good enough if at least 5 or 6 observations belong to the class $C_{j}$.

In other words, the statistic $U(X)$ may be compared with a critical value $\lambda_{\alpha}$ based on the theory of random sampling in a finite population to determine whether the null hypothesis $\mathrm{H}_{0}$ is to be retained or rejected as in a classical statistical test. This critical value corresponds to the value of the criterion $U$ which would be exceeded by chance with some specified and small probability $\alpha$ (say 0.01 or 0.05 ) if the null hypothesis is true. $\alpha$ represents the significance level of the test. Intuitively, this significance level is the risk of erroneously rejecting the null-hypothesis (statistical type I error) as in a formal statistical test.

The procedure outlined above may be applied to each grid-point in the dataset and to each group of years defined in the composite analysis in order to assess the significance of the composite maps. Finally, it should be noted that if there is only two groups in the composite analysis, our test procedure may also be used to test the difference between the means in the two groups. In other words, testing the significance of the mean in one group is the same as 
testing the mean in the other group, or the difference between the two group means in this case. Finally, it should be mentioned that our procedure does not solve the problem of multiple tests since the procedure is applied separately to each group in the composite analysis rather than to all the groups together. 


\section{REFERENCES}

Ailikun, B., and T. Yasunari, 2001: ENSO and Asian Summer Monsoon : Persistence and Transitivity in the Seasonal March. J. Meteor. Soc. Japan, 79, 145-159.

Annamalai, H., J.M. Slingo, K.R. Sperber, and K. Hodges, 1999: The mean evolution and variability of the Asian summer monsoon: Comparison of ECMWF and NCEP/NCAR reanalysis. Mon. Wea.Rev., 127, 1157-1186.

Behera S. K., and T. Yamagata, 2001: Subtropical SST dipole events in the southern Indian Ocean. G. R. L., 28, 327-330.

Brown T.J., and B.L. Hall, 1999: The Use of t Values in Composite Analyses. J. Climate, 12, 2941-2944.

Cadet, D., 1983: The monsoon over the Indian Ocean during summer 1975. Part II: Break and active monsoons. Mon. Wea. Rev., 111, 95-108.

Chandrasekar, A., and A. Kitoh, 1998: Impact of localized sea surface temperature anomalies over the equatorial Indian Ocean on the Indian summer monsoon. J. Meteor. Soc. Japan, 76, 841-853.

Chang, C.-P., Y. Zhang, and T. Li, 2000: Interannual and interdecadal variations of the East Asian summer monsoon and the tropical sea-surface temperatures. Part I: Roles of the subtropical ridge. J. Climate, 13, 4310-4325.

Charney, J.G., and J. Shukla, 1981: Predictability of Monsoon. Monsoon Dynamics. J. Lighthill and R.P. Pierce, Eds., Cambridge University Press, 99-108.

Chen, T.C., and H. Van Loon, 1987: Interannual variation of the tropical easterly jet. Mon. Wea. Rev., 115, 1739-1759.

Clark, C.O., J.E. Cole, and P.J. Webster, 2000: Indian Ocean SST and Indian summer rainfall: Predictive relationships and their decadal variability. J. Climate, 13, 2503-2519.

Goswami B. N., V. Krishnamurty, and H. Annamalai, 1999: A broad-scale circulation index for the interannual variability of the Indian summer monsoon. Q. J. R. Meteorol. Soc., 125, 611-633.

Hastenrath, S., and L. Greischar, 1993: The monsoonal heat budget of the hydrosphereatmosphere system in the Indian Ocean sector. J. Geophys. Res., 98, 6869-6881.

Ju J., and J. Slingo, 1995: The Asian summer monsoon and ENSO. Q. J. R. Meteorol. Soc., 121, 1133-1168.

Kalnay, E., and Coauthors, 1996: The NCEP/NCAR 40-year reanalysis project. Bull. Amer. Meteor. Soc., 77, 437-471. 
Kidson, J.W., and J.A. Renwick, 2002: The Southern hemisphere evolution of ENSO during 1981-99. J. Climate, 15, 847-863.

Kinter, J.L., K. Miyakoda., and S. Yang, 2002: Recent change in the connection from the Asian Monsoon to ENSO. J. Climate, 15, 1203-1215.

Kirtman, B. P., and J. Shukla, 2000: Influence of the Indian summer monsoon on ENSO. Q. J. R. Meteorol. Soc., 126, 213-239.

Krishnamurti, T.N. and H.N. Bhalme, 1976: Oscillations of a monsoon system. Part I. Observational aspects. J. Atmos. Sci., 33, 1937-1954.

Krishnamurthy, V. and J. Shukla, 2000: Intraseasonal and interannual variability of rainfall over India. J. Climate, 13, 4366-4377.

Larkin, N.K., and D.E. Harrison, 2001: Tropical Pacific ENSO cold events, 1946-1995: SST, SLP, and surface wind composite anomalies. J. Climate, 14, 3904-3931.

Lau, K-M., K-M. Kim, and S. Yang, 2000: Dynamical and boundary forcing characteristics of regional components of the Asian summer monsoon. J. Climate, 13, 2461-2482.

Lau, N.C., and M.J. Nath, 2000: Impact of ENSO on the variability of the Asian-Australian monsoons as simulated in GCM experiments. J. Climate, 13, 4287-4309.

Lawrence, D.M., and P.J. Webster, 2001: Interannual variations of intraseasonal convection in the South Asian monsoon region. J. Climate, 14, 2910-2922.

Lebart, L., A. Morineau, and M. Piron, 1995: Statistique exploratoire multidimensionnelle. Dunod, 439 pp.

Meehl, G. A., 1987: The annual cycle and interannual variability in the tropical Indian and Pacific Ocean regions. Mon. Wea. Rev., 115, 27-50.

Meehl, G. A., 1997: The South Asian monsoon and the tropospheric biennial oscillation. $J$. Climate, 10, 1921-1943.

Meehl, G. A., and J. M. Arblaster, 1998: The Asian-Australian Monsoon and El NiñoSouthern Oscillation in the NCAR Climate System Model. J. Climate, 11, 1356-1385.

Meehl, G.A., and J. Arblaster, 2002a: The tropospheric biennial oscillation and the AsianAustralian monsoon rainfall. J. Climate, 15, 722-744.

Meehl, G.A., and J. Arblaster, 2002b: Indian monsoon GCM sensitivity experiments testing tropospheric biennial oscillation transition conditions. J. Climate, 15, 923-944.

Morrison D.F., 1990 : Multivariate Statistical Methods. 3rd edition, Mac Graw Hill, New York.

Nicholls, N., 1984: The Southern Oscillation and Indonesian sea surface temperature. Mon. Wea. Rev., 112, 424-432. 
Nicholls, N., 2001: The Insignificance of Significance Testing. Bull. Amer. Meteor. Soc., 81, 981-986.

Nitta, T., and S. Yamada, 1989: Recent warming of tropical sea surface temperature and its relationship to the northern hemisphere circulation. J. Meteor. Soc. Japan, 67, 375-383.

Noreen, E.W., 1989 : Computer-intensive methods for testing hypotheses: an introduction. John Wiley \& Sons, New York.

Normand, C., 1953: Monsoon seasonal forecasting. Q. J. R. Meteorol. Soc., 79, 463-473.

Palmer, T.N., 1994: Chaos and the predictability in forecasting the monsoons. Proc. Indian Natn. Sci. Acad. Part A. 60, 57-66.

Parthasarathy B., A.A. Munot and D.R. Kothawale, 1995 : All India monthly and seasonal rainfall series: 1871-1993. Theor. and Appl. Climatol., 49, 217-224.

Rao, K.G., and B.N. Goswami, 1988:Interannual variations of sea surface temperature over the Arabian Sea and the Indian monsoon: A new perspective. Mon. Wea.Rev., 116, 558-568.

Saji, N.H., B.N. Goswami, P.N. Vinayachandran, and, T. Yamagata, 1999: A dipole mode in the tropical Indian Ocean, Nature, 401, 360-363.

Shukla, J., and D.A. Paolino, 1983: The Southern Oscillation and long-range forecasting of the summer monsoon rainfall over India. Mon. Wea. Rev., 111, 1830-1837.

Shukla, J., 1987: Interannual variability of monsoons. Monsoons, J.S. Fein and P.L. Stephens, Eds., Wiley, 399-464.

Slingo, J.M., and H. Annamalai, 2000: 1997: The El Niño of the century and the Response of the Indian Summer Monsoon. Mon. Wea. Rev., 128, 1778-1797.

Smith, T.M., R.W. Reynolds, R.E. Livezey, and D.C. Stokes, 1996: Reconstruction of historical sea surface temperatures using empirical orthogonal functions. J. Climate, 9, 14031420 .

Terray, P., 1994: An evaluation of climatological data in the Indian Ocean area. J. Meteor. Soc. Japan, 72, 359-386.

Terray, P., 1995: Space/Time structure of monsoons interannual variability. J. Climate, 8, 2595-2619.

Torrence C., and P. Compo, 1998: A practical guide to Wavelet Analysis. Bull. Amer. Meteor. Soc., 79, 61-78.

Torrence C., and P.J. Webster, 1998: The annual cycle of persistence in the El Niño/Southern Oscillation. Q.J.R. Meteorol. Soc., 124, 1985-2004. 
Wang, B., and Z. Fan, 1999: Choice of South Asian summer monsoon indices. Bull. Amer. Meteor. Soc., 80, 629-638.

Wang, B., R. Wu, and K.-M. Lau, 2001: Interannual Variability of the Asian Summer Monsoon: Contrasts between the Indian and the Western North Pacific-East Asian Monsoons. J. Climate, 14, 4073-4090.

Webster P. J., and S. Yang, 1992: Monsoon and ENSO: Selectively interactive systems. Q. J. R. Meteorol. Soc., 118, 877-926.

Webster, P.J., V.O. Magana, T.N. Palmer, J. Shukla, R.A. Tomas, M. Yanai, and T. Yasunari, 1998: Monsoons: Processes, predictability and the prospects for prediction. J. Geophys. Res. , 103 (C7), 14 451-14 510.

Webster, P.J., A.M. Moore, J.P. Loschnigg, and R.R. Leben, 1999: Coupled oceanatmosphere dynamics in the Indian Ocean during 1997-98. Nature, 401, 356-360.

Xie P., and P.A. Arkin, 1997 : Global precipitation: A 17-year monthly analysis based on gauge observations, satellite estimates and numerical model outputs. Bull. Amer. Meteor. Soc., 78, 2539-2558. 


\section{FIGURE CAPTIONS}

FIGURE 1: The spatial pattern of the first three EOFs of ISM rainfall standardized anomalies over the 29 Indian meteorological subdivisions during the 1871-1998 period. The number in parentheses shows the percentage of variance accounted for by the mode. (a) EOF1, (b) EOF2, (c) EOF3, (d) global wavelet power spectrum of the first PC. The $10 \%$ confidence level for a white-noise process is also plotted.

FIGURE 2: Wavelet modulus analysis of the LISM IMI1.(a) The time series of LISM IMI1 (b) The local wavelet power spectrum of (a) using the Morlet wavelet. The left axis is the period (in year). The bottom axis is time (in year). Contours indicate the total variance at a particular frequency explained at a particular time in the time series. The thick contour encloses regions of greater than $10 \%$ confidence level for a white-noise process. Cross-hatched regions on either end indicate the cone of influence where edge effects become important. Methods used are described in Torrence and Compo (1998).

FIGURE 3: Composite analysis of ISM $200 \mathrm{hPa}$ stream function fields with respect to strong and weak ISMs during June-July and August-September. The strong and weak ISMs are defined with the help of ISM AIRI. See text for more details. (a) June-July composite $200 \mathrm{hPa}$ stream function means for strong ISMs. (b) June-July composite $200 \mathrm{hPa}$ stream function standardized anomalies for strong ISMs. (c) Probability maps showing critical probabilities associated with the composite maps in (b).

Only the 10,1, 0.1\% confidence levels are plotted. (d), (e), (f) same as (a), (b), (c), but for AugustSeptember of strong ISMs. (g), (h), (i) same as (a), (b), (c), but for June-July of weak ISMs. (j), (k), (l) same as (a), (b), (c), but for August-September of weak ISMs. 
FIGURE 4: Composite analysis of monthly SST fields with respect to weak ISMs. The weak ISMs are defined with the help of the ISM AIRI. (a), (b), (c) composite SST standardized anomalies over the Indian and Pacific Oceans for January, February and March before the weak ISMs. (d), (e) and (f) probability maps showing critical probabilities associated with the composite maps in (a), (b) and (c), respectively. Only the $10,1,0.1 \%$ confidence levels are plotted. See text for more details.

FIGURE 5: Same as in Figure 4, but for the strong ISMs.

FIGURE 6: Composite analysis of February-March SST fields with respect to strong/weak EISMs and LISMs. The strong and weak EISMs (LISMs) are defined with the help of the EISM (LISM) AIRI. (a) composite SST standardized anomalies over the Indian and Pacific Oceans for FebruaryMarch before the strong EISMs. (b) probability map showing critical probabilities associated with the composite map in (a). Only the $10,1,0.1 \%$ confidence levels are plotted. See text for more details. (c) and (d) same as (a) and (b), but for the strong LISMs. (e) and (f) same as (a) and (b), but for the weak EISMs. (g) and (h) same as (a) and (b), but for the weak LISMs

FIGURE 7: (a) Lead/lag correlations between (L)ISM AIR indices and the monthly Niño3 SST anomaly. (b) Lead/lag correlations between (L)ISM IMI1 and the monthly SOI. (c) Lead/lag correlations of (L)ISM VSI with monthly SOI and Darwin SLP anomaly. Also shown are the 5\% confidence levels. The correlations are computed during the period 1948-1998. See text for the definition of the indices.

FIGURE 8: Wavelet modulus analysis of the winter (January, February, March) SST SDM time series. Same conventions as in Figure 2. 
FIGURE 9: Lagged correlations of winter (January, February, March) SEIO SST anomaly with monthly meridional wind index over the Somali Jet area (VSOMAI) and monthly zonal wind indices over the west (UWARAI) and east (UEARAI) Arabian Sea in the preceding/following months. The $5 \%$ confidence level is also plotted. The wind time series are computed from the COADS dataset using the method described in section 2 .

FIGURE 10: Auto-correlations of winter (January, February, March) SST SDM indices and ENSO indices with monthly SST SDM indices and ENSO indices, respectively. The 5\% confidence level is also plotted. See text for the definition of the indices.

FIGURE 11: Lead/lag correlations of monthly SST SDM indices with LISM rainfall and dynamical indices during the year of ISM. The row axis labels indicate which monthly SST SDM indices are correlated with the LISM indices. Also shown are 5\% confidence levels. See text for the definition of the indices.

FIGURE 12: (a) and (d), composite maps of LISM wind anomaly over the Indian region with respect to the 8 strong and 9 weak LISM years, respectively. The anomalous LISMs are defined with the help of the LISM AIRI. (b), (c) and (e), (f), the critical probability maps associated with the zonal (U) and meridional (V) wind composites for the strong and weak LISM years, respectively. Only the $10,1,0.1 \%$ confidence levels are plotted.

FIGURE 13: Same as in Figure 12, but for SLP.

FIGURE 14: Same as in Figure 12, but for latent heat flux.

FIGURE 15: Same as in Figure 12, but for SST. 
FIGURE 16: (a) and (c), composite maps of LISM rainfall standardized anomaly for 29 meteorological subdivisions over India with respect to the 10 warm and 12 cold winter SEIO SST years, respectively. The anomalous SEIO SST years are defined with the help of the winter SEIOI. (b) and (d), the critical probability maps associated with the rainfall composites are for warm and cold years, respectively. Only the 10,1,0.1\% confidence levels are plotted.

FIGURE 17: (a) and (d), composite maps of LISM wind anomaly over the Indo-Pacific region with respect to the 10 warm and 12 cold winter SEIO SST years. (b), (c) and (e), (f), the critical probability maps associated with the zonal (U) and meridional (V) wind composites for warm and cold years, respectively. Only the $10,1,0.1 \%$ confidence levels are plotted. 


\section{TABLE CAPTIONS}

Table 1. Means, standard-deviations of monthly AIR indices and cross-correlations among seasonal (AIRI) and monthly (AIRI6, AIRI7, AIRI8, AIRI9) AIR indices during the 18711998 period. Statistical significance at the 5,1 and $0.1 \%$ confidence levels is shown by one, two, three stars, respectively. Statistical significance has been assessed with a classical two tail t-test. See the text for the definition of the indices.

Table 2. Cross-correlations between the seasonal AIRI, the first three PCs of seasonal ISM rainfall and seasonal dynamical indices constructed from the NCEP reanalysis and COADS dataset. The correlation coefficients have been computed during the 1948-1998 and 19481992 periods for NCEP and COADS indices, respectively. Statistical significance at the 5, 1 and $0.1 \%$ confidence levels is shown by one, two, three stars, respectively. Statistical significance has been assessed with a classical two tail t-test. See the text for the definition of the indices.

Table 3. Cross-correlations between PC1 of the seasonal ISM rainfall and monthly dynamical indices constructed from the NCEP reanalysis and COADS dataset. The correlation coefficients have been computed during the 1948-1998 and 1948-1992 periods for NCEP and COADS indices, respectively. Statistical significance at the 5, 1 and $0.1 \%$ confidence levels is shown by one, two, three stars, respectively. Statistical significance has been assessed with a classical two tail t-test. See the text for the definition of the indices.

Table 4. Composite standardized monthly anomalies of rainfall and dynamical indices for 8

strong ISMs during the period 1948-1998. The strong ISMs are defined with the help of the 
ISM AIRI. Anomalies significant at the 5, 1 and $0.1 \%$ confidence levels are followed by one, two, three stars, respectively. Critical probabilities are computed by the method explained in Appendix A. All the indices have been computed from NCEP reanalysis, including WSOMAI, UWARAI and WEARAI which are defined at $1000 \mathrm{hPa}$.

Table 5. Same as Table 4, but for 11 weak ISMs extracted from the observations during the period 1948-1998.

Table 6. Cross-correlations between late winter (January, February and March) SST SEIOI from COADS and Reynolds datasets and (L)ISM rainfall and dynamical indices. The correlation coefficients have been computed during the 1948-1998 and 1948-1992 periods for Reynolds and COADS SST indices, respectively. Statistical significance at the 5, 1 and $0.1 \%$ confidence levels is shown by one, two, three stars, respectively. Statistical significance has been assessed with a classical two tail t-test. See the text for the definition of the indices.

Table 7. Composite standardized anomalies of (L)ISM rainfall and dynamical indices for 12 cold and 10 warm winter SEIO SST years extracted from the observations during the period 1950-1998. The anomalous years are defined with the help of winter SEIOI SST (winter SEIO SST anomalies below -0.75 or above 0.75 standard-deviation). Anomalies significant at the 5,1 and $0.1 \%$ confidence levels are followed by one, two, three stars, respectively. Critical probabilities are computed by the method explained in Appendix A. 


\section{Tables}

Table 1

\begin{tabular}{|c|c|c|c|c|}
\hline & AIRI6 & AIRI7 & AIRI8 & AIRI9 \\
\hline Mean & 163.3 & 273.9 & 243.6 & 171.1 \\
\hline \multirow[t]{2}{*}{ STD } & 36.4 & 36.5 & 38.2 & 37.7 \\
\hline & \multicolumn{4}{|c|}{ correlations } \\
\hline AIRI & $0.38 * * *$ & $0.59 * * *$ & $0.59 * * *$ & $0.65 * * *$ \\
\hline AIRI6 & 1 & & & \\
\hline AIRI7 & -0.01 & 1 & & \\
\hline AIRI8 & -0.05 & 0.10 & 1 & \\
\hline AIRI9 & -0.06 & $0.24 * *$ & $0.24 * *$ & 1 \\
\hline
\end{tabular}

Table 2

\begin{tabular}{|c|c|c|c|c|}
\hline Variable & AIRI & $\mathrm{PC} 1$ & $\mathrm{PC} 2$ & PC3 \\
\hline IMI1 & $0.70 * * *$ & $0.70 * * *$ & $-0.39 * *$ & 0.07 \\
\hline IMI2 & $0.58 * * *$ & $0.51 * * *$ & -0.10 & 0.23 \\
\hline VSI & $0.46^{* *}$ & $0.31 *$ & -0.22 & $0.28 *$ \\
\hline WSOMAI & 0.20 & $0.30 *$ & 0.09 & -0.01 \\
\hline UWARAI & $0.29 *$ & $0.32 *$ & -0.06 & 0.11 \\
\hline WEARAI & $0.51 * * *$ & $0.41^{* *}$ & $-0.30 *$ & 0.26 \\
\hline
\end{tabular}


Table 3

$\begin{array}{lccll}\text { Variable/month } & \text { June } & \text { July } & \text { August } & \text { September } \\ \text { IMI } & 0.24 & 0.25 & 0.40^{* *} & 0.66^{* * *} \\ \text { IMI2 } & 0.04 & 0.26 & 0.40^{* *} & 0.65^{* * *} \\ \text { VSI } & -0.07 & 0.16 & 0.27 * & 0.48^{* * *} \\ \text { WSOMAI } & -0.13 & 0.09 & 0.33^{*} & 0.48^{* * *} \\ \text { UWARAI } & -0.19 & -0.04 & 0.26 & 0.64 * * \\ \text { WEARAI } & 0.05 & 0.01 & 0.16 & 0.67 * *\end{array}$

Table 4

$\begin{array}{lllll}\text { Var/month } & \text { June } & \text { July } & \text { August } & \text { September } \\ \text { AIRI } & 0.83 * & 0.89 * * & 0.75^{*} & 1.02 * * * \\ \text { IMI1 } & 0.74 * & 0.49 & 0.79 * & 0.86 * * \\ \text { IMI2 } & 0.26 & 0.08 & 0.63 & 0.85 * * \\ \text { VSI } & 0.12 & 0.09 & 0.60 & 0.91 * * \\ \text { WSOMAI } & 0.15 & -0.04 & 0.57 & 0.85 * * \\ \text { UWARAI } & 0.39 & -0.08 & 0.77 * & 1.07 * * * \\ \text { WEARAI } & 0.38 & 0.43 & 0.38 & 1.02 * * \\ & & & & \end{array}$

Table 5

$\begin{array}{lllll}\text { Var/month } & \text { June } & \text { July } & \text { August } & \text { September } \\ \text { AIRI } & -0.67 * & -0.94 * * * & -1.15 * * * & -1.02 * * * \\ \text { IMI1 } & -0.49 & -0.74 * * & -0.74 * * & -0.82 * * \\ \text { IMI2 } & -0.21 & -0.75 * * & -0.70 * * & -0.95 * * * \\ \text { VSI } & -0.02 & -0.77 * * & -0.68 * & -0.55 * \\ \text { WSOMAI } & -0.23 & -0.64 * & -0.65 * & -0.70 * * \\ \text { UWARAI } & -0.11 & -0.45 & -0.63 * & -0.84 * * \\ \text { WEARAI } & -0.11 & -0.37 & -0.40 & -0.89 * *\end{array}$


Table 6

Variable SEIOI(Reynolds) SEIOI(COADS)

\begin{tabular}{|c|c|c|}
\hline AIRI(6-9) & $0.37 * *$ & $0.43^{* *}$ \\
\hline AIRI(8-9) & $0.48 * * *$ & $0.54 * * *$ \\
\hline PC1 & $0.47 * * *$ & $0.50 * * *$ \\
\hline IMI1(6-9) & $0.38 * *$ & $0.40 * *$ \\
\hline IMI1(8-9) & $0.38 * *$ & $0.43 * *$ \\
\hline IMI2(6-9) & $0.35^{*}$ & $0.38 * *$ \\
\hline IMI2(8-9) & $0.40 * *$ & $0.43 * *$ \\
\hline VSI(6-9) & $0.36^{* *}$ & $0.47 * * *$ \\
\hline VSI(8-9) & $0.47 * * *$ & $0.54 * * *$ \\
\hline
\end{tabular}

Table 7

Variable cold SEIO SST warm SEIO SST

$\begin{array}{lll}\text { AIRI(6-9) } & -0.46 & 0.56 * \\ \text { AIRI(8-9) } & -0.64 * * & 0.83 * *\end{array}$

$\begin{array}{lll}\operatorname{IMI} 1(6-9) & -0.46 & 0.84 * * \\ \operatorname{IMI} 1(8-9) & -0.49 & 0.94 * * *\end{array}$

$\begin{array}{lll}\text { IMI2(6-9) } \quad-0.50 * & 0.49\end{array}$

IMI2(8-9) $-0.47 \quad 0.68 *$

$\begin{array}{lll}\text { VSI(6-9) } & -0.52 * & 0.38 \\ \text { VSI(8-9) } & -0.50 * & 0.73 * *\end{array}$


高
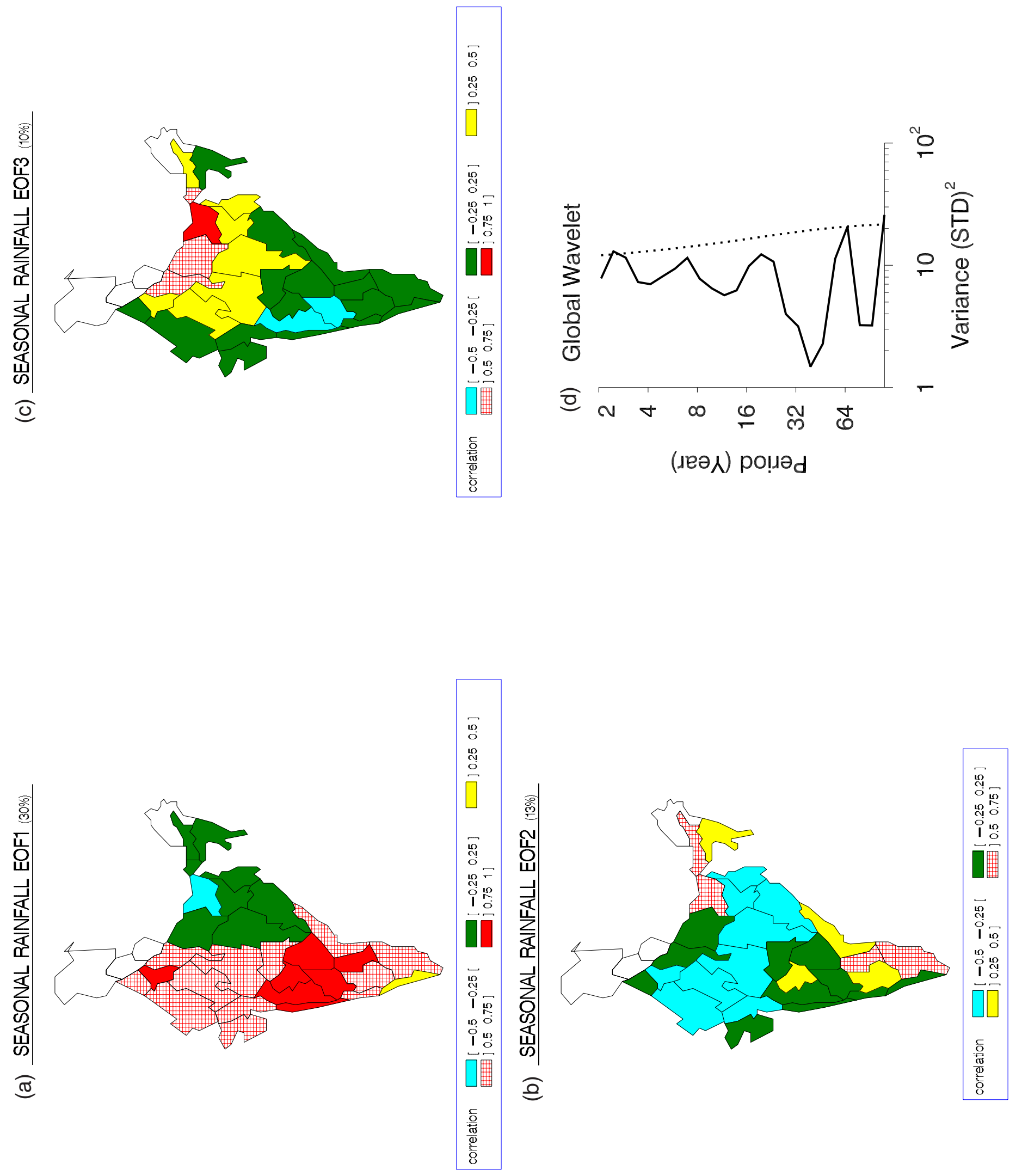


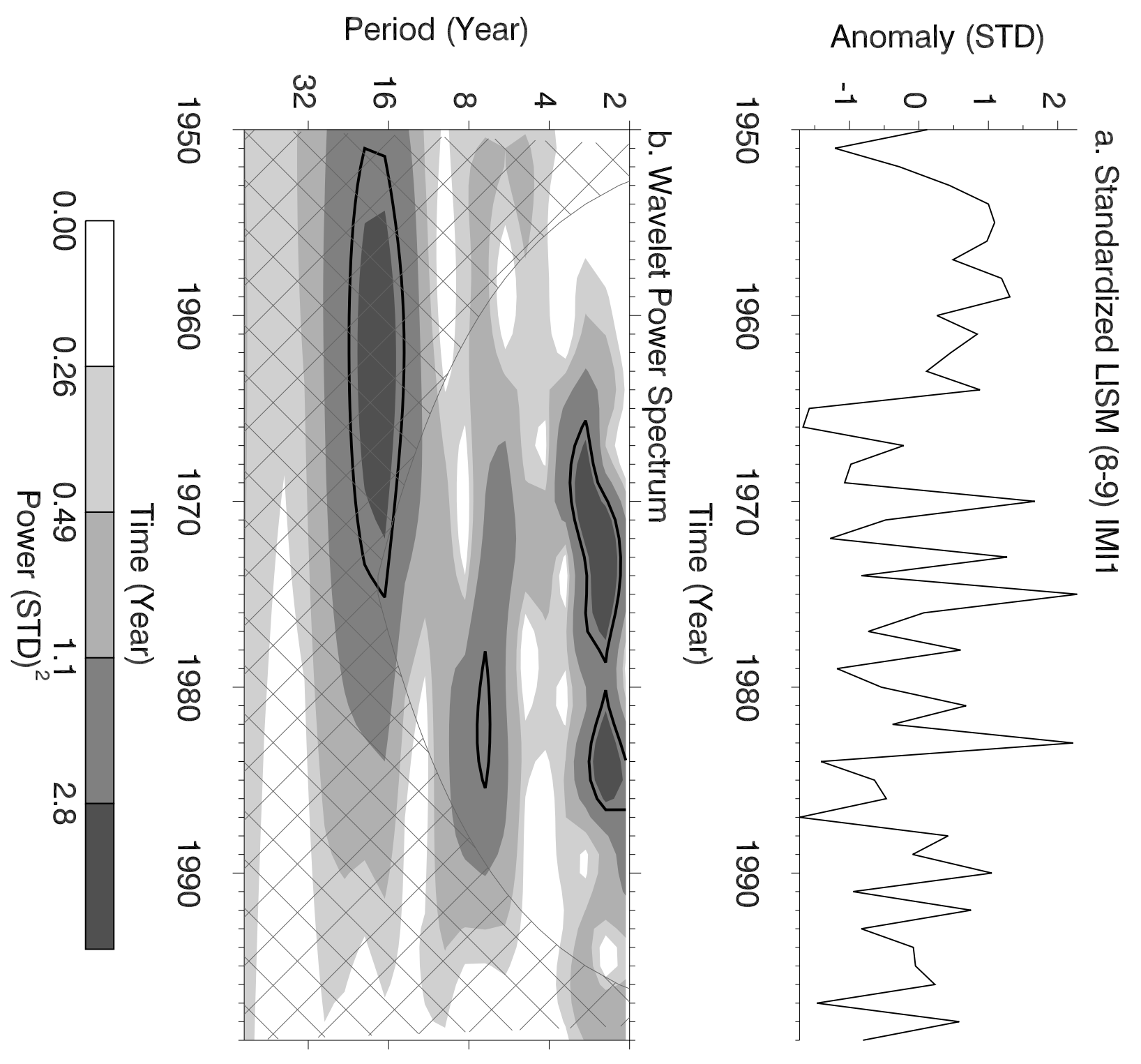


a)

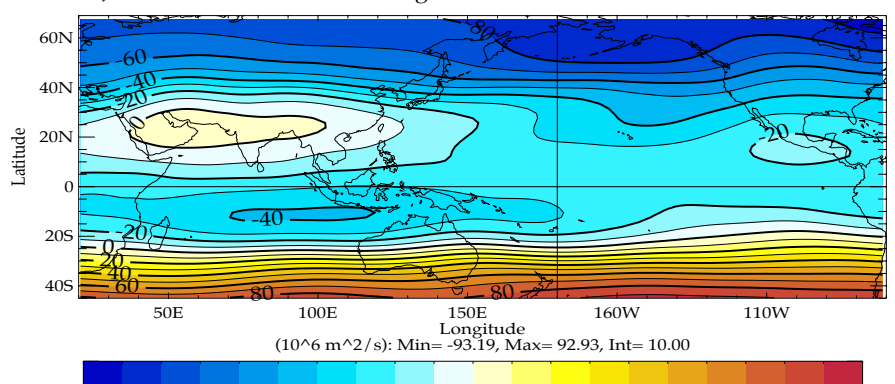

b)

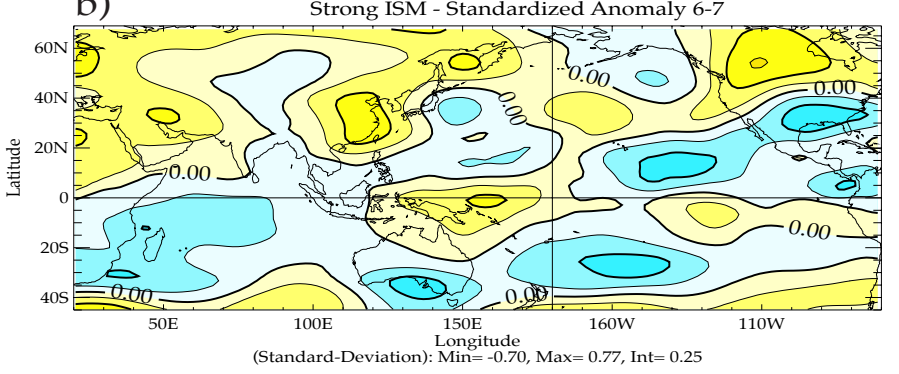

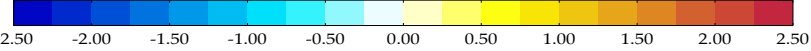

C) Strong ISM - Critical Probability 6-7

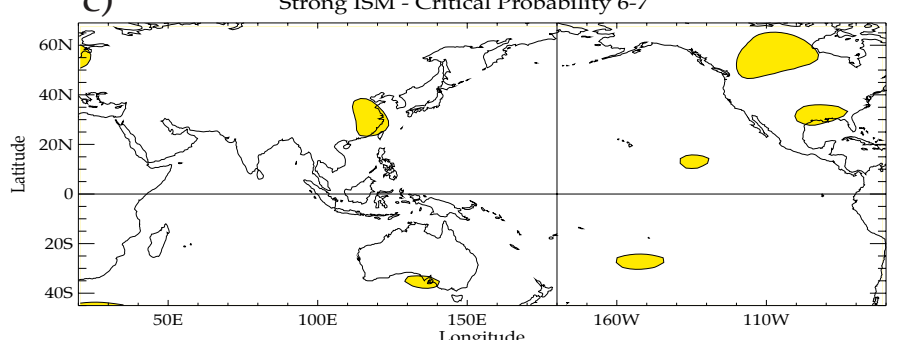

d)

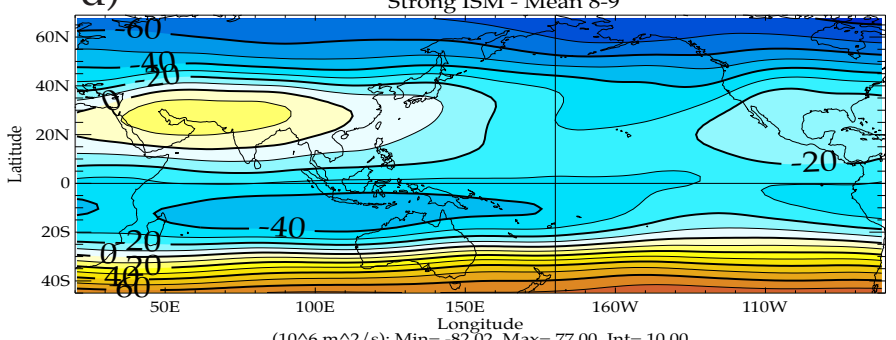

$\left(10^{\wedge} 6 \mathrm{~m}^{\wedge} 2 / \mathrm{s}\right):$ Min $=-82.02$, Max $=77.00$, Int $=10.00$

e)

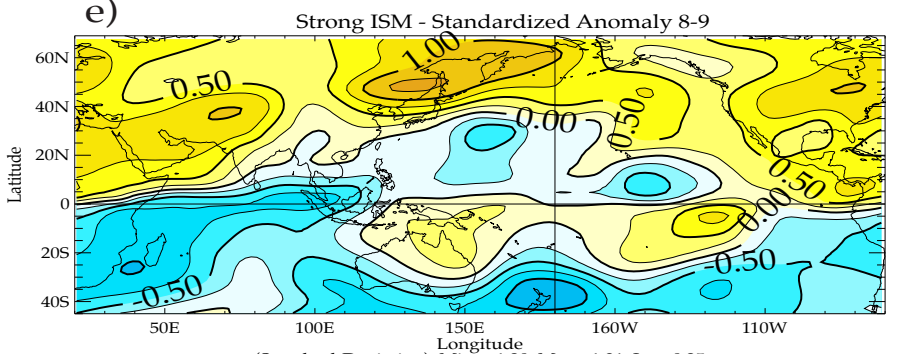

(Standard-Deviation): $\begin{aligned} & \text { Ling }=-1.20, \\ & \text { Max }=1.31, \mathrm{Int}=0.25\end{aligned}$

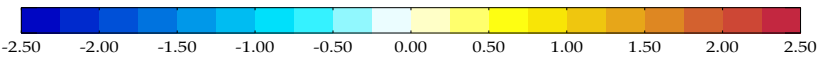

f)

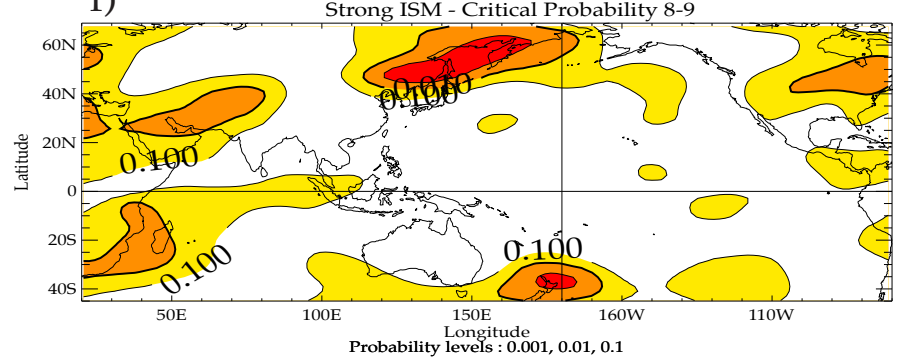

g)

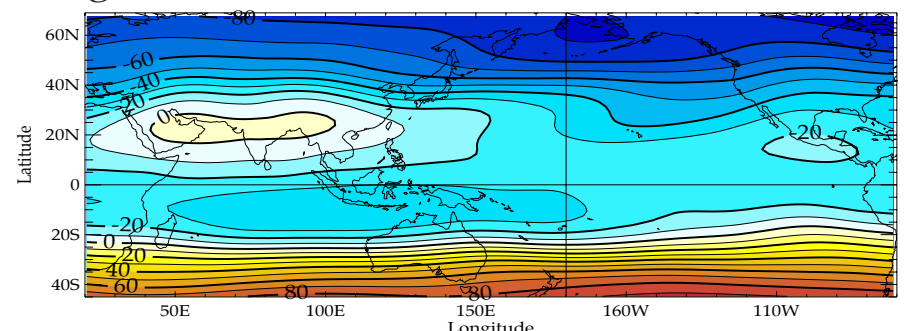

Longitude
$\left(10^{\wedge} 6 \mathrm{~m}^{\wedge} 2 / \mathrm{s}\right):$ Min $=-95.02$, Max $=92.83$, Int $=10.00$

h)
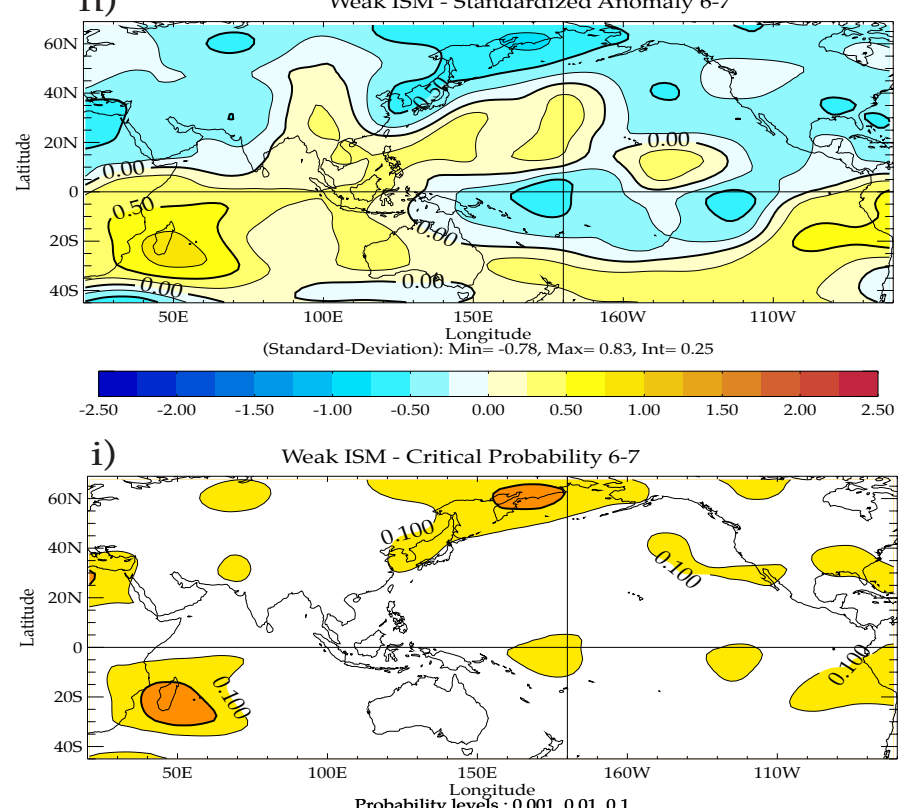

j)

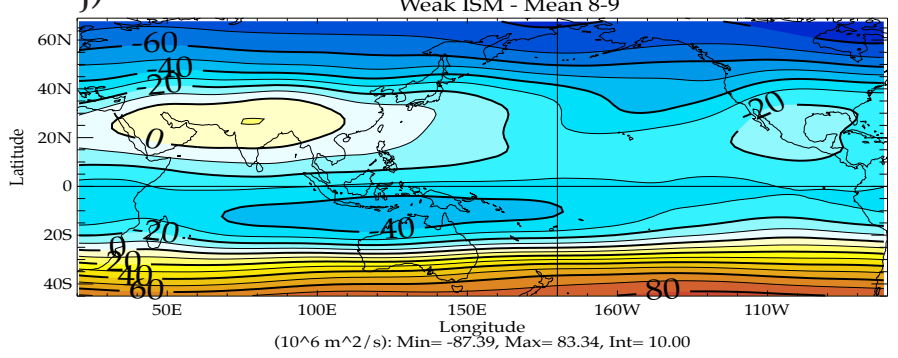

$\left(10^{\wedge} 6 \mathrm{~m}^{\wedge} 2 / \mathrm{s}\right):$ Min $=-87.39$, Max $=83.34$, Int $=10.00$

k)

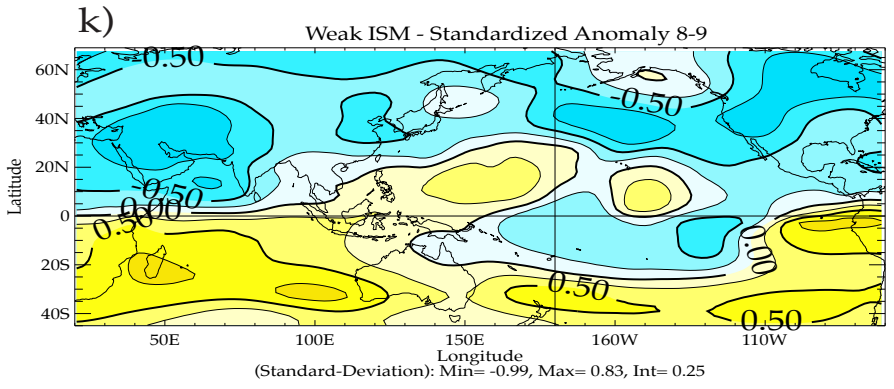

(Standard-Deviation): Min $=-0.99$, Max $=0.83$, Int $=0.25$

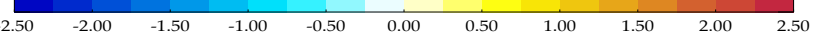

1)

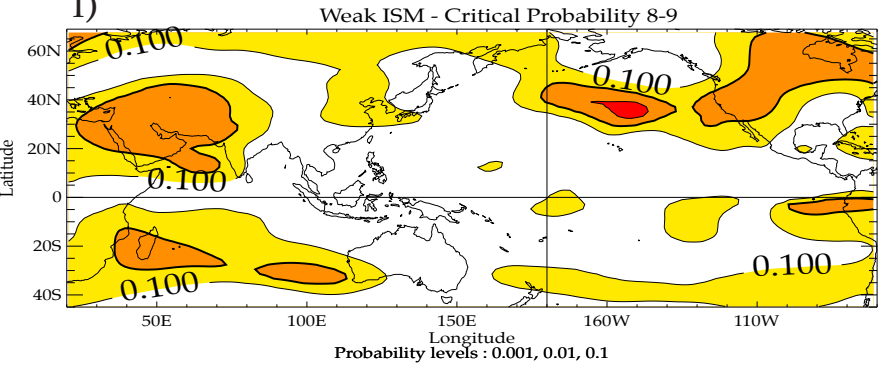


Figure 4

\section{Weak ISM (6-9) SST composite - REYNOLDS - Year 0}

(a)

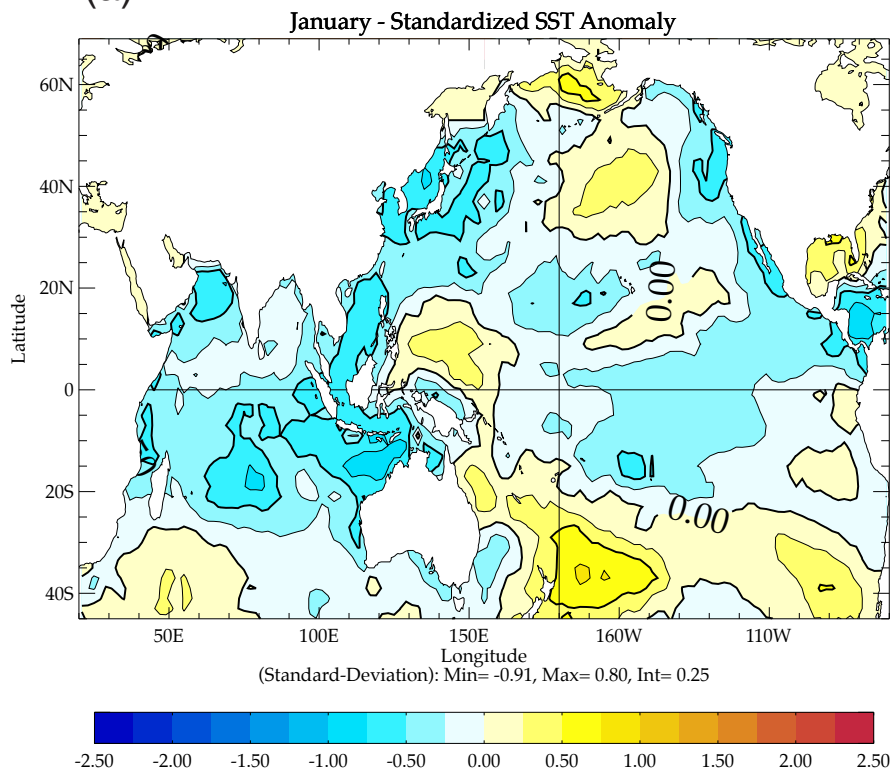

(b)

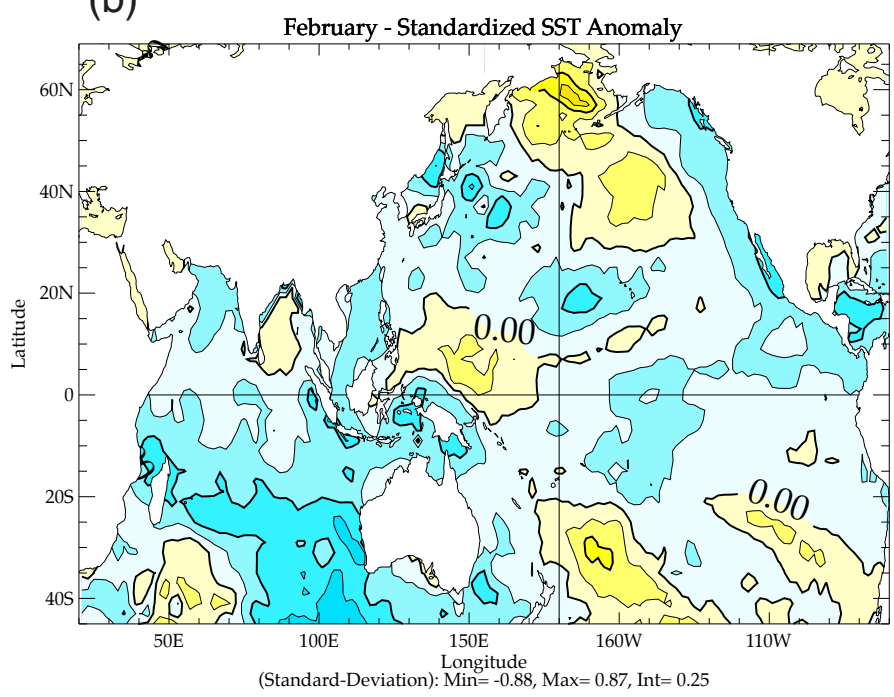

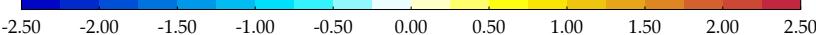

(c)

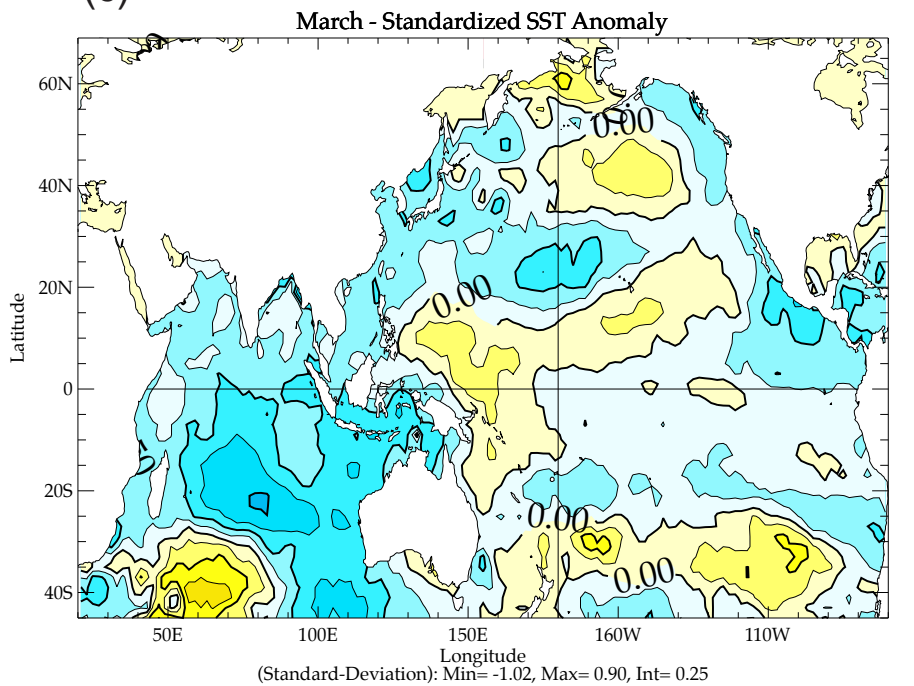

(d)

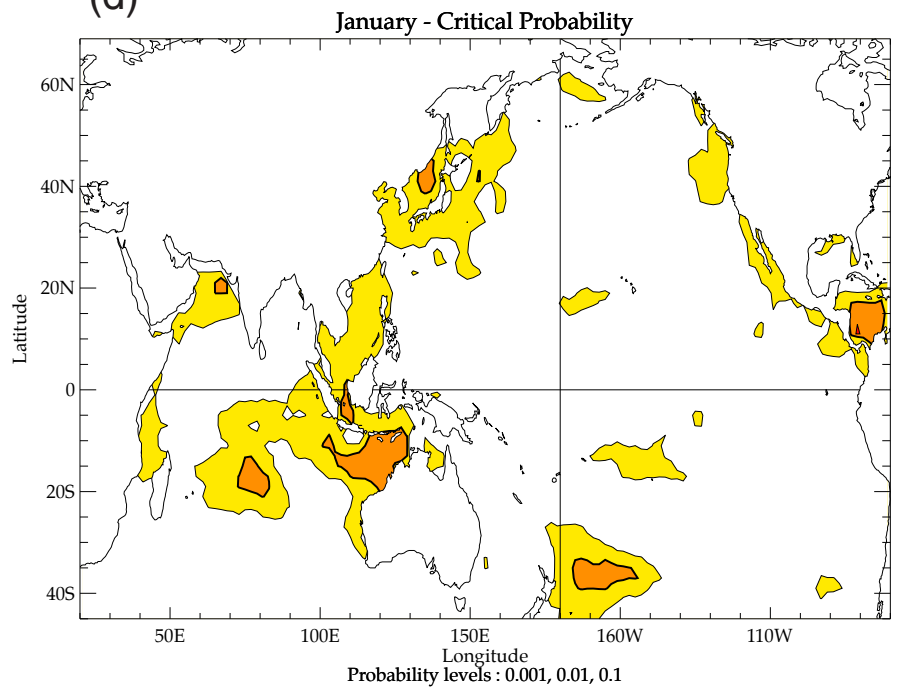

(e)

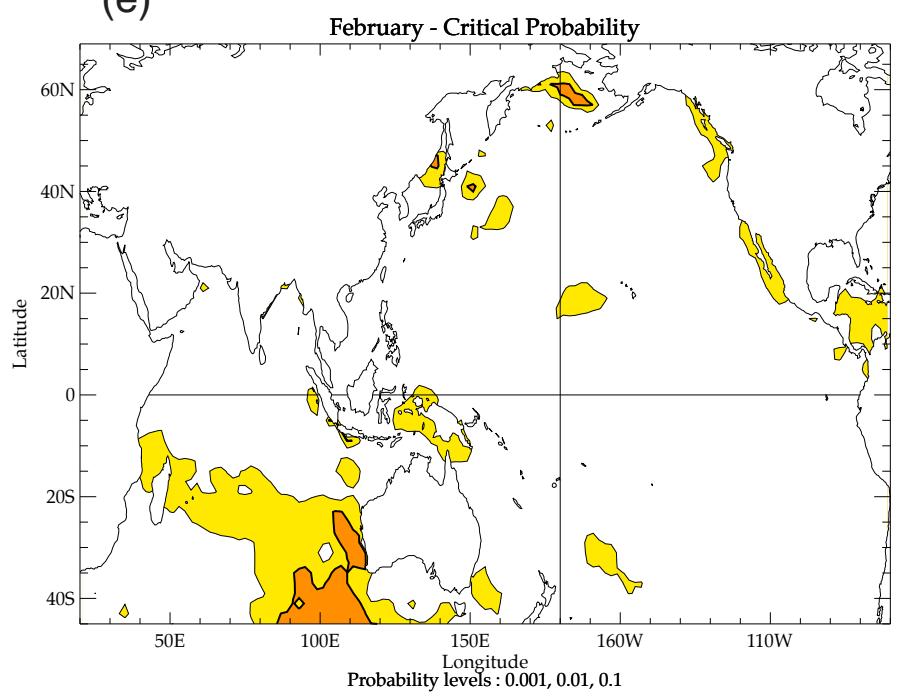

(f)

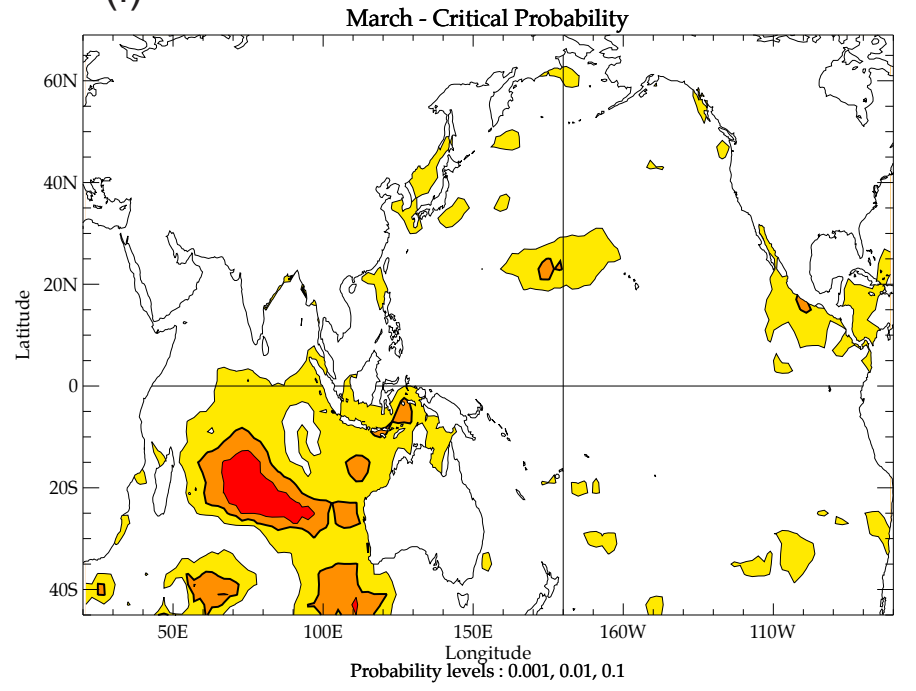


Figure 5

\section{Strong ISM (6-9) SST composite - REYNOLDS - Year 0}

(a)

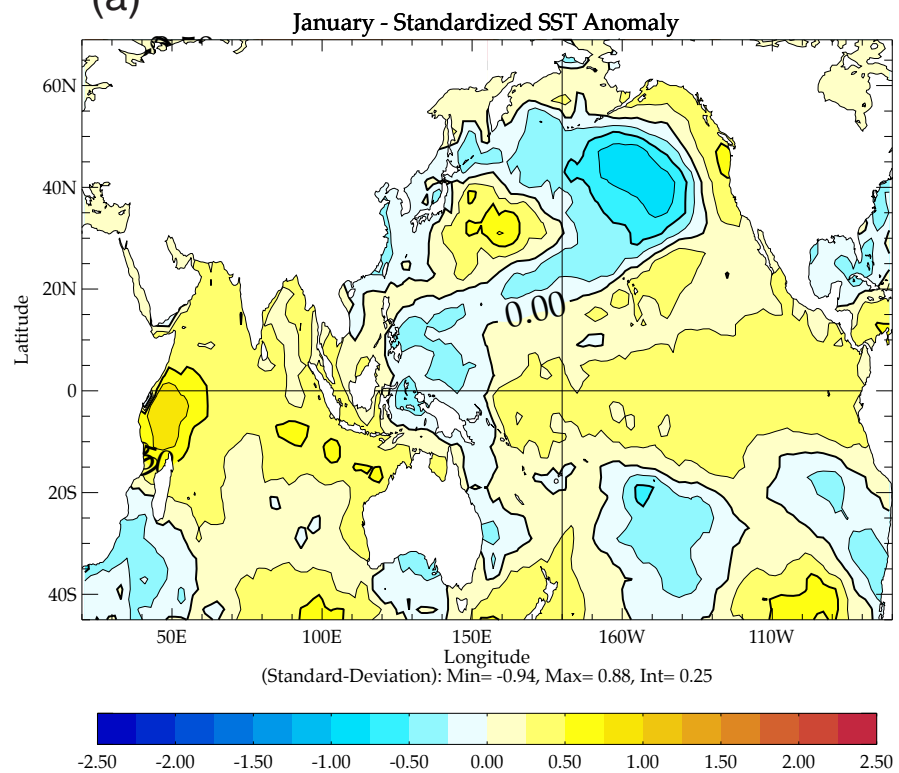

(b)

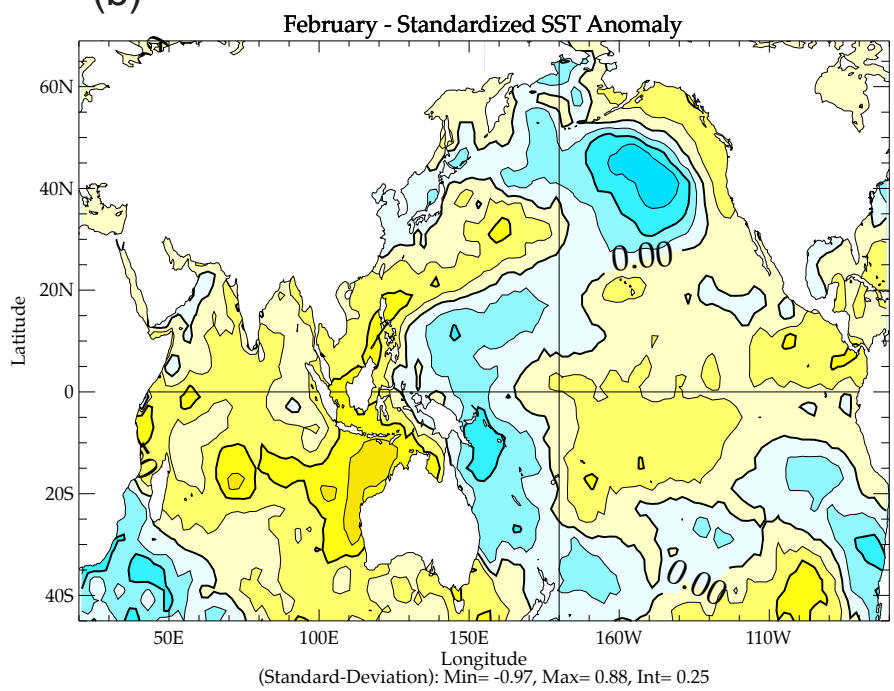

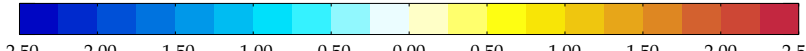

(c)

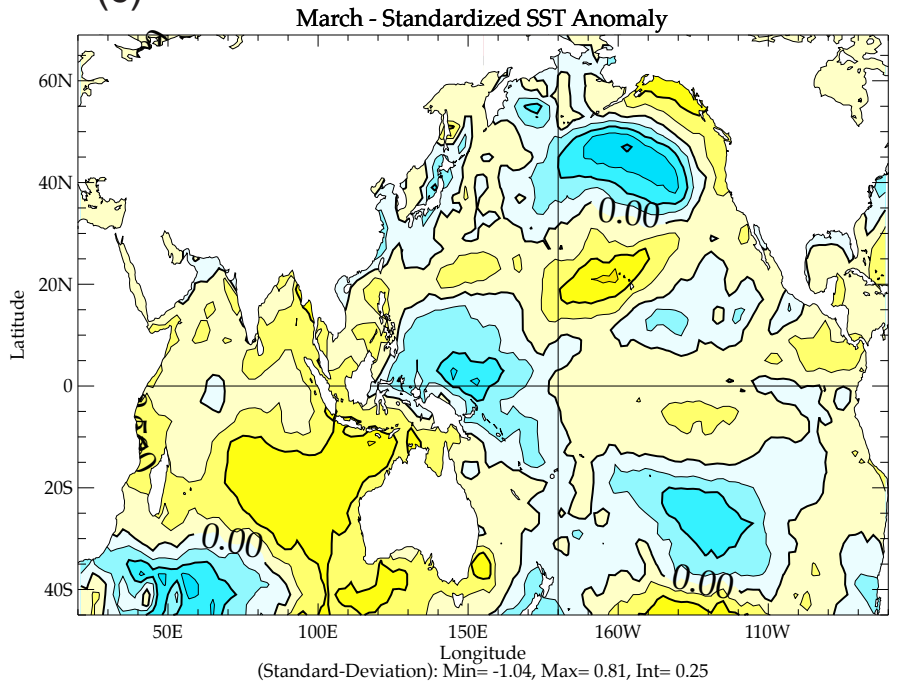

(d)

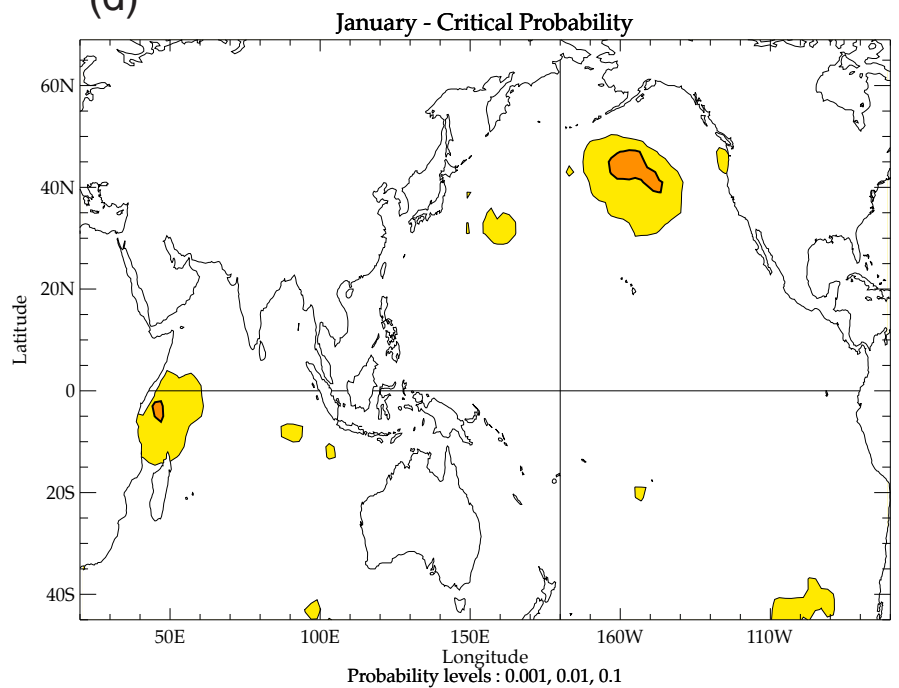

(e)

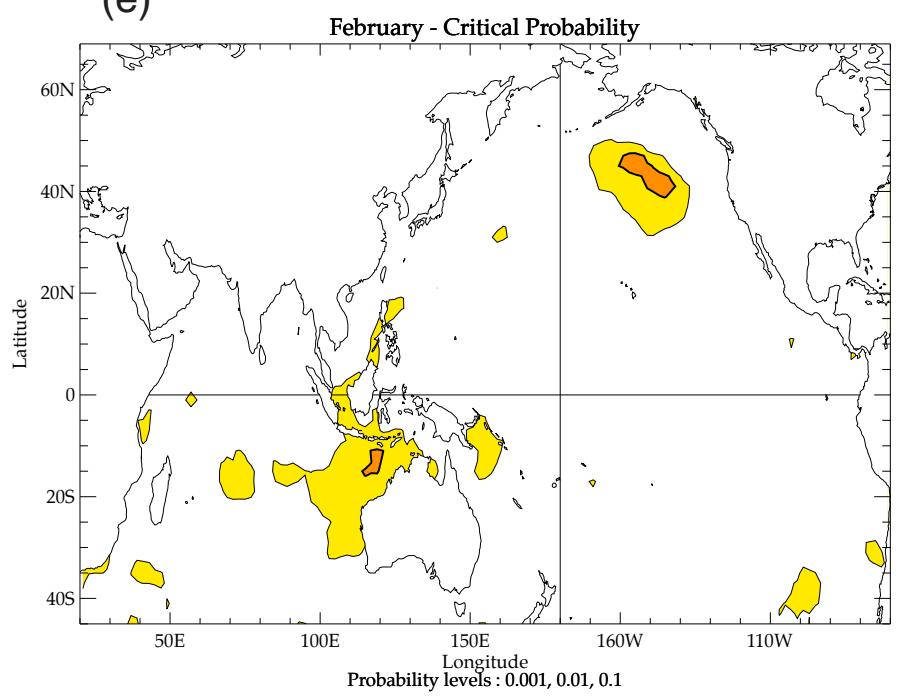

(f)

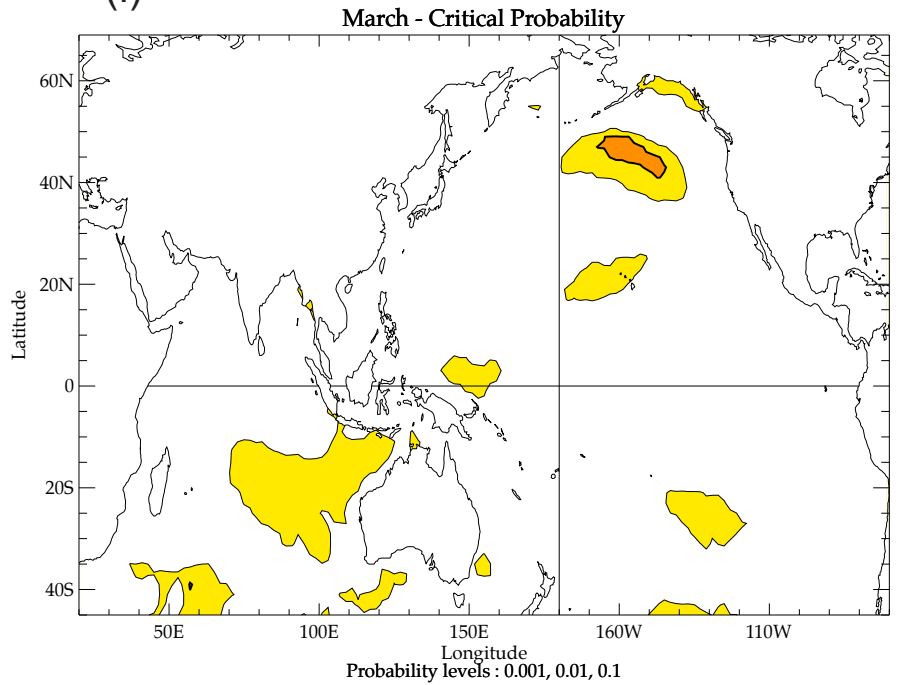


Figure 6

Strong ISM (6-7) SST composite - REYNOLDS - Year 0,
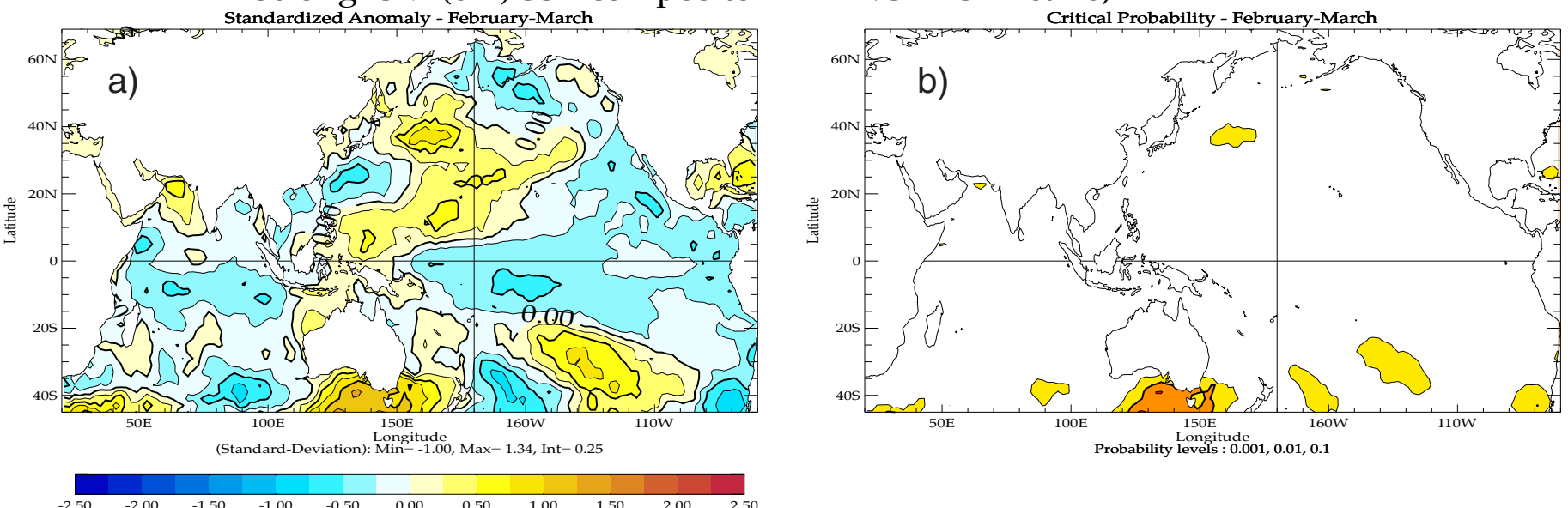

Strong ISM (8-9) SST composite - REYNOLDS - Year 0,
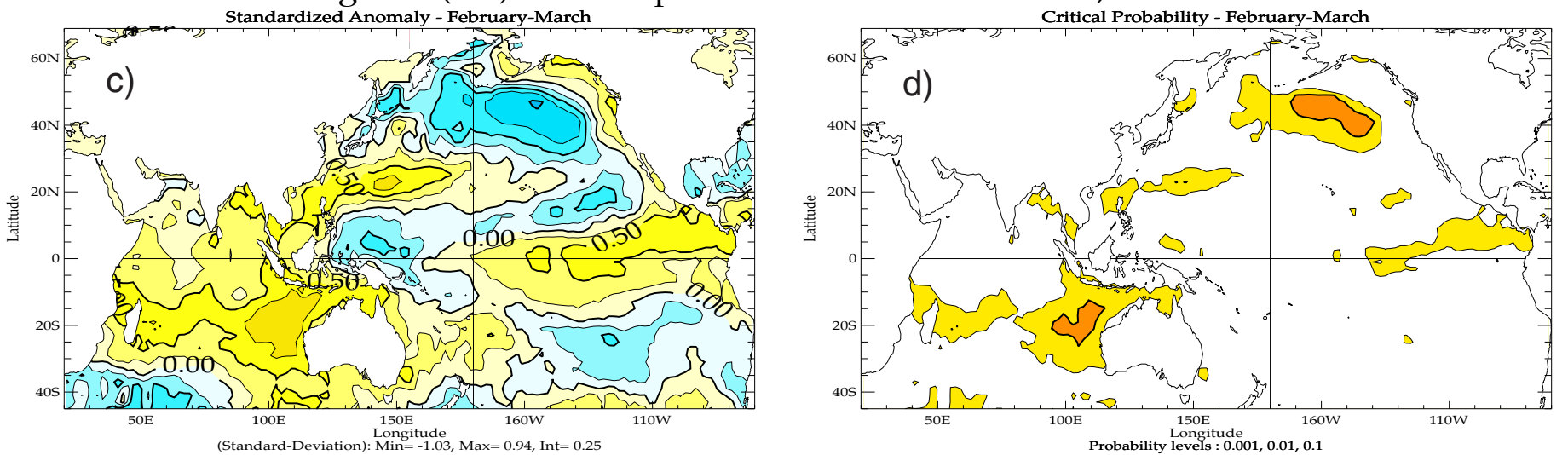

Weak ISM (6-7) SST composite - REYNOLDS - Year 0,
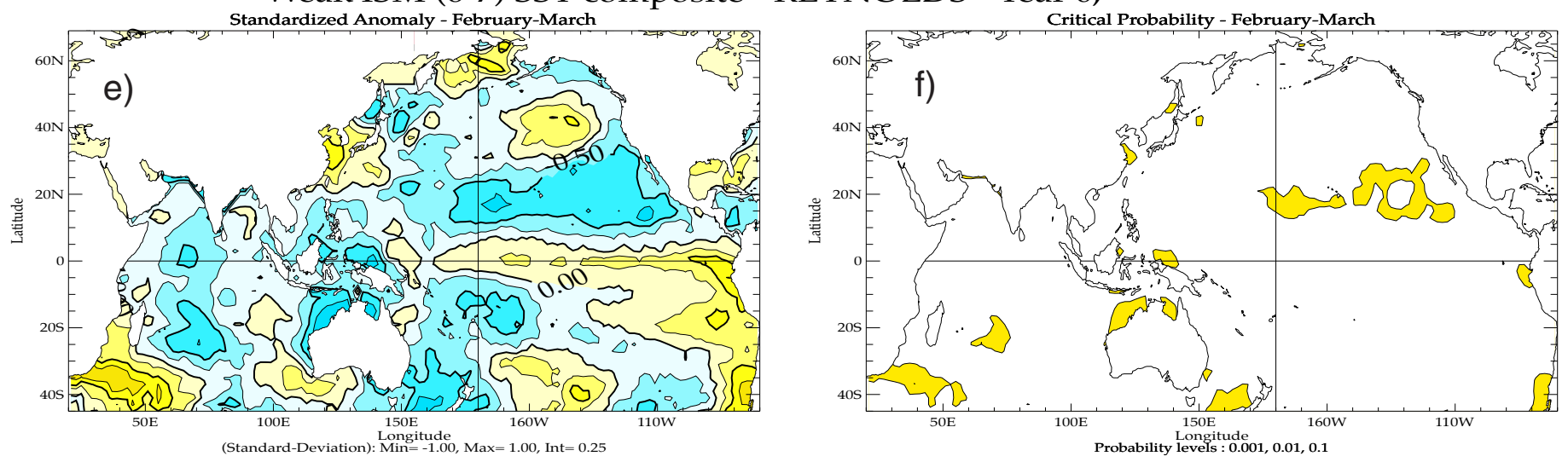

Weak ISM (8-9) SST composite - REYNOLDS - Year 0,
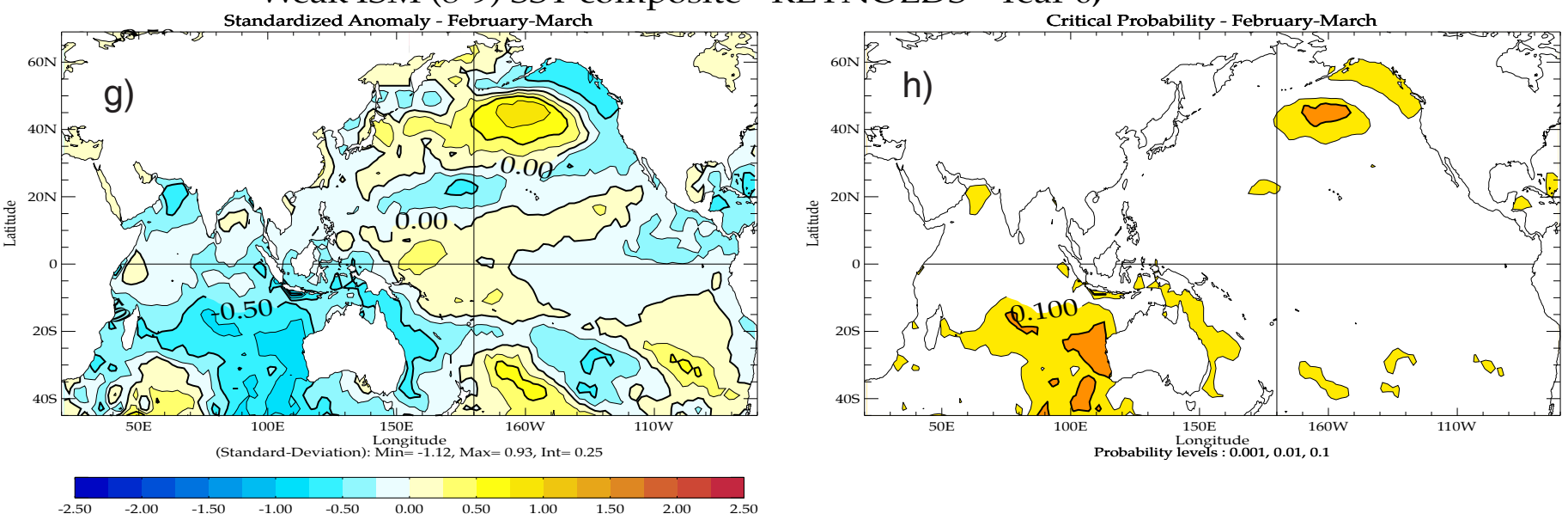


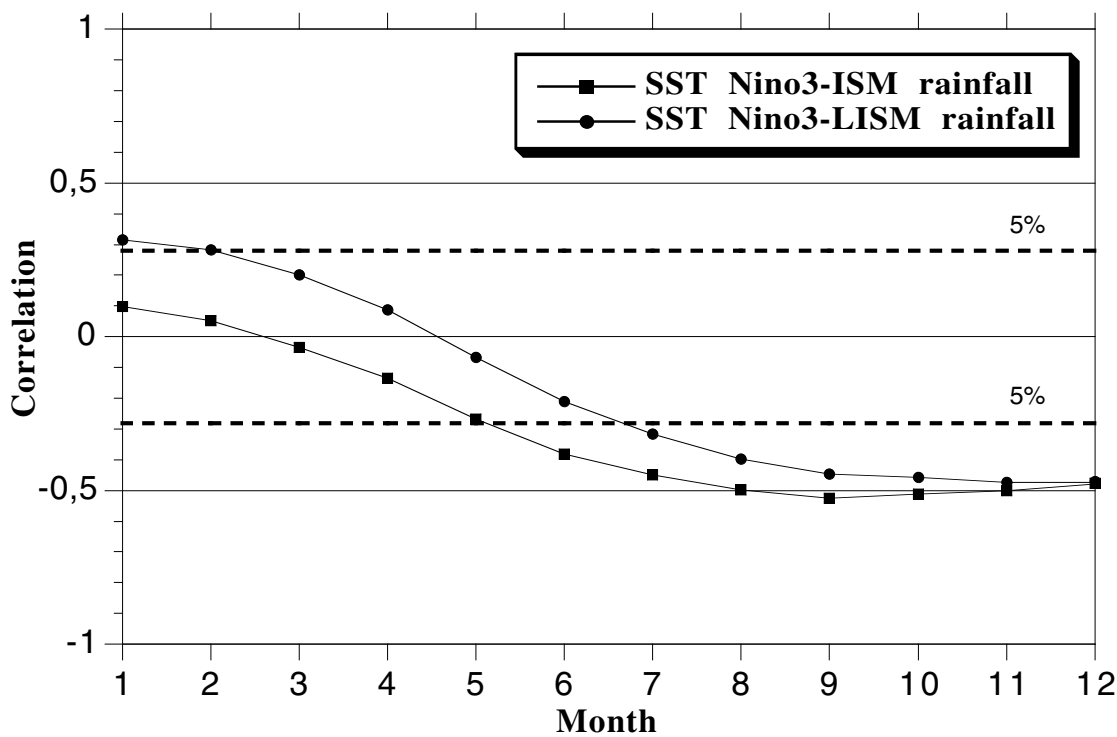

(b) Lead/lag correlations between monthly SO index and IMI1

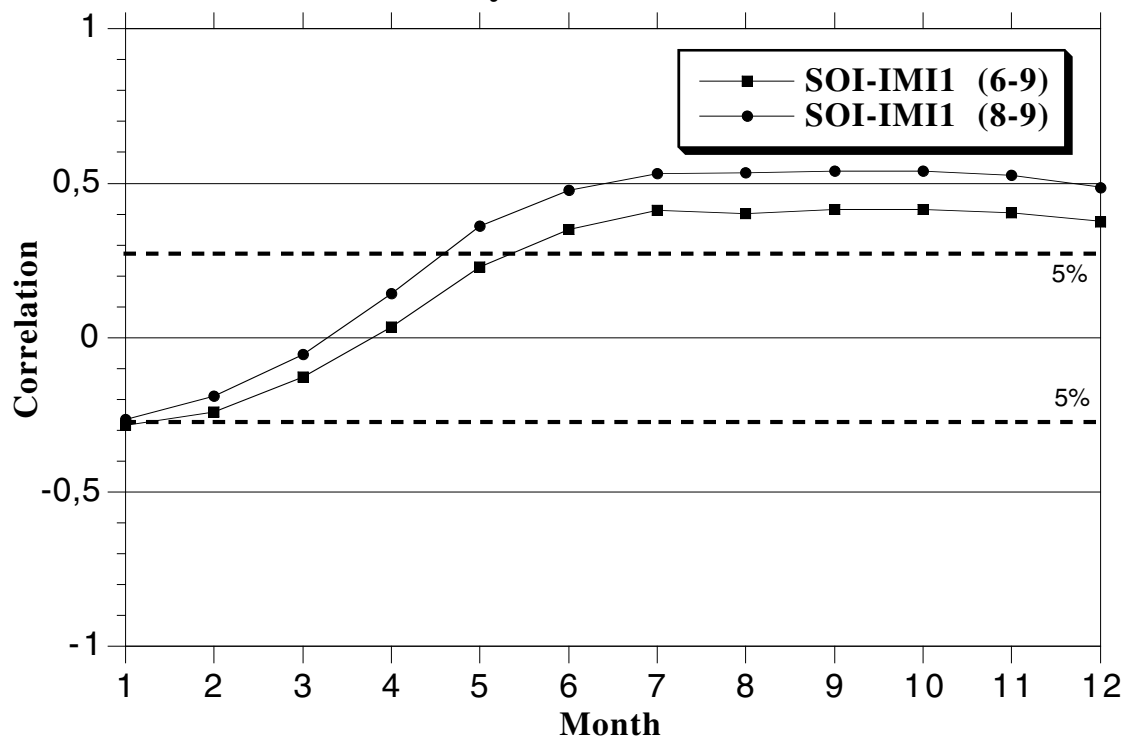

(c) Lead/lag correlations between monthly SO indices and (L)ISM VSI

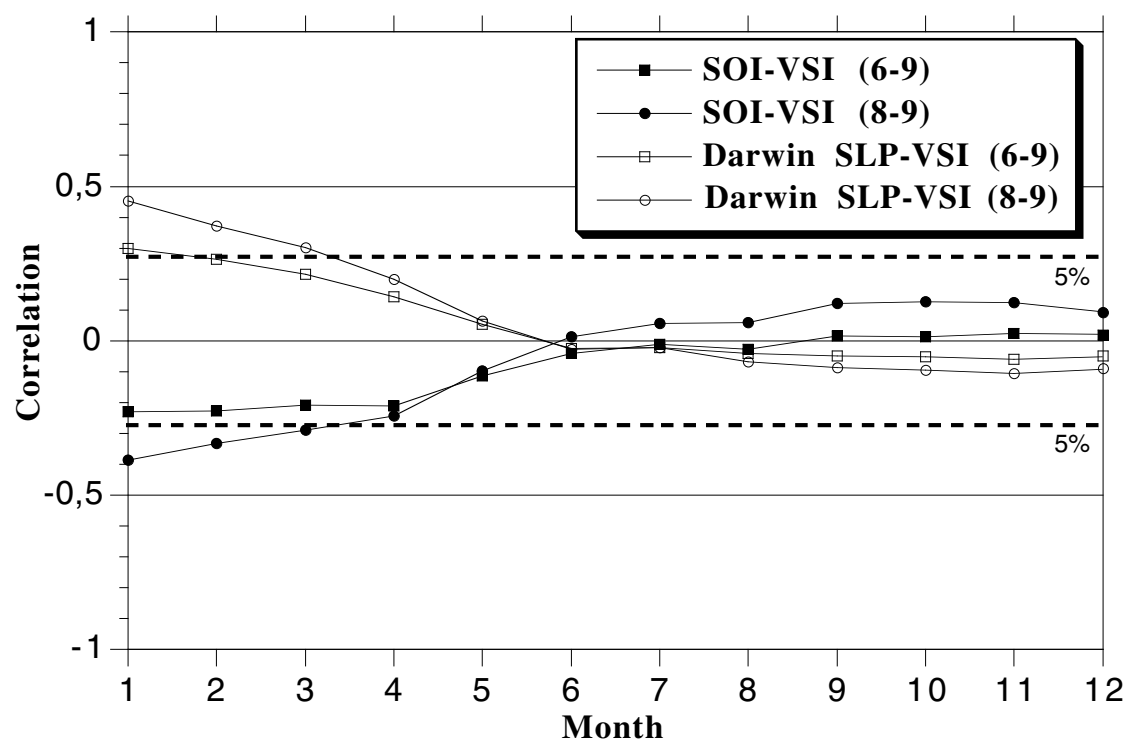




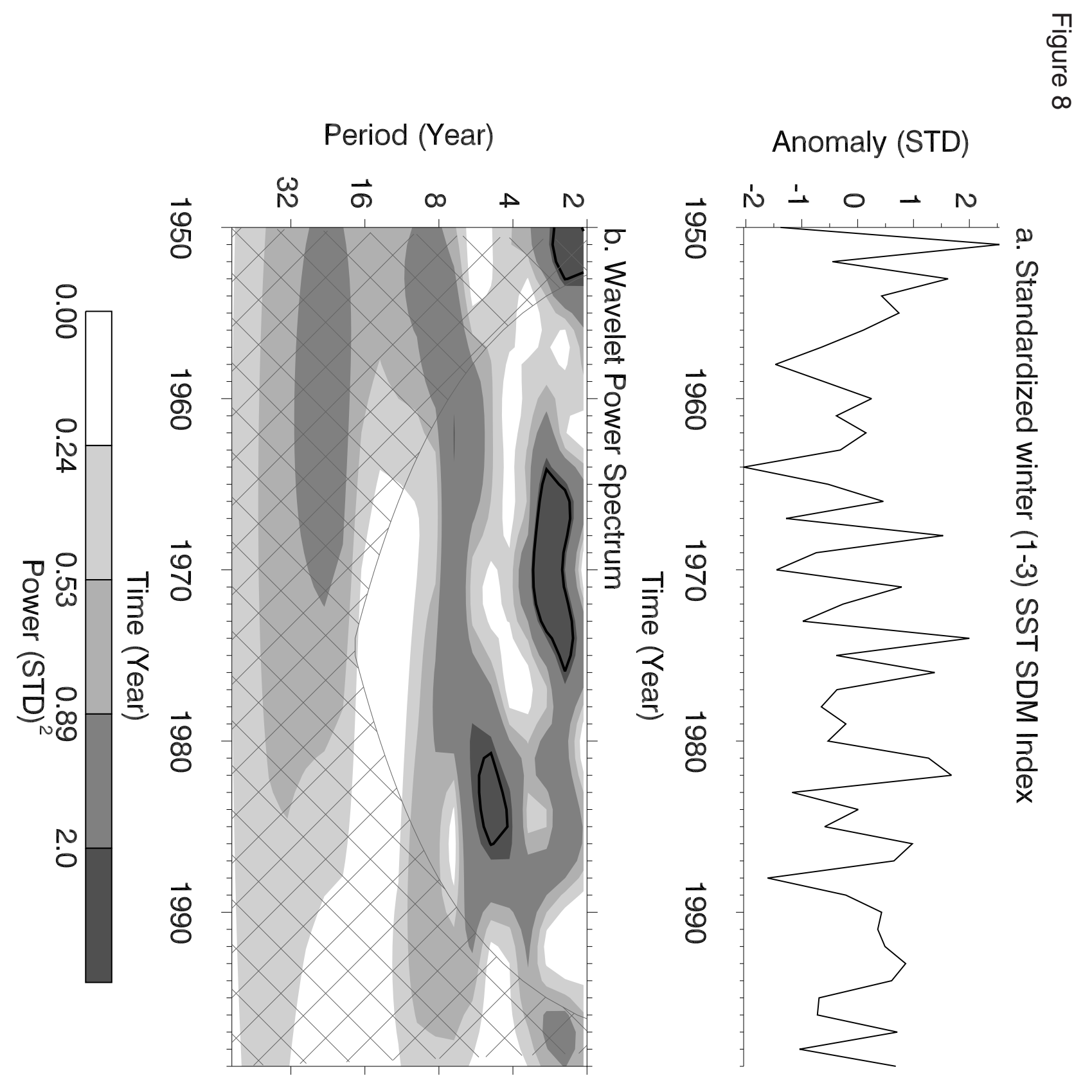


Figure 9

Lead/lag correlations between

winter (1-3) SST SEIO index and monthly wind time series

(COADS, Period : 1948-1992)

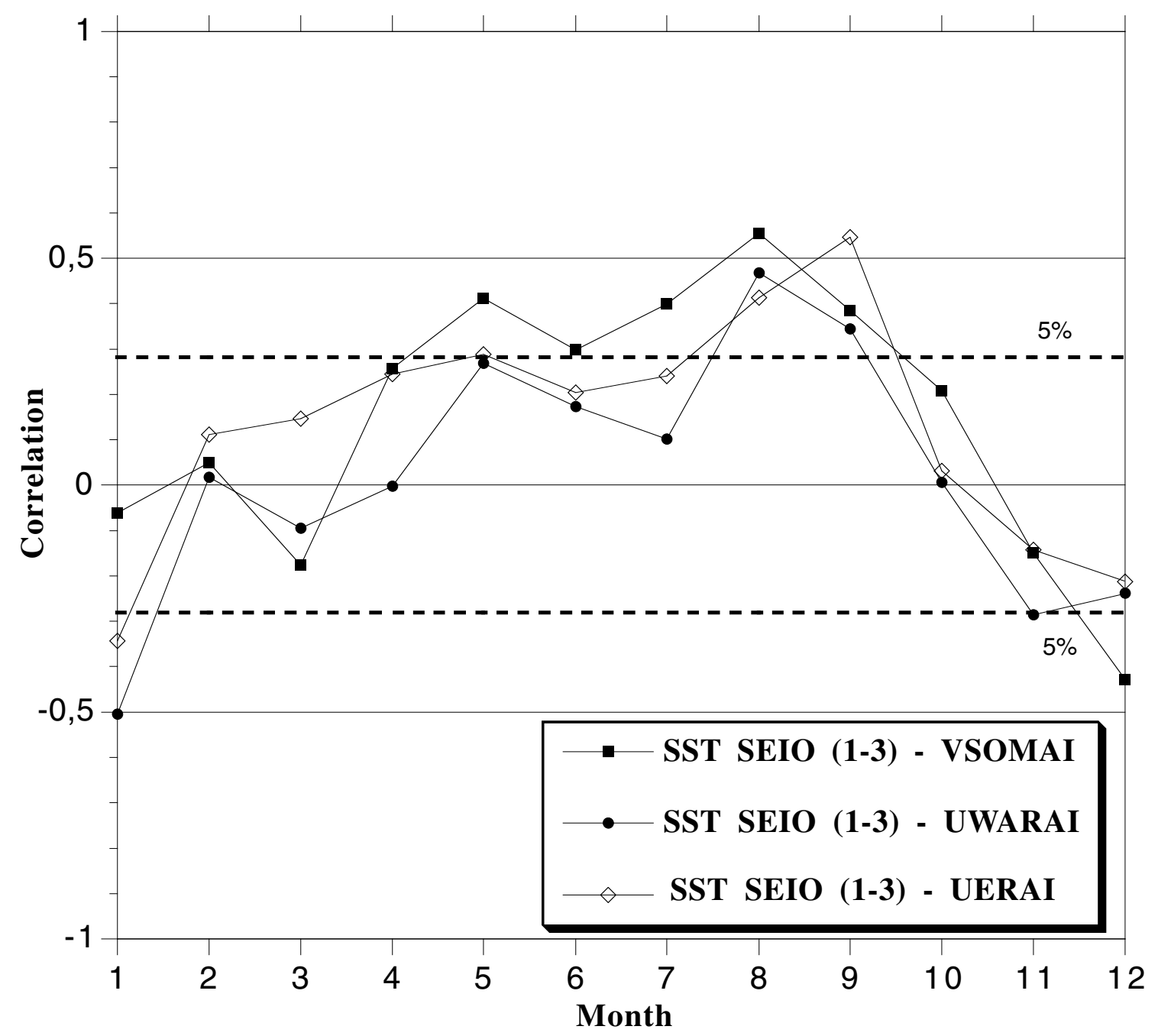


Figure 10

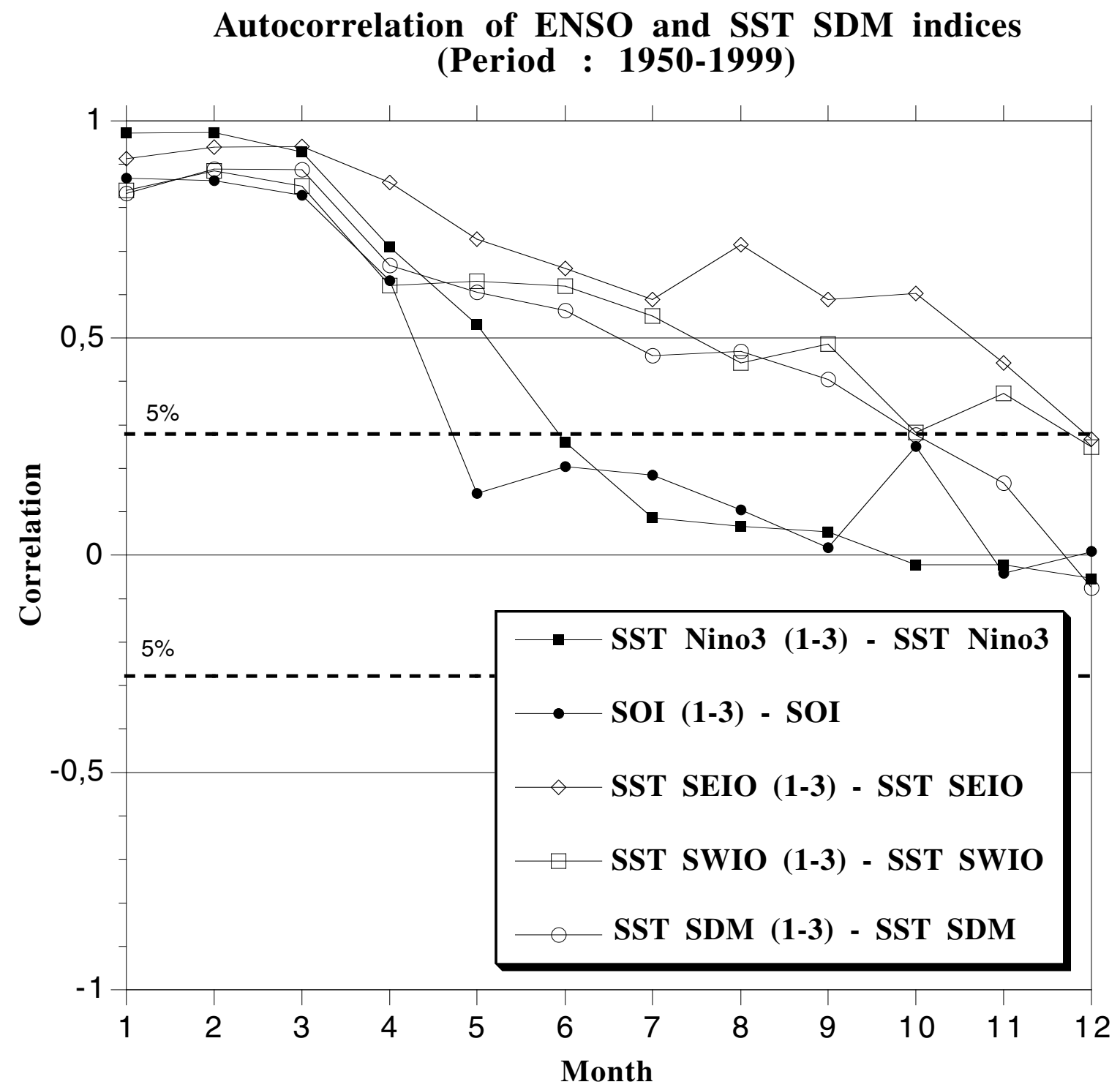


Figure 11

Lead/lag correlations between monthly SST SDM indices and LISM dynamical and rainfall indices

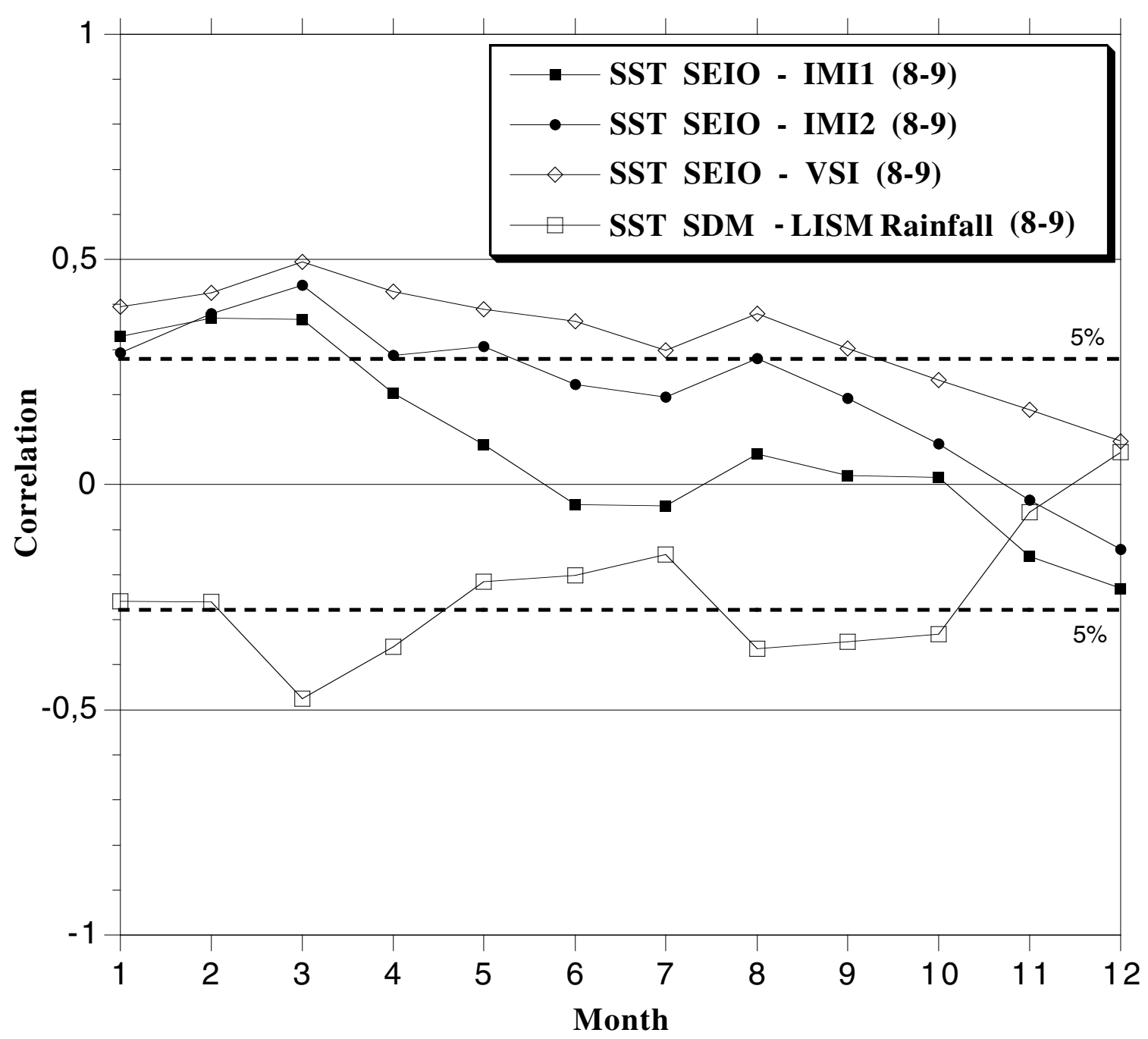


Figure 12

(a) Strong LISM Rainfall $850 \mathrm{hPa}$ wind Anomaly, August-September

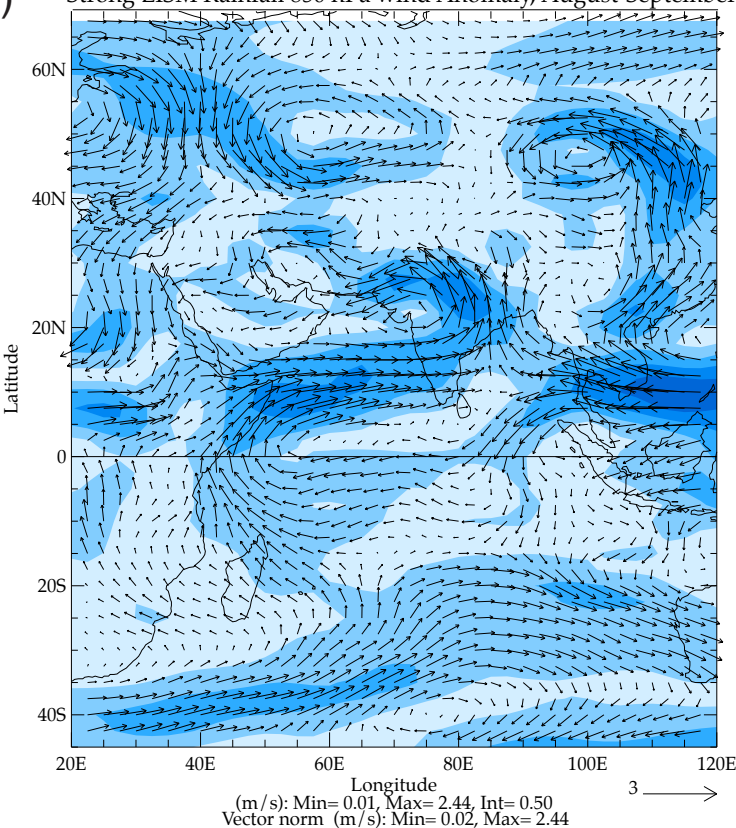

(b) Strong LISM Rainfall $850 \mathrm{hPa} U$ Critical Probability

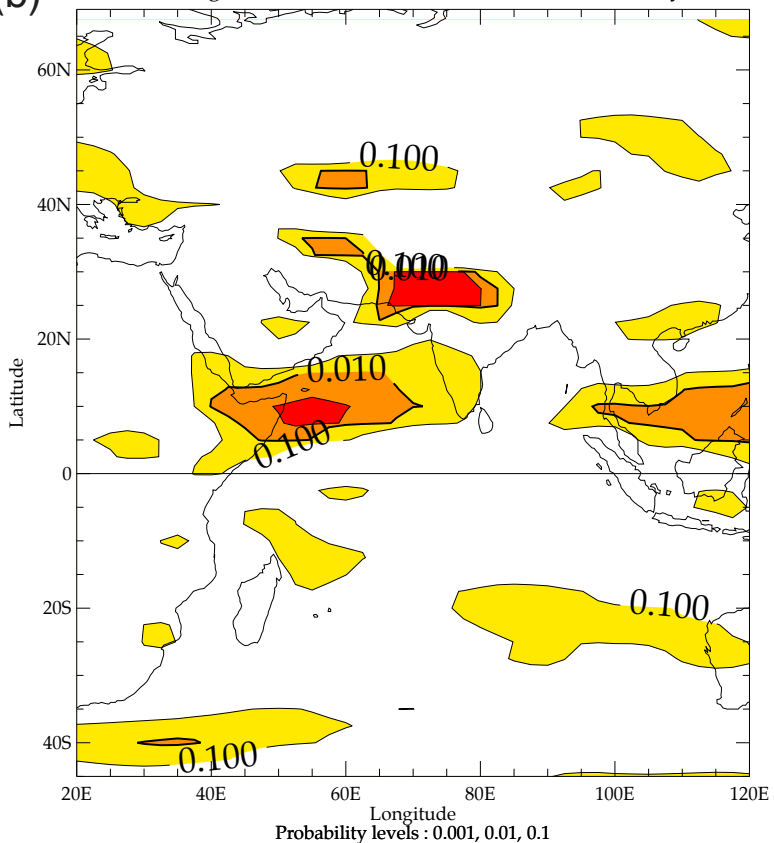

(c) Strong LISM Rainfall $850 \mathrm{hPa}$ V Critical Probability

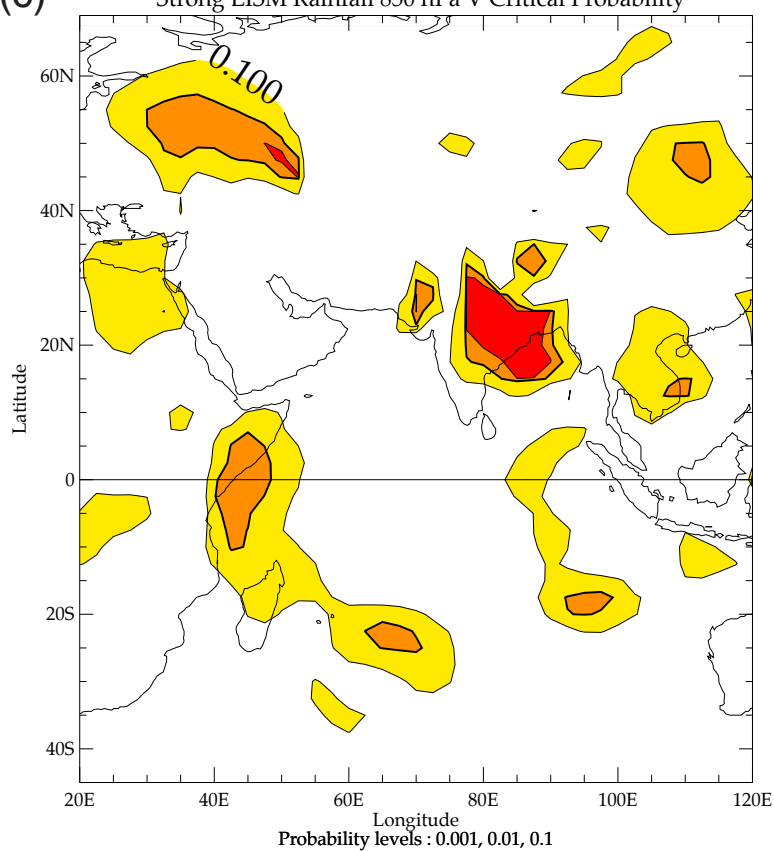

(d) Weak LISM Rainfall $850 \mathrm{hPa}$ wind Anomaly, August-September

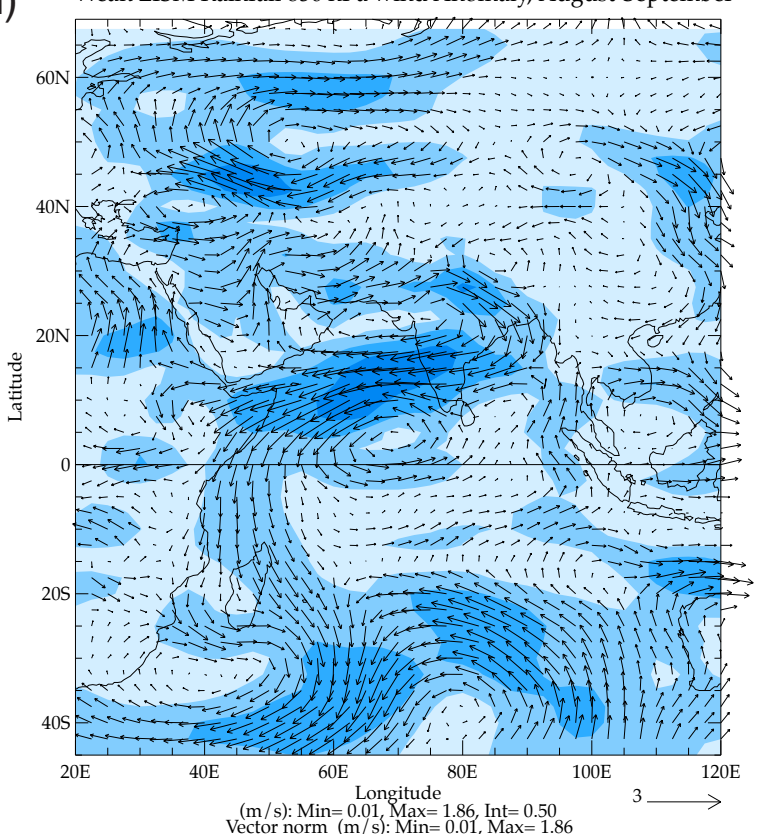

(e) Weak LISM Rainfall $850 \mathrm{hPa} U$ Critical Probability

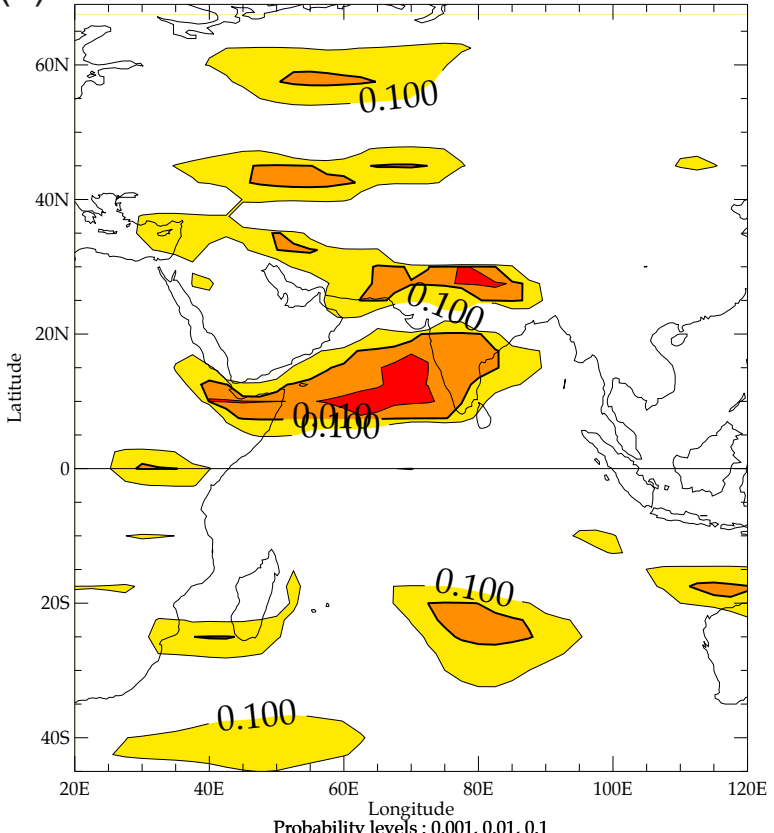

(f) Weak LISM Rainfall $850 \mathrm{hPa}$ V Critical Probability

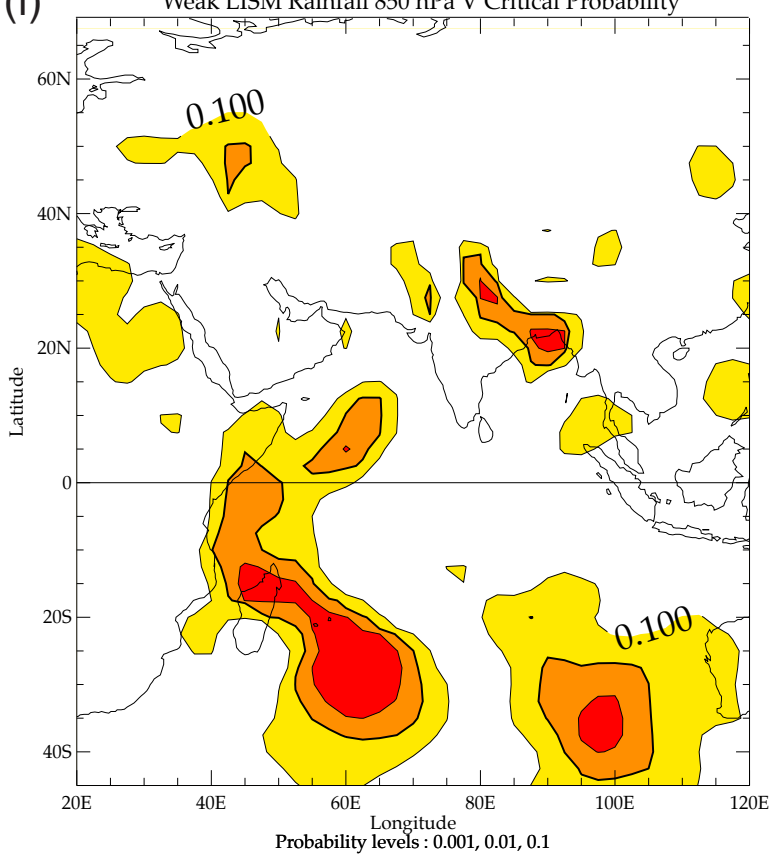




\section{LISM Sea Level Pressure - NCEP - Year 0, August-September}

(a)

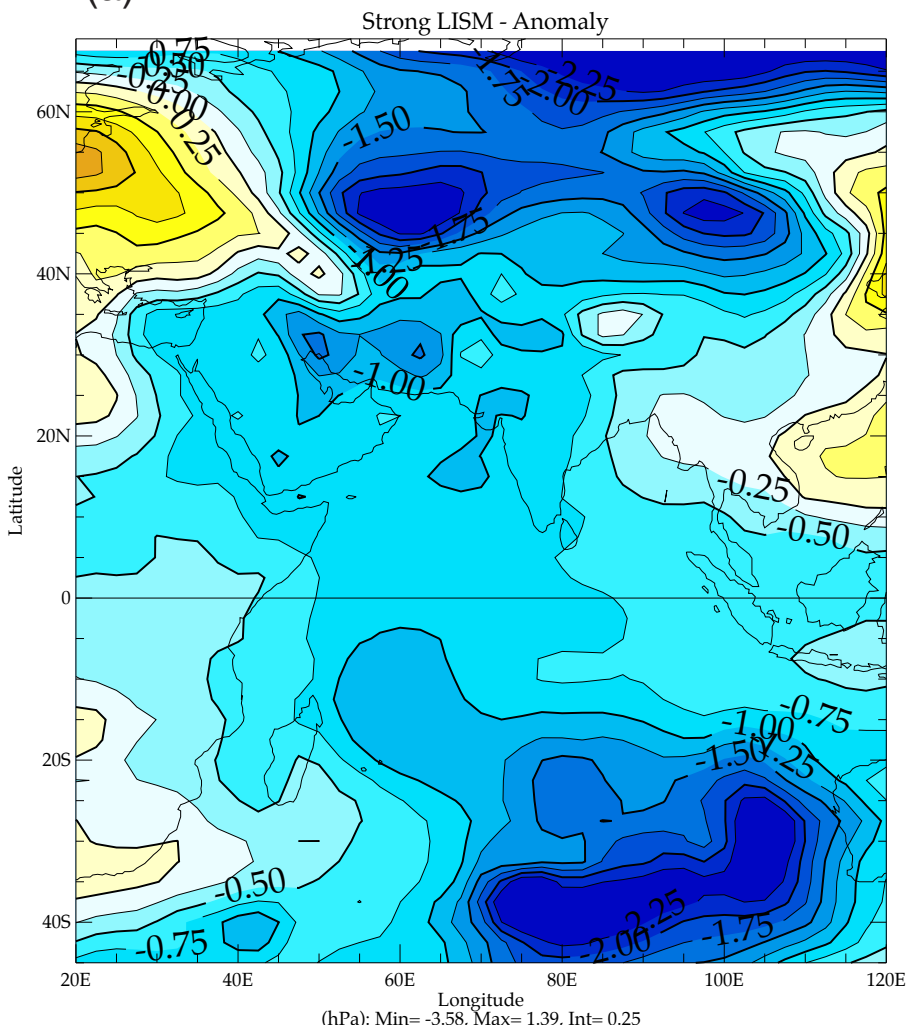

(b)

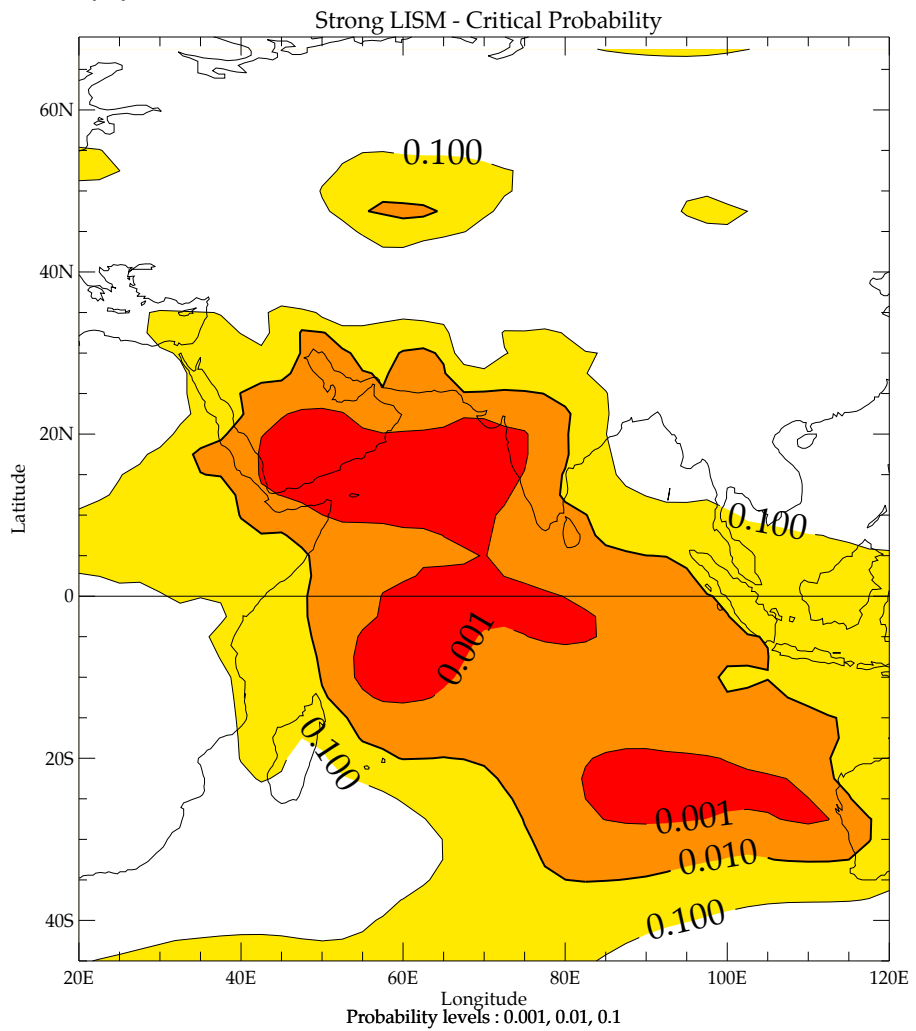

(c)

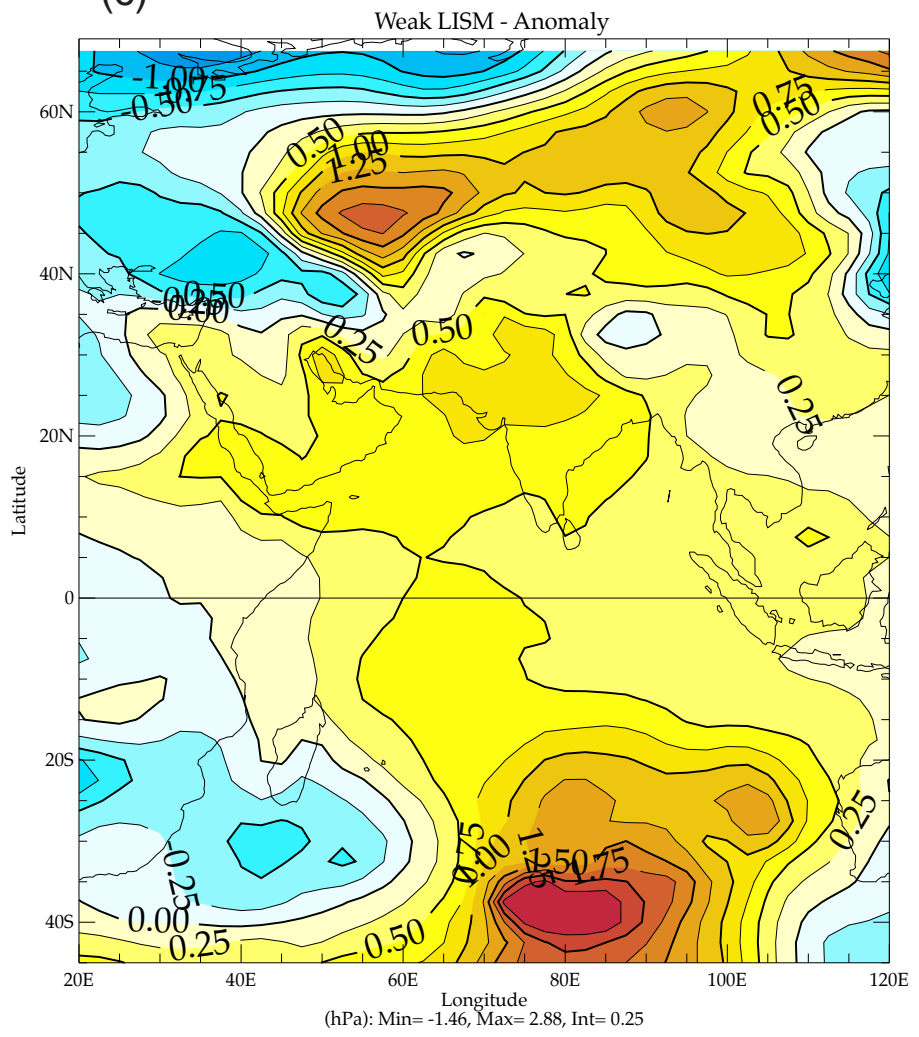

(d)

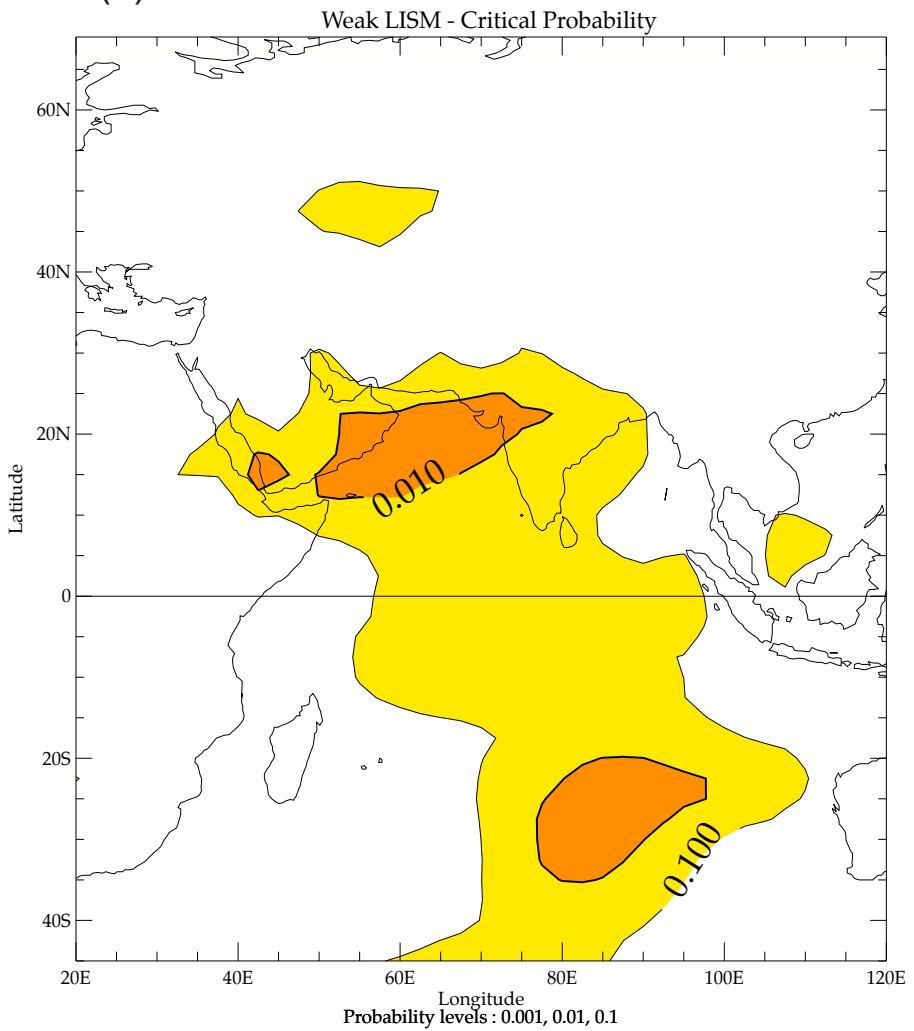


Figure 14

LISM Latent Heat Net Flux composite - NCEP - Year 0, August-September

(a)

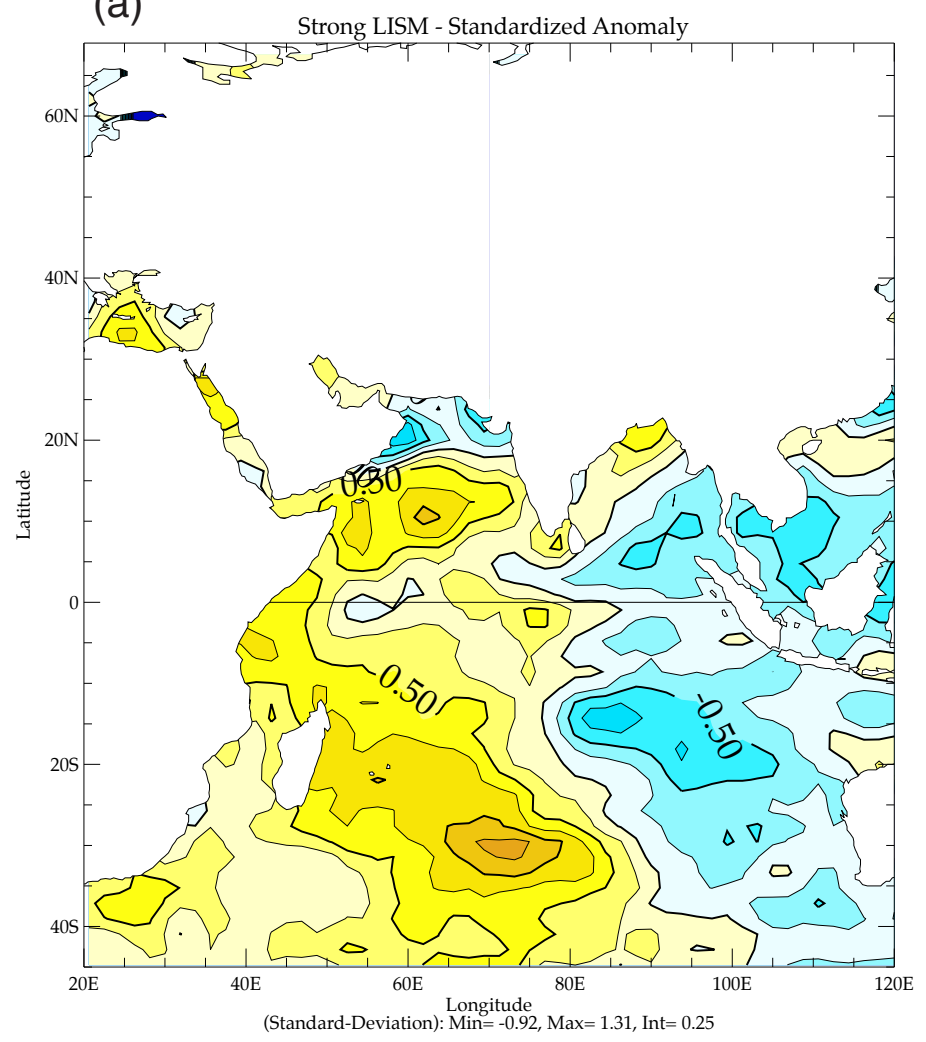

(Standard-Deviation): Min=-0.92, Max $=1.31, \mathrm{Int}=0.25$

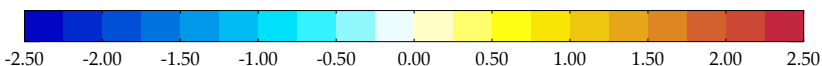

(b)

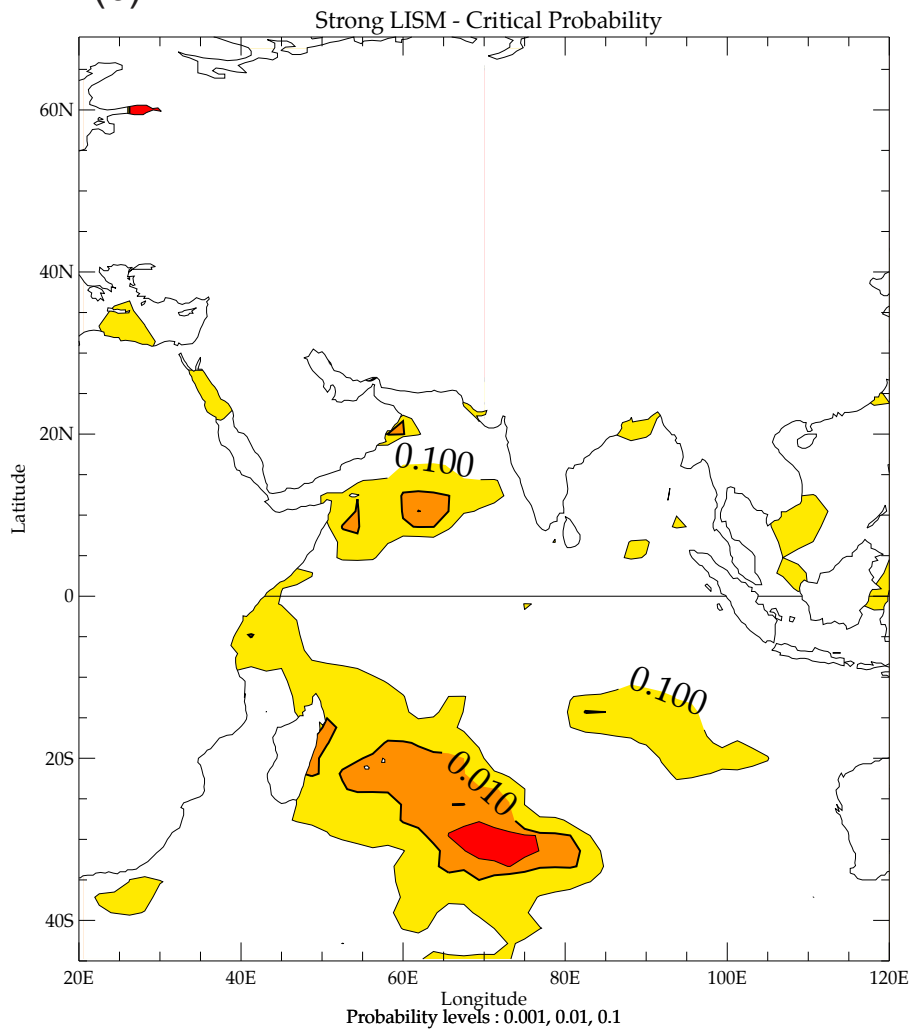

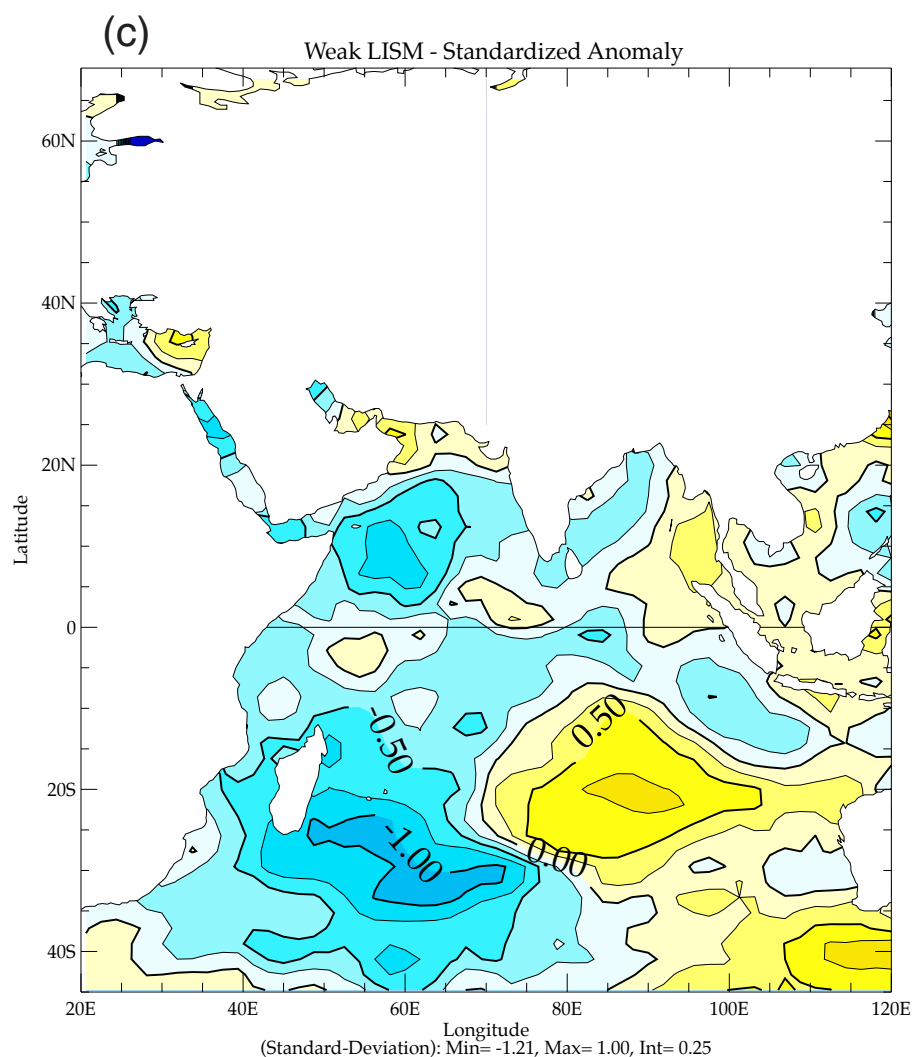

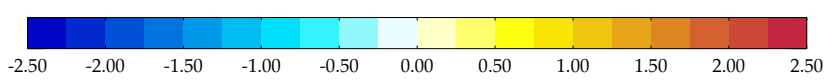

(d)

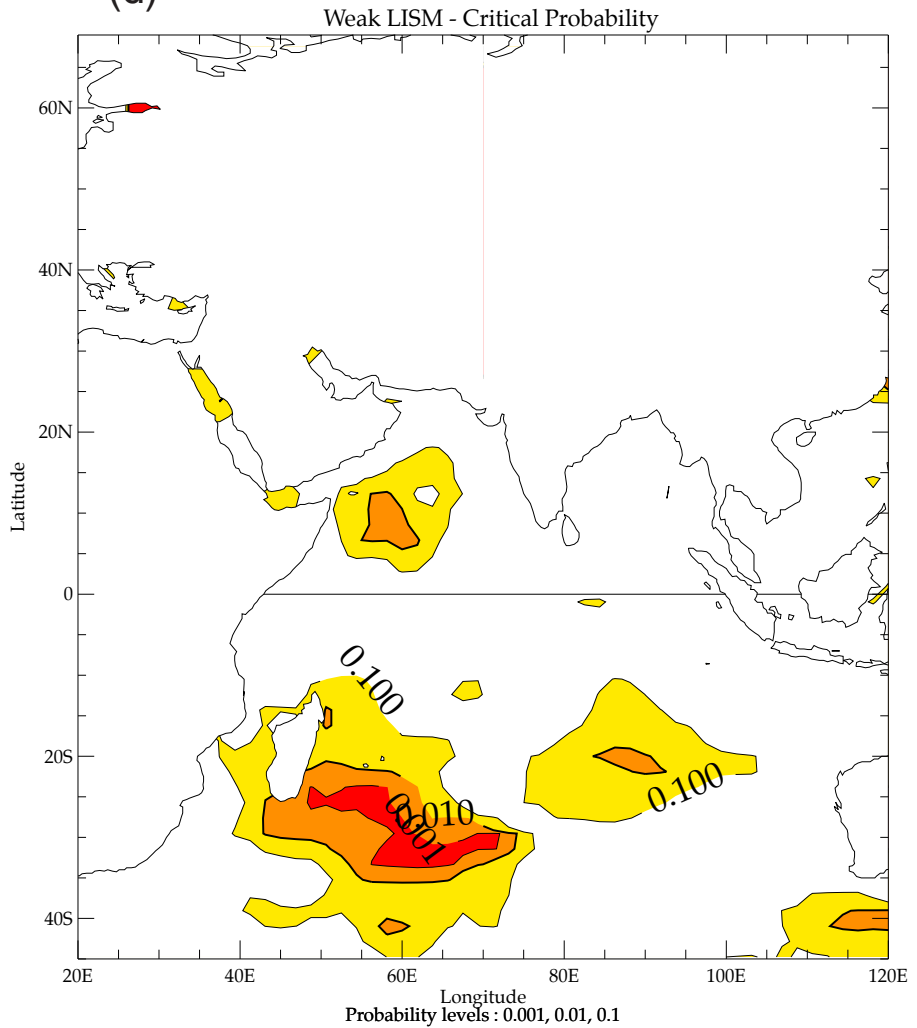


Figure 15

LISM SST composite - REYNOLDS - Year 0, August-September

(a)

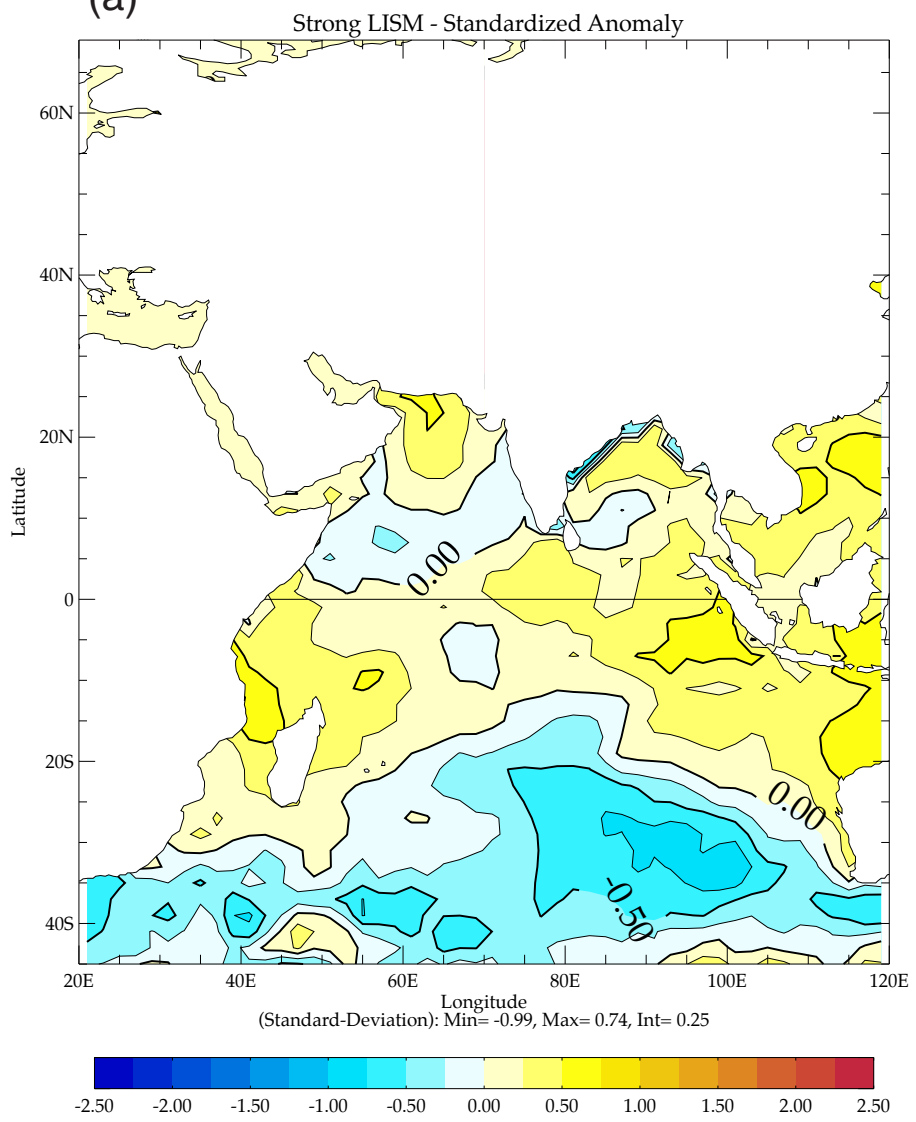

(b)

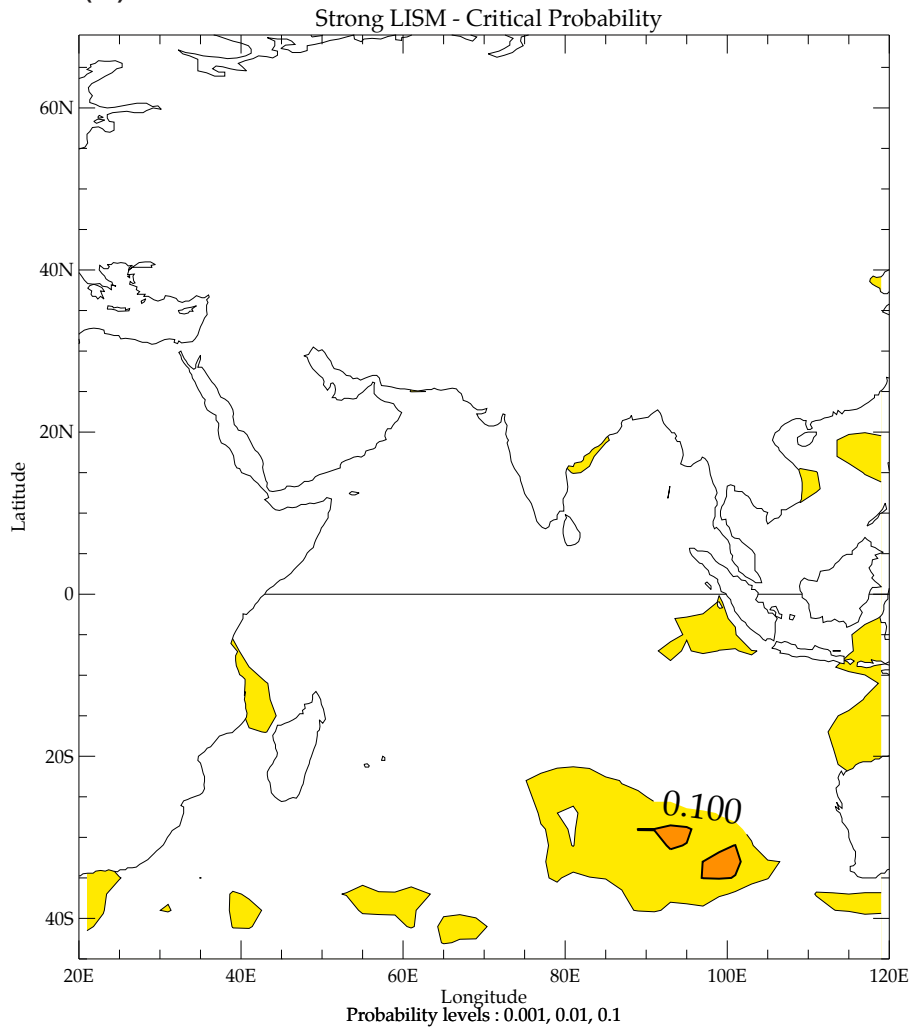

(c)
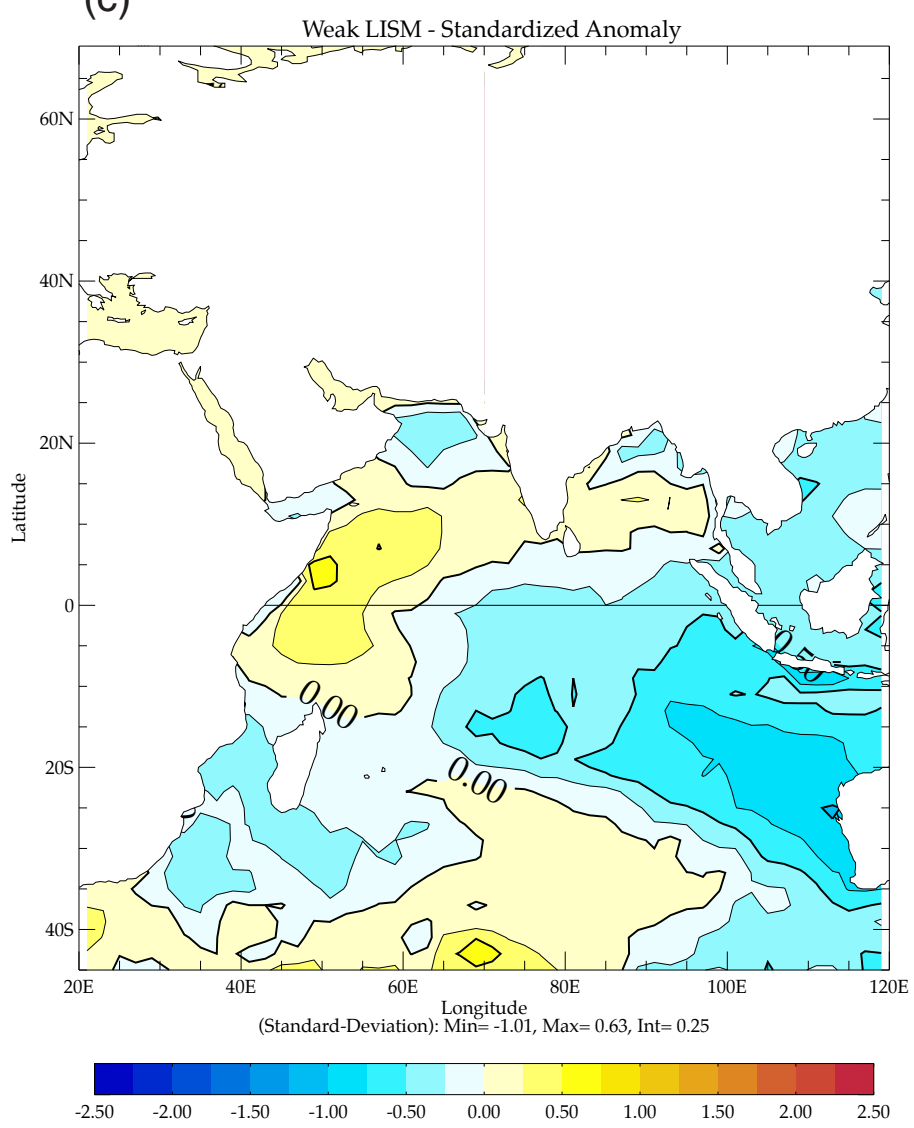

(d)

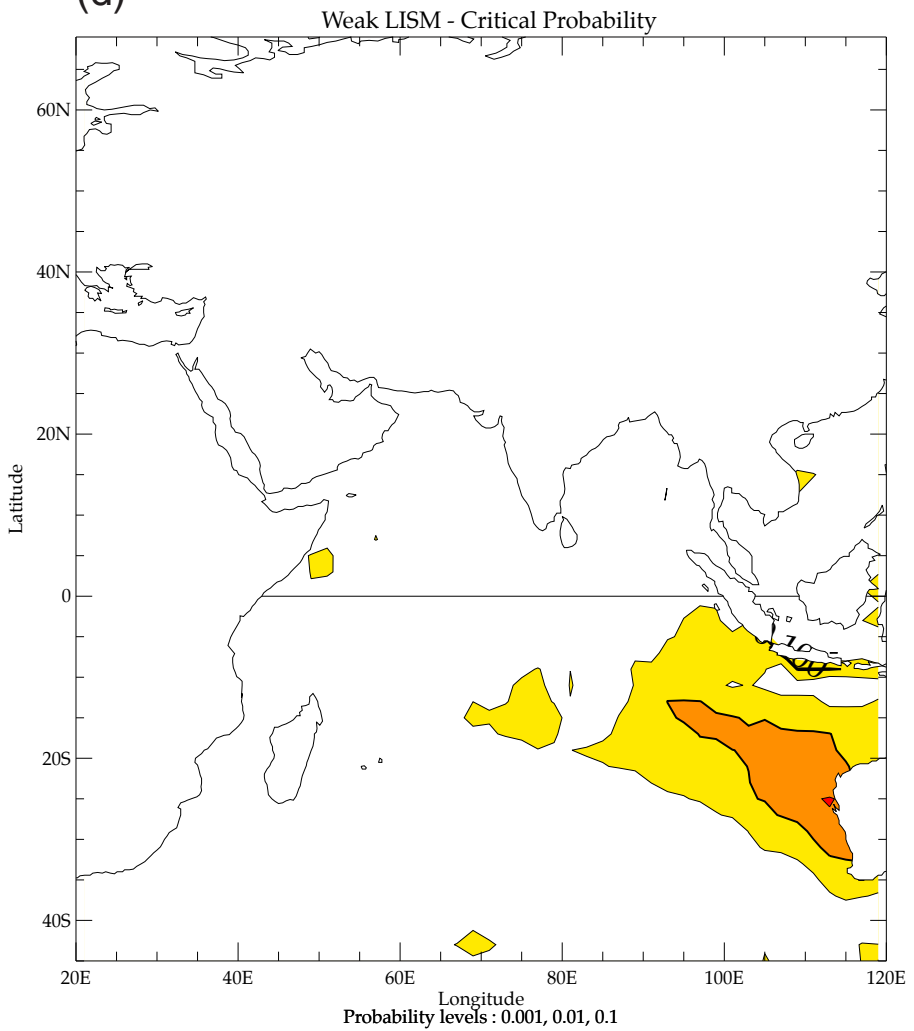



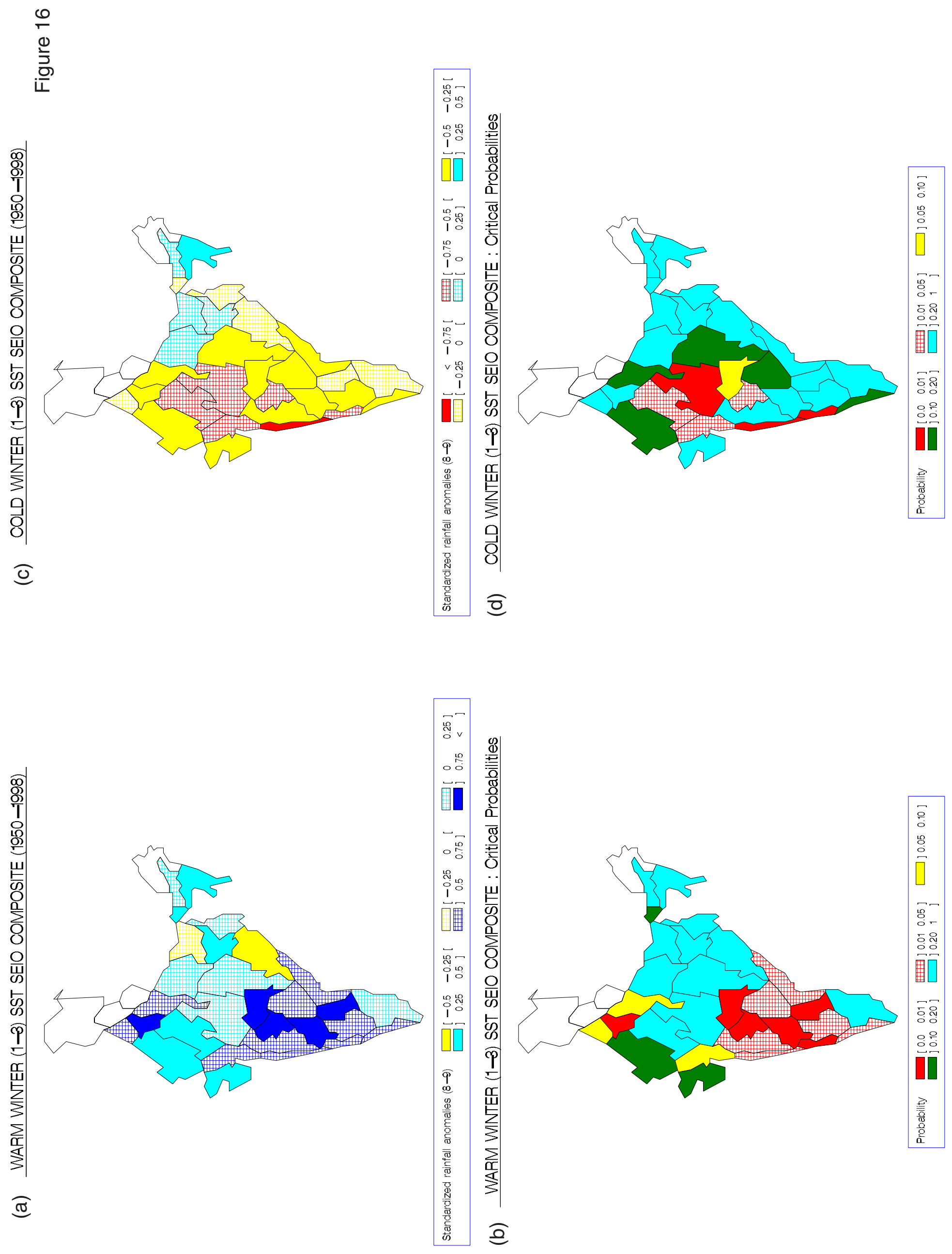


\section{Figure 17}

\section{winter SST SEIO 850 hPa wind composite - NCEP - Year 0, August-September}

(a)

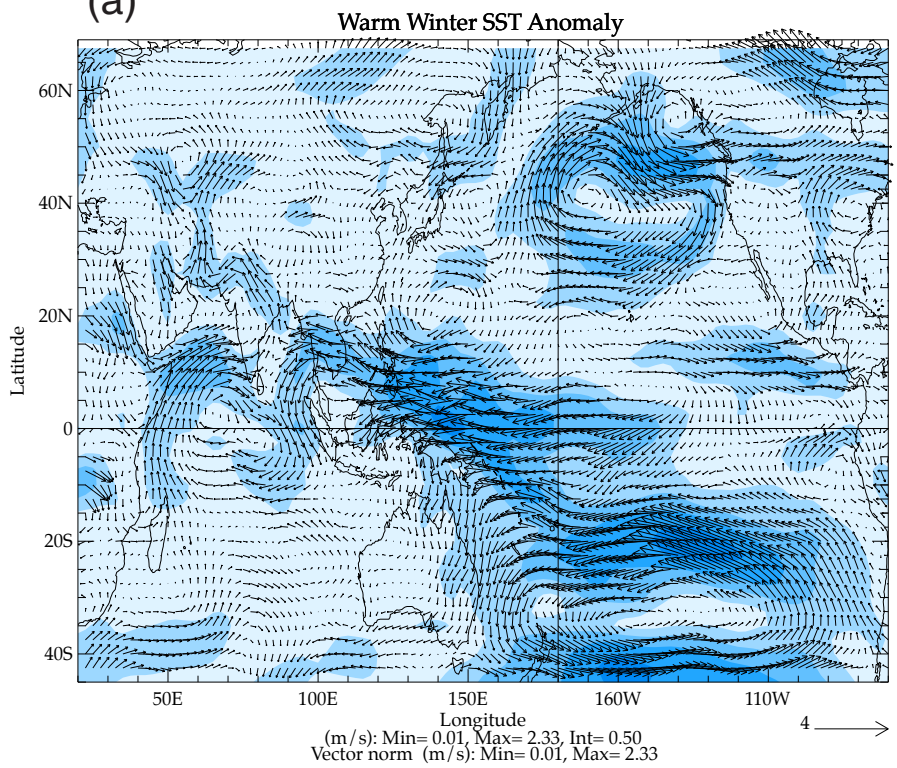

(b)

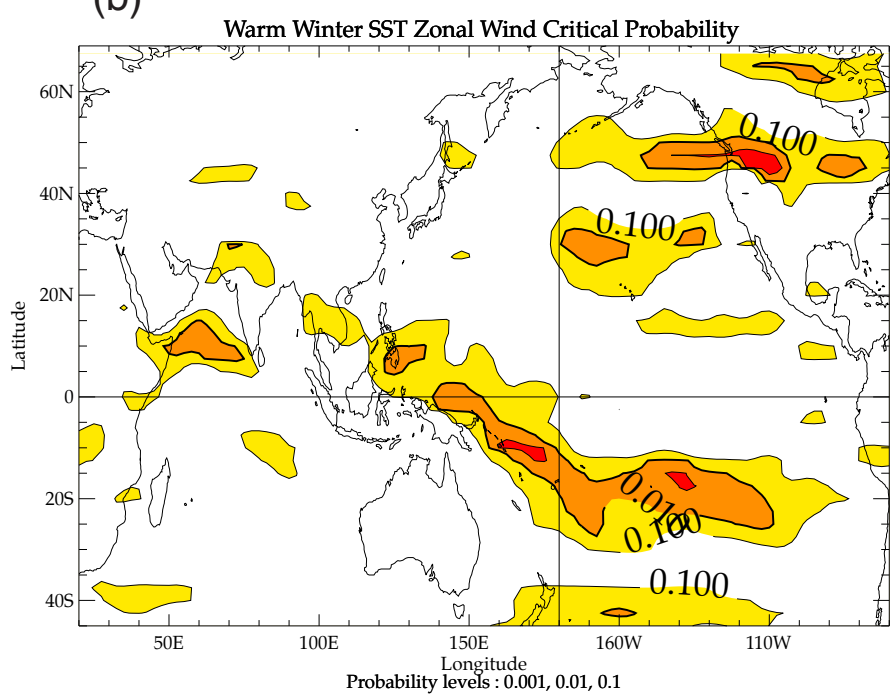

(c)

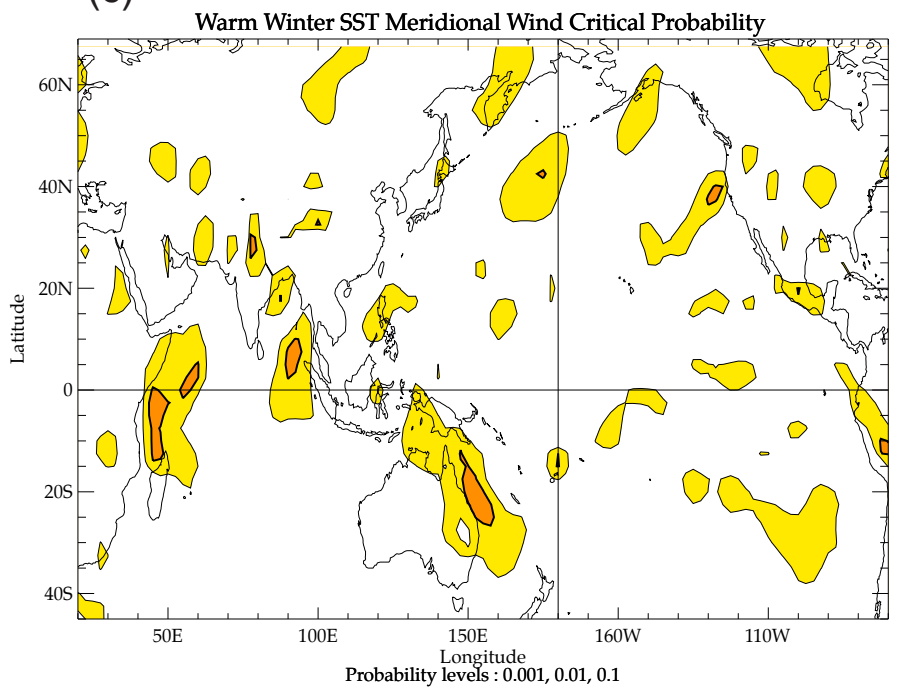

(d)

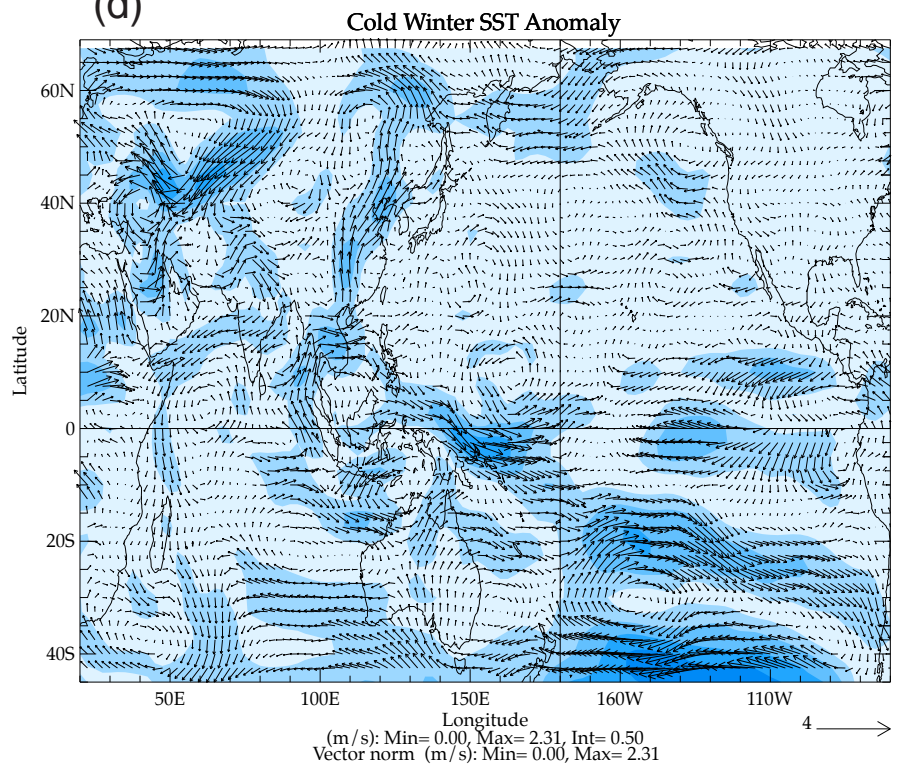

(e)

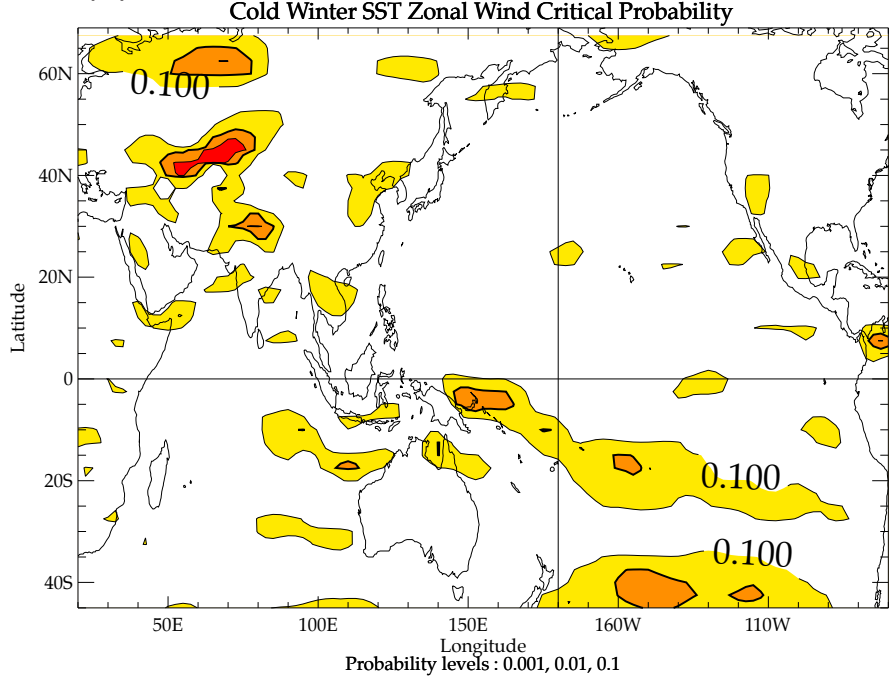

(f)

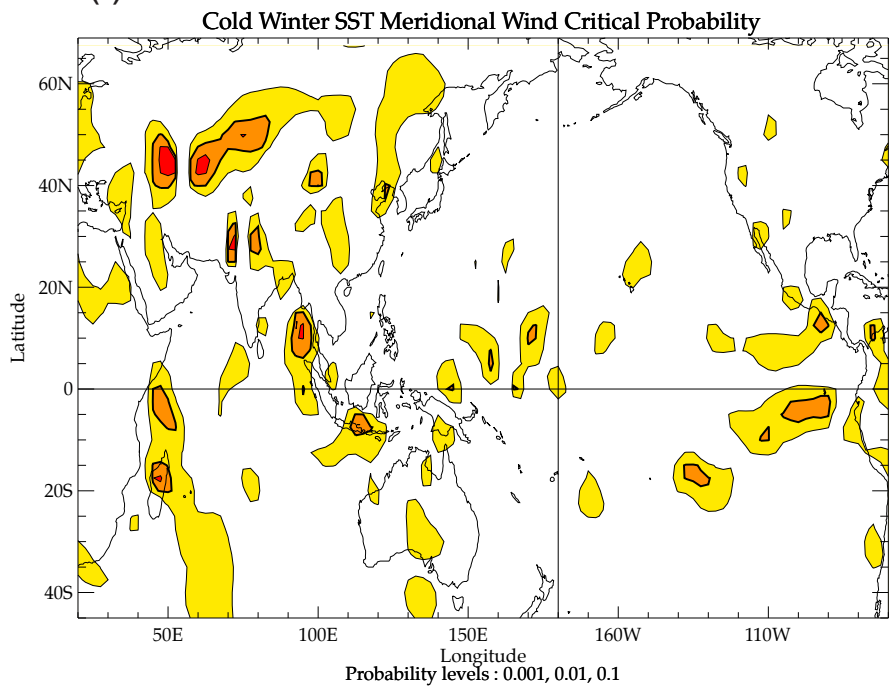

